\title{
ESTUDIO TEÓRICO DE PROPIEDADES FISICOQUÍMICAS DE COMPUESTOS DE INTERÉS FARMACOLÓGICO
}

\section{TESIS DOCTORAL}

Tesista: Carlos Franca Director: Dr. Reinaldo Pis Diez

\footnotetext{
Departamento de Química Facultad de Ciencias Exactas Universidad Nacional de la Plata
} 
Franca, Carlos Alberto

Estudio teórico de propiedades fisicoquímicas de compuestos de interés farmacológico. - 1a ed. - La Plata : Universidad Nacional de La Plata, 2012.

E-Book.

ISBN 978-950-34-0855-1

1. Farmacología. 2. Tesis de Doctorado. I. Título CDD 615.10711

Fecha de catalogación: 31/05/2012 
a Juan, a Felipe y a Tadeo a Vanesa a mis padres 


\section{GRACIAS}

Finalmente cerramos una etapa de trabajo en donde, injustamente, la hoja de agradecimientos, siempre queda chica. Sin embargo, para que este trabajo vea la luz, fueron necesarios todos aquellos destinatarios de estas líneas. Aún sin saber ellos mismos el papel que jugaron. Algunos con sus enseñanzas, muchos con su apoyo, su cariño, su aliento, sus charlas.

Gracias Vanesa por aguantarme, Juan, Felipe y Tadeo, amores incondicionales, cuatro que llenan mi vida de felicidad.

A mis queridos hermanos, mis amados sobrinos.

A mis compañeros de trabajo, Alicia, Verónica, Magui, Martín.

A mi director de tesis Pili por aportar su talento en esta empresa y su amistad en la vida. A mis compañeros del CEQUINOR que son otra familia, Anita, Bea, Sonia, Betty, Elizabeth, Evelina, Patricia.

A mis compañeros de cátedra Luciana, Larisa, Gustavo, Alejandro, Matías, Andrés, María Eugenia, Micaela, Antonela, Daniela, Emilia, Mauricio, Mario, Lucas R y Lucas M, Marcos, Marta, Paula C y Paula D.

A mis amigos de ayer y de hoy.

A profesores de esta facultad que dejaron algo de su saber en mi cabeza, y quiero recordar a algunos pecando de injusto con los omitidos. Mocoroa, Baragatti, Donati, Baran, Varetti, Aymonino, Capparelli, Thomas.

Al Dr. Castro por su confianza y apoyo.

Al Dr. Carlos Della Védova, director del CEQUINOR, por permitirme trabajar libremente en el centro.

A la Facultad de Ciencias Exactas por su cuota de responsabilidad en mi formación.

A la UNLP por la beca otorgada para financiar una parte del doctorado.

Al CONICET por la financiación durante el período de elaboración de la tesis.

Y, permiso Violeta, a la vida que me ha dado tanto. 
1 INTRODUCCIÓN

$1.1 \quad$ El problema _ 5

1.1.1 La combretastatina 8

1.2 La ciencia detrás de la escena __ 9

1.2.1 Un poco de historia 10

1.2.2 El concepto de receptor 15

1.2.3 El descubrimiento, el diseño y el desarrollo ___ 17

1.2.4 El farmacóforo 18

1.2.5 Las correlaciones estructura/actividad __ 21

$1.3 \quad$ El trabajo__ 23

2 EL MÉTODO

2.1 La Ecuación de Schrödinger _ 26

2.2 El Hamiltoniano Molecular _ 28

2.3 La aproximación de Born-Oppenheimer _ 29

2.4 El Teorema Variacional___ 31

$2.5 \quad$ La Teoría de Perturbaciones __ 33

2.6 El método de Hartree-Fock _ 34

2.7 Las funciones base

2.7.1 Funciones de polarización y difusas __ 46

2.8 Teoría del Funcional de la Densidad___ 47

2.8.1 Aproximación local de la Densidad 49

2.8.2 Aproximación generalizada del gradiente $\quad 50$

2.8.3 Métodos híbridos del Funcional de la Densidad___ 51

2.9 Métodos semiempíricos _ $\mathbf{5 2}$

2.9.1 El método AM1 _ 53

3 EL SISTEMA, SU CONTEXTO Y SU ESTUDIO __

3.1 Los compuestos y su proteína

3.2 La Dinámica Molecular _ 61

3.2.1 Resultados de la Dinámica Molecular___ 63

3.3 La optimización de la geometría __ 79

3.4 Análisis vibracional: los conceptos __ 82

3.4.1 Coordenadas internas _ 83

3.4.2 Vibraciones de grupos característicos __ 90

3.5 Análisis vibracional: los resultados _ 92

3.5.1 Cálculo de frecuencias e intensidades infrarrojas ___ 92

3.6 La Resonancia Magnética Nuclear 103

3.6.1 Algunos apuntes 103

3.6.2 Cálculo de los apantallamientos magnéticos isotrópicos___ 106

3.7 El Potencial Electrostático Molecular _ 118

4 ALGUNAS CONCLUSIONES 125 
Capítulo 1: INTRODUCCIÓN 


\section{INTRODUCCIÓN}

\subsection{El problema}

Las leucemias agudas son enfermedades hematológicas malignas que resultan de la alteración en la proliferación y diferenciación de un grupo de células inmaduras, de origen mieloide o linfoide, hasta reemplazar completamente la médula ósea. La pérdida de la médula ósea y sangre periférica normal, produce los síntomas característicos y, sin tratamiento, la muerte ocurre en pocos meses. Desde el punto de vista de laboratorio, se habla de leucemia cuando la población de células inmaduras (blastos) corresponde a más de un $20 \%$ de las células en una muestra, ya sea mielograma o biopsia de médula ósea.

No existe una sola etiología que dé cuenta de todas las leucemias, sino que se postulan varios mecanismos que podrían llevar a su producción; dentro de éstos, podemos citar: alteraciones genéticas, exposición a radiación, químicos y virus.

Una de ellas, la leucemia mieloide crónica o leucemia granulocítica crónica, es aquélla que se manifiesta con aumento de la producción de glóbulos blancos en la médula ósea. Como la médula tiene la función de producir las células de la sangre (blancas, rojas y plaquetas), en ella se encuentran las células jóvenes no diferenciadas aún en leucocitos, hematíes o plaquetas. En la leucemia, los blastos (células inmaduras) que se están transformando en leucocitos polimorfonucleares (granulocitos) no maduran y son muy numerosos y por ello aparecen en la sangre ${ }^{1}$.

Las terapias de cáncer corrientes son altamente tóxicas y a menudo no específicas. Un acercamiento potencialmente menos tóxico al tratamiento de esta enfermedad prevalente emplea agentes que modifican la diferenciación de célula cancerosa llamada “terapia de diferenciación”. Este tratamiento está basado en la asunción tácita de que tipos de células neoplásicas presentan defectos reversibles en la diferenciación, y con el tratamiento apropiado causan una reprogramación de tumor y la pérdida consecuente de la capacidad proliferativa e inductiva de diferenciación terminal o apoptosis (muerte de célula programada).

\footnotetext{
${ }^{1}$ http://escuela.med.puc.cl/paginas/publicaciones/TemasMedicinaInterna/leucemias_agudas.html
} 
Algunos estudios de laboratorio enfocados en la dilucidación de mecanismos de la acción están demostrando la eficacia de la terapia de "diferenciación", que aventura una traslación promisoria en el ajuste clínico.

La quimioterapia convencional está frecuentemente asociada con el desarrollo de resistencia y toxicidad sistémica, lo que limita la eficacia terapéutica. Con el objeto de disminuir o eliminar estas complicaciones terapéuticas se busca desarrollar otras alternativas que incluyen el uso de quimioterapia en combinación con otras modalidades de tratamiento, como terapia de radiación, inmunoterapia, terapia de diferenciación, y terapia de inhibición de angiogénesis ${ }^{2}$.

El hallazgo de que ciertos compuestos químicos (ésteres del forbol) reestablecerían un programa normal de diferenciación en células leucémicas representó uno de los primeros ejemplos de terapia de diferenciación ${ }^{3}$.

Éstos han culminado en la introducción exitosa de todos los ácidos retinoicos trans (ATRA) como un tratamiento primario en pacientes con leucemia promielocítica aguda $^{4}$.

Los ensayos de extractos vegetales y productos naturales han mostrado que cada vez mayor número de plantas representan una fuente potencial de nuevos agentes terapéuticos, así como de nuevos principios naturales para potenciales compuestos líderes en la búsqueda de nuevos fármacos ${ }^{5}$.

Se han reportado efectos directos de acción antitumoral de extractos herbarios que contienen cumarinas, los cuales manifestaron capacidad de inhibir el crecimiento para varias líneas de células malignas in vitro ${ }^{6,7,8}$.

La fusión de un anillo de pirona con uno de benceno conduce a una clase de compuestos heterocícliclos conocidos como benzopironas, de las cuales se distinguen dos tipos distintos: (I) benzo- $\alpha$-pirona, comúnmente llamadas cumarinas y (II) benzo- $\gamma$-pironas,

\footnotetext{
${ }^{2}$ M. Leszczyniecka, T. Roberts, P. Dent, S. Grant, P.B. Fishe; Pharmacol. Ther. 90 (2001) 105-156

${ }^{3}$ J. Domen, I.L. Weissman; Mol. Med. Today 5 (1999) 201-208

${ }^{4}$ J. Drach, T. McQueen, H. Engel, M. Andreeff, K. Robertson, S.J. Collins, F. Malavasi, K. Mehta; Cancer Res. 54 (1994) 1746-1752

${ }^{5}$ R.N. Lawrence; Drug Discov. Today 4 (1999) 449-451

${ }^{6}$ T. Fujioka, K. Furumi, H. Fujii, H. Okabe, K. Mihashi, Y. Nakano, H. Matsunaga, M. Katano, M. Mori; Chem. Pharm. Bull. 47 (1999) 96-100

${ }^{7}$ C. Kofinas, L. Chinou, A. Loukis, C. Harvala, C. Roussakis, M. Maillard, K. Hostettmann; Planta Med. 64 (1998) 174-176

${ }^{8}$ S. Kawaii, Y. Tomono, K. Ogawa, M. Sugiura, M. Yano, Y. Yoshizawa; Anticancer Res. 21 (2001) 917-923
} 
llamadas cromonas, y la diferencia radica en la posición que ocupa el grupo carbonilo en la molécula.

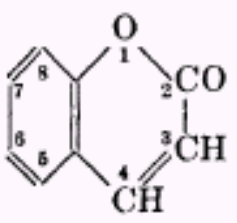

Benzo- $\alpha$-pyrone

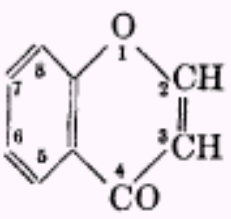

Benzo- $\gamma$-pyrone

Estas moléculas están ampliamente distribuidas en el reino de las plantas, ya sea en forma libre o combinada, en particular en las familias de las orquidáceas, fabáceas, rutáceas y apiáceas. La sustancia madre de todas fue aislada por primera vez de porotos de tonka, una especie de haba que crece en Venezuela y Guyana, en $1820^{9}$.

Las cumarinas naturales, como otras lactonas no saturadas, pueden provocar varios efectos en los organismos vivos. Hay abundante información acerca de las propiedades químicas y bioquímicas de cumarinas simples y complejas ${ }^{10,11,12}$.

Las cumarinas simples pueden ser sustituidas en posiciones diferentes del núcleo aromático y pueden ser clasificadas de acuerdo a su forma de oxigenación. Sin embargo, la mayoría de los estudios farmacológicos y bioquímicos han sido realizados en la propia cumarina y en monohidroxi-y dihidroxicumarinas o metoxicumarinas ${ }^{13,14}$.

Estudios recientes describieron un gran número de efectos biológicos para cumarinas naturales y sintéticas como, actividad antibacterial ${ }^{15}$, propiedades antimutagénicas $^{16}$, captura de especies con oxígeno reactivo ${ }^{17}$, inhibición de la agregación plaquetaria en humanos ${ }^{18}$ y actividad anti-HIV-PR ${ }^{19}$.

\footnotetext{
${ }^{9}$ S. Sethna, N. Shah; N.Chem. Rev. 36 (1945) 1-62

10 R.D.H. Murray, J. Méndez, R.A. Brown; The Natural Coumarins: Occurrence, Chemistry and Biochemistry; Wiley, New York, NY, 1982

${ }^{11}$ R.D. Murray, Coumarins, in: W. Herz, G.W. Kirby, W. Steglich, C. Tamm (Eds.). Progress in the Chemistry of Organic Natural Products, Springer, New York, NY (1997) 2-119

${ }^{12}$ R.D.H. Murray; Coumarins, Nat. Prod. Rep. 8 (1989) 591-624

${ }^{13}$ J. Hoult, M. Paya; Gen. Pharmacol. 27 (1996) 713-722

${ }^{14}$ D. Egan, R. O’Kennedy, E. Moran, R.D. Thornes; Drug Metab. Rev. 22 (1990) 503-529

${ }^{15}$ P. Laurin, M. Klich, C. Dupis-Hamelin, P. Mauvais, P. Lassaigne, A. Bonnefoy, B. Musicki; Bioorg. Med. Chem. Lett. 9 (1999) 2079-2084

${ }^{16}$ S. Pillai, S. Menon, L. Mitscher, C. Pillai, D. Shankel; J. Nat. Prod. 62 (1999) 1358-1362

${ }^{17}$ W.L. Lin, C.J. Wang, Y.Y. Tsai, C.L. Liu, J.M. Hwang, T.H. Tseng; Arch. Toxicol. 74 (2000) 467-472

${ }^{18}$ G. Roma, M.D. Braccio, A. Carrieri, G. Grossi, G. Leoncini, M. Grazia Signorello, et al.; Bioorg. Med. Chem. 11 (2003) 123-138

${ }^{19}$ S. Kirkiacharian, D.T. Thuy, S. Sicsic, R. Bakhchinian, R. Kurkjian, T. Tonnaire; Farmaco 57 (2002) 703-708
} 
Las cumarinas y sus derivados producen cambios significativos en la regulación de la respuesta inmune, el crecimiento celular y la diferenciación ${ }^{20,21}$. Muchas se han reportado por ser antitumorales ${ }^{22,23,24}$ y por poseer sinergismo con ATRA en la diferenciación de células leucémicas humanas ${ }^{25}$.

Algunas cumarinas sustituidas aisladas de la especie Pterocaulon polystachyum demostraron inducir diferenciación celular ${ }^{26}$.

\subsubsection{La combretastatina}

La combretastatina A-4 (CA4, Figura 1) es un producto natural aislado en 1989 por Pettit y colaboradores de un sauce originario del sur de África, el Combretum caffrum $^{27}$. Este compuesto inhibe la polimerización de la tubulina por unirse al sitio de la colchicina. Esta importante propiedad ha convertido a la combretastatina y sus derivados análogos en objeto de enorme cantidad de estudios para la búsqueda de nuevos prototipos para el diseño de potenciales fármacos destinados a las terapias anticancerígenas.

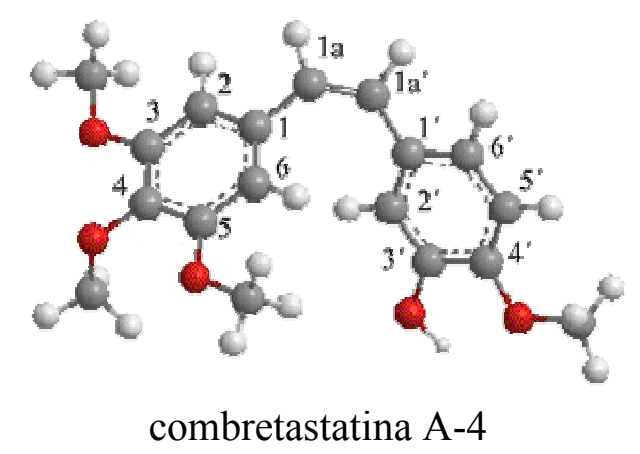

Figura 1.1

\footnotetext{
${ }^{20}$ B. Seliger, in: R. O'Kennedy, R.D. Thornes (Eds.); The Effects of Coumarin and its Metabolites on Cell Growth and Development; (1997) pp 93-102

${ }^{21}$ G.J. Zlabinger, in: R. O'Kennedy, R.D. Thornes (Eds.); Coumarin as an Immunomodulator; (1997) pp $103-124$

${ }^{22}$ M. Noguchi, M. Earashi, M. Minami, I. Miyazaki, M. Tanaka, T. Sasaki; Prostaglandins Leukot. Essent. Fatty Acids 53 (1995) 325-329

${ }^{23}$ S. Chimichi, M. Boccalini, B. Cosimelli, G. Viola, D. Vedaldi, F. Dall'Acqua; Tetrahedron Lett. 43 (2002) 7473-7476

${ }^{24}$ F.A. Jimenez-Orozco, J.A. Molina-Guarneros, N. Mendoza- Patino, F. Leon-Cedeno, B. Flores-Perez, E. Santos-Santos, et al.; Melanoma Res. 9 (1999) 243-247

${ }^{25}$ J. Hofmanova, A. Kozubik, L. Kusek, J. Pachemik; Eur. J. Pharmacol. 350 (1998) 273-284

26 M.E. Riveiro,C. Shayo, F. Monczora, N. Fernández, A. Baldi, A, N. De Kimpe, J. Rossi, S. Debenedetti, C. Davio; Cancer Letters 210 (2004) 179-188

${ }^{27}$ G.R. Pettit, S.B. Singh, E. Hamel, C.M. Lin, D.S. Alberts, D. Garcia-Kendall; Experientia 45 (1989) 209-211
} 
La proteína tubulina está constituida por estructuras celulares denominadas microtúbulos que se ensamblan en el proceso de polimerización para darle forma a la misma. Estas estructuras participan en el proceso de la división celular y, los compuestos que modulen la polimerización de la tubulina tendrán eventualmente capacidad para inhibir la proliferación de células cancerosas ${ }^{28}$.

Un grupo de estos compuestos son los derivados análogos de combretastatina que se ligan al sitio de la colchicina (colchicina y combretastatina) ${ }^{29}$. La presencia del doble enlace cis entre los dos anillos A y B parece tener una importancia clave en la actividad citotóxica $29 b, 30,30$. Christian Bailly y sus colaboradores sintetizaron y evaluaron la actividad biológica de nuevos derivados de 4-arilcumarinas, análogos de combretastatina. Dos de ellos mostraron inhibir el ensamble de tubulina y, además, los mismos son los que presentan citotoxicidad ${ }^{31}$.

\subsection{La ciencia detrás de la escena}

La Química Medicinal o Farmacéutica empieza a sobresalir con peso propio, no tanto como una rama de la Química sino, más bien, como el andamiaje y continente de variadas disciplinas de la investigación que orienta su brújula científica a la búsqueda de prototipos de interés farmacológico y al desarrollo racional de nuevos fármacos.

De las diversas disciplinas que nutren a la Química Médica se destacan la Bioquímica, la Farmacología Molecular y la Química Computacional, en especial en lo que respecta a las técnicas de Modelado Molecular.

\footnotetext{
${ }^{28}$ (a) E. K. Rowinsky, R. C. Donehower; Pharmacol. Ther. 52 (1991) 35. (b) E. Hamel; Med. Res. Rev. 16 (1996) 207. (c) Q. Shi, K. Chen, S. L. Morris-Natschke, K. H. Lee; Curr. Pharm. Des. 4 (1998) 219. (d) A. Jordan, J. A. Hadfield, N. J. Lawrence, A. T. McGown; Med. Res. Rev. 18 (1998) 259. (e) Q. Li, H. Sham, S. Rosenberg; Annu. Rep. Med. Chem. 34 (1999) 139. (f) E. von Angerer; Expert Opin. Ther. Pat. 9 (1999) 1069

${ }^{29}$ (a) G. R. Pettit, G. M. Cragg, S. B. Singh; J. Nat. Prod. 50 (1987) 386-391. (b) G. R. Pettit, S. B. Singh, M. R. Boyd, E. Hamel, R. K. Pettit, J. M. Schmidt, F. Hogan; J. Med. Chem. 38 (1995) 16661672. (c) G. R. Pettit; J. Nat. Prod. 59 (1996) 812-821

${ }^{30}$ C. M. Lin, S. B. Singh, P. S. Chu, R. O. Dempcy, J. M. Schmidt, G. R. Pettit, E. Hamel; Mol. Pharmacol. 34 (1988) 200-208

${ }^{31}$ C. Bailly, C. Bal, P. Barbier, S. Combes, J. P. Finet, M. P. Hildebrand, V. Peyrot, N. Wattez; J. Med. Chem. 46 (2003) 5437-5444
} 
Por ello la IUPAC la define como "la disciplina científica que se ocupa del diseño, síntesis, identificación, evaluación e interpretación a nivel molecular del modo de acción de nuevos compuestos biológicamente activos" ${ }^{32}$.

En toda la historia de la humanidad se han usado drogas de diferente origen con fines medicinales o rituales, para evolucionar hasta nuestros días hasta convertirse en una verdadera especialización.

\subsubsection{Un poco de historia}

Hace más de cinco mil años se utilizaban en China drogas de origen vegetal como el "ma huang", que contiene compuestos activos como la efedrina. El Chenopodium anthelminticum, que contiene el antihelmíntico ascaridol, fue usado por los romanos. Los aztecas usaron hongos para sus rituales. Hipócrates (siglo V a. C.) usó compuestos metálicos. Galeno (131-200) usó productos naturales para el tratamiento de diferentes afecciones y Paracelso (1493-1541) sales metálicas en lugar de plantas $^{33}$.

El siglo XVII estuvo signado por el uso de drogas de origen vegetal. La droga más representativa de esta época fue la corteza de la quina. Carlos Linneo, en su obra Genera Plantarum (1742), clasificó el árbol de la corteza de quina en el nuevo género Cinchona. Este nombre proviene de Chinchón-ciudad ubicada al sudeste de Madrid en España, y fue inspirado por el relato "clásico", pero no cierto, del médico Sebastiano Bado, quien en 1663 describió la llegada de la quina a la medicina occidental como consecuencia de la administración de esta corteza a la esposa de Luis Jerónimo Fernández de Cabrera y Bobadilla, Conde de Chinchon y virrey del Perú, quien padecía "fiebres tercianas" (paludismo). Lo que sí es cierto es el difundido uso que se le dio a esta corteza como primer agente antimalárico. Varios años después, Pelletier y Caventou extrajeron en 1823 quinina de la "corteza peruana"34.

\footnotetext{
${ }^{32}$ Technical Report No 13 ; IUPAC Information Bulletin; 1974

${ }^{33}$ M. Avendaño; "Introducción a la Química Farmacéutica"; McGraw-Hill/Madrid 1993

${ }^{34} \mathrm{http}$ ://www.mujeryciencia.es/2008/08/23/ana-de-osorio-condesa-de-chinchon-y-la-corteza-de-quina/
} 


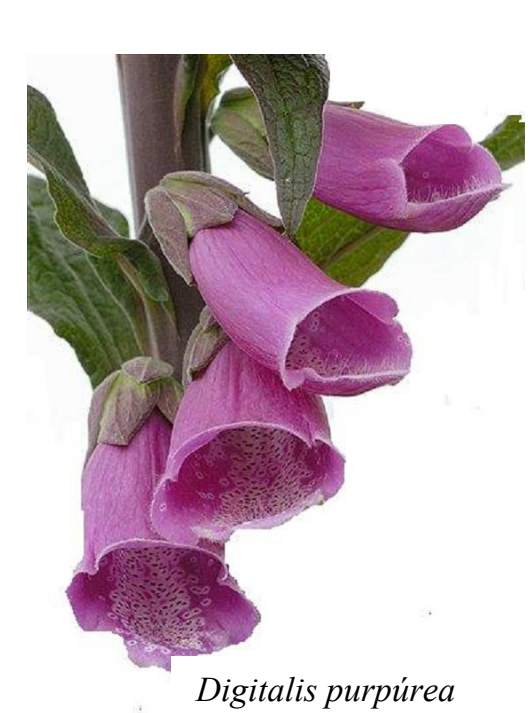

En el siglo XVIII se creía que existía una relación entre la acción de la droga y el órgano del cuerpo afectado. La dedalera roja salvaje (Digitalis purpúrea) se menciona en escritos galeses de 1250, pero sólo 500 años más tarde, en 1785 el médico inglés William identificó sus hojas como principio activo para tratar la hidropesía. En su libro "An account of the foxglove and some of it's medical uses" reconocía que la digital "tiene poder sobre el movimiento del corazón con intensidad hasta ahora no observada en ninguna otra medicina, y que este poder puede emplearse con fines saludables" ${ }^{35}$.

A comienzos del siglo XIX el farmacólogo alemán Friedrich Wilhelm Sertürner aisló morfina tras descubrir que ésta reacciona con ácidos formando sales. Luego en Francia Pierre Pelletier, siguiendo la estrategia de Sertürner, aisló emetina de la ipecacuana, droga importada de Sudamérica cuyos rizomas y raíces se utilizaban para tratar la disentería. Junto con Jean Bienaimé Caventou, también aisló estricnina, brucina, veratrina, piperina y delfinina. En 1819 el químico alemán Wilhelm Meissner denominó a estas sustancias alcaloides por su comportamiento similar a los álcalis. Se genera así una familia de compuestos de vital importancia en la historia de la medicina ${ }^{36}$.

El médico Crawford Williamson Long, conocedor de los trabajos de Humpry Davy con el óxido nitroso y su uso como anestésico, operó de un tumor en el cuello a un paciente suyo en el año 1842 en Georgia, Estados Unidos usando éter por primera vez en una intervención quirúrgica ${ }^{37}$.

\footnotetext{
${ }^{35} \mathrm{http}: / /$ www.historiadelamedicina.org/farmac.html

${ }^{36}$ T. Kaufman, E. Rúveda: Ciencia Hoy, 14 (2004) 81

${ }^{37} \mathrm{http}: / /$ revistaplatensedeanestesia.blogspot.com/2009_02_01_archive.html
} 
En la Alemania de 1861 existían ya unas 500 industrias químicas. En el lavadero de una casa de Barmen, Friedrich Bayer obtuvo colorantes de anilina que ensayó el maestro tintorero Friedrich Weskott. Ambos fundaron en 1863 la Empresa comercial Friedr. Bayer et com. Más tarde obtuvieron como producto secundario en la fabricación de colorantes la fenacetina. Esta sustancia, estudiada y probada en la Universidad de Friburgo por sus propiedades

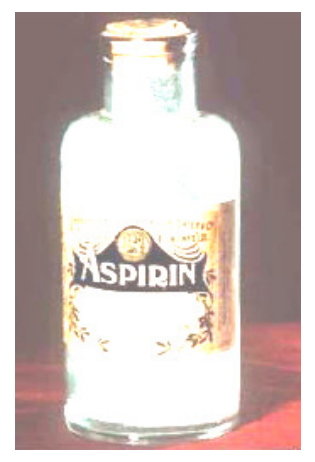
antitérmicas, mostró gran eficacia y superioridad frente a otros preparados existentes en ese momento en el mercado. En el año 1888, el Consejo de Administración tomó la decisión de crear un Departamento farmacéutico y en 1890 montó en Elberfeld un laboratorio farmacológico. Arthur Eichengrün, director del grupo de investigación de nuevos fármacos de la Compañía Bayer en 1896, encargó a Félix Hoffmann la resolución de una variante del ácido salicílico que redujera los efectos secundarios del original. En 1897, Hoffmann informa el procedimiento seguido para la obtención del llamado ácido acetilsalicílico, registrado luego como Aspirina.

A fines del siglo XIX Paul Erlich, bacteriólogo alemán, Nobel de Medicina 1908 y fundador de la quimioterapia, planteó el concepto de receptor, de enorme importancia para la química farmacéutica

La idea de estudiar la relación existente entre la composición química de los fármacos y su modo de acción sobre el organismo y sobre las células del cuerpo condujo a Paul Ehrlich a desarrollar el salvarsán, o "arsénico que salva" para el tratamiento de la sífilis, cuyo agente causal había sido descubierto poco antes en 1905.

Igual que sucedía en inmunología, uno de sus propósitos era encontrar los productos específicos que tuvieran afinidad por los organismos patógenos. Su concepto acerca de actuar sobre la causa de la enfermedad pero no sobre el huésped significó una revolución en la farmacología y, por tanto, en la terapéutica. En poco tiempo surgieron las sulfamidas, después los antibióticos y luego toda una serie de productos orgánicos con eficacia terapéutica.

En 1912 Hoerlein alteró la estructura del Veronal (dietilfenilacetamida) con el objetivo de obtener un compuesto sedante más estable para tratar pacientes epilépticos. Para ello sustituyó un radical fenilo por uno de los dos radicales etilos en el anillo del ácido barbitúrico obteniendo como producto de la reacción el ácido 5,5 feniletilbarbitúrico, el 
fenobarbital, que probó ser más efectivo y menos tóxico que los bromuros en los pacientes que lo tomaron ${ }^{38}$.

Posteriormente entre 1936 y 1945, Merrit y Putnam introducen la difenilhidantoína (fenitoína), que resultó uno de los compuestos de mayor actividad anticonvulsivante combinada con un menor efecto sedante.

En 1930, el farmacólogo italiano Daniel Bovet, que trabajaba en el Instituto Pasteur de París, investigó la adrenalina y sus efectos sobre el sistema nervioso simpático y consiguió sintetizar sustancias similares, en estructura y efecto. En 1937 advirtió que uno de esos compuestos inhibía la histamina. Ese compuesto fue el primer antihistamínico sintético.

Los primeros antihistamínicos eran demasiado tóxicos para ser administrados a seres humanos, pero hacia 1942 ya habían sido modificados para poder ser utilizados en el tratamiento de las alergias y en la actualidad se dispone de más de 25 drogas antihistamínicas.

En 1938 el agrónomo francés Rene Jules Dubos, dedicado a la microbiología en el Instituto Rockefeller para la Investigación Médica, descubre la gramicidina y la tirocidina, que se convierte en el primer antibiótico comercial efectivo. En las investigaciones conducidas sobre las sustancias antibacterianas producidas por ciertos microorganismos del suelo descubre la enzima que produce la destrucción de la cápsula de los pneumococos.

Se dio entonces el nombre de penicilina a la mezcla de compuestos naturales que presentan un núcleo estructural común se diferencian por la naturaleza específica de un grupo lateral. Los nombres químicos indican precisamente la identidad de este grupo: bencilpenicilina, n-amilpenicilina, etc.

El médico australiano Howard Walter Florey y el bioquímico alemán Ernst Boris Chain, desarrollaron un método de purificación y producción en masa de la penicilina que permitió su síntesis y distribución comercial para el conjunto de la población, para su utilización sobretodo en gonorrea y sífilis. Unos años antes, en 1928, al inspeccionar sus cultivos y cuando se disponía a destruirlos, Alexander Fleming había notado que una colonia de un hongo había crecido como un contaminante en una de las placas de Petri

\footnotetext{
${ }^{38}$ J.W. Dundee, P.D. McIlroy; “The history of barbiturates”. Anaesthesia 37(7) (1982) 726/34
} 
sembrada con Staphylococcus aureus. Fleming comunicó su descubrimiento sobre la penicilina al British Journal of Experimental Pathology en 1929, no obstante la comunidad científica creyó que la penicilina sólo sería útil para tratar infecciones banales y por ello no le prestó atención.

En 1943 Selman A. Waksman, bioquímico estadounidense de origen ucraniano, aisló de determinada cepa de la especie Streptomyces, la estreptomicina, antibiótico eficaz contra los flagelos de la tuberculosis, la meningitis y la pulmonía.

Ya entrada la segunda mitad del siglo XX el azar va dejando lugar a una búsqueda cada vez más sistemática de la actividad de un compuesto y su posterior desarrollo y perfeccionamiento estructural para mejorar la toxicidad, biodisponibilidad, eficacia y especificidad, así como también minimizar los efectos adversos.

Un temprano ejemplo de diseño específico, ya clásico, fue el desarrollo del inhibidor de la enzima conversora de la angiotensina, que culminó con la obtención de un medicamento de gran aplicación actual en el tratamiento de la hipertensión arterial, el captopril. El origen de la hipertensión está vinculado con la producción de angiotensina en la sangre, un polipéptido que aumenta la presión arterial. Dado que los péptidos son destruidos durante la digestión, el químico argentino Miguel Ondetti, del laboratorio Squibb, se orientó hacia al diseño racional de inhibidores de la enzima conversora de angiotensina (ACE) más potentes y específicos, que no tuviesen estructura de péptidos. Para ello, compensaron la falta de conocimiento detallado de la estructura de la ACE con la información provista por una enzima pancreática muy similar, denominada carboxipeptidasa A (CPA), cuya arquitectura molecular terminaban de aclarar Quiocho y Lipscomb. El estudio de los complejos que resultan de la unión de la CPA con sus sustratos permitió establecer una serie de etapas y alcanzar con éxito el potente hipotensor $^{39}$.

Ni la razón estuvo ausente durante los largos períodos de la historia de la medicina en los cuales predominó el hallazgo azaroso, ni en la búsqueda y el diseño racional de un fármaco está negada esa cuota de suerte, a veces necesaria para llegar a un resultado promisorio.

\footnotetext{
${ }^{39}$ Revista Ciencia Hoy/Volumen 6 - No34 - 1996
} 


\subsubsection{El concepto de receptor}

El diseño racional de un fármaco se apoya en un pilar fundacional de la ciencia farmacéutica moderna como es el concepto de receptor biológico. Estos receptores son biomoléculas que presentan una afinidad especial por el fármaco. Erlich es el primero en utilizar el término "receptor" al referirse al grupo combinante de la molécula protoplasmática.

Hoy se acepta que la acción farmacológica de un medicamento es aparentemente desencadenada en su inicio por la formación de un complejo entre la molécula de fármaco y su sitio receptor en una macromolécula biológica. Un modelo primario para la comprensión de la interacción fármaco-receptor está basado en que todos los receptores biológicos para un fármaco son idénticos, que cada receptor es independiente de los demás y que la respuesta biológica obtenida es proporcional al número de receptores ocupados.

Si se asume que el proceso de interacción entre el fármaco y el receptor es bimolecular

$$
[\mathrm{F}]+[\mathrm{R}] \square \quad[\mathrm{FR}]
$$

La constante de disociación del complejo fármaco-receptor será

$$
\mathrm{K}_{\mathrm{D}}=[\mathrm{F}][\mathrm{R}] /[\mathrm{FR}]
$$

y de acuerdo con la hipótesis de la ocupación, el efecto máximo se obtendrá cuando estén ocupados todos los receptores, que será la suma de los receptores libres más los ocupados

$$
\left[\mathrm{RT}_{\mathrm{T}}\right]=[\mathrm{R}]+[\mathrm{FR}]
$$

Se puede deducir de estas ecuaciones la relación entre el efecto observado E y el máximo observable Emáx que corresponde a la totalidad de los receptores ocupados

$$
\mathrm{E}=\mathrm{E}_{\text {máx }}[\mathrm{F}] /\left(\mathrm{K}_{\mathrm{D}}+[\mathrm{F}]\right)
$$


Donde $\mathrm{K}_{\mathrm{D}}$ sería la concentración del fármaco que produce el $50 \%$ del efecto máximo. Esta ecuación es análoga a la de Michaelis-Menten que describe la actividad enzimática cuando ésta interacciona con un sustrato para formar el complejo y finalmente generar un producto.

Esta teoría explica bien la acción antagónica de determinados fármacos en términos de competencia por el receptor.

Por supuesto, a este modelo simple de interpretar la interacción fármaco-ligando le siguieron otros como el de Ariens. Este último permite explicar la existencia de agonistas parciales considerando primero una etapa previa de afinidad A y una segunda etapa en la que se produce el efecto fisiológico controlada por la actividad intrínseca $(\alpha)$ del fármaco

$$
[\mathrm{F}]+[\mathrm{R}] \square \quad[\mathrm{FR}] \rightarrow \text { efecto }
$$

La relación entre el efecto observado y el máximo tiene una expresión similar a la del modelo anterior pero modulada por la actividad intrínseca del fármaco, de forma tal que si $\alpha=1$ estamos en presencia de agonistas puros y si $\alpha=0$ serán antagonistas.

Una visión más abarcadora concibe a los receptores, en la mayoría de los casos lipoproteínas confinadas en las membranas plasmáticas, no sólo como diana de muchos fármacos sino también como destinatarios de continuos estímulos eléctricos y químicos responsables del control del transporte molecular y de la transformación de moléculas en otras. La interacción es ahora más compleja e involucra sustancias endógenas, exógenas (fármacos) y el receptor. Se puede disparar una cascada de acontecimientos que provoquen una respuesta biológica. Esta cascada puede transducir un mecanismo bioquímico que supone la liberación de un segundo mensajero o la apertura de un canal iónico ${ }^{40}$.

En el primer mecanismo se destacan el AMPc (adenosilmonofosfato cíclico), el GMPc (guanosilmonofosfato cíclico), el ion calcio y varios fosfoinositoles.

El receptor reconoce características estructurales del mensajero (hormonas, neurotransmisores y fármacos) que generan un alto grado de especificidad y afinidad.

\footnotetext{
${ }^{40}$ Ref. 34 capítulo 6
} 
La unión del mensajero al receptor puede provocar cambios conformacionales en la molécula del receptor que permiten la asociación con otra molécula. Este efecto puede permitir la interacción con una enzima en el lado citoplasmático de la membrana celular. Los cambios conformacionales en la enzima, a su vez, hacen que se active su sitio catalítico. Es más, en algunos casos, el complejo receptor "activado" podría, físicamente, abrir un canal iónico en la membrana o tener otros impactos profundos sobre su estructura. Este proceso se conoce como TRANSDUCCIÓN DE LA SEÑAL y a las moléculas participantes en las interacciones se los llama genéricamente transductores o moléculas transductoras.

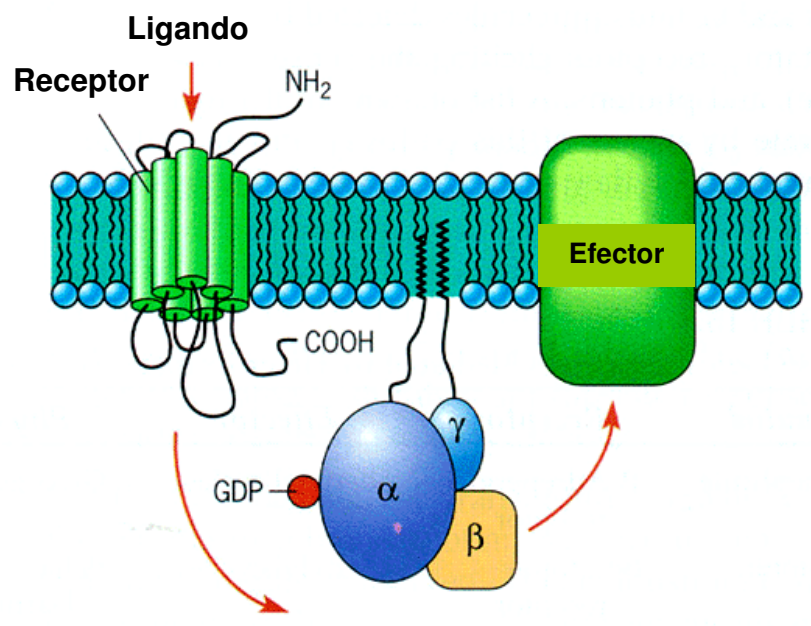

Por su racionalidad, el diseño específico es intelectualmente el más atractivo. En teoría, conociendo la estructura de la molécula biológica a la que se debe vincular una droga para actuar, es posible inferir cómo debe ser esta químicamente. Como las enzimas y los receptores son proteínas, el uso del diseño específico debió esperar que, en la segunda mitad del siglo, se realizaran progresos en la purificación y determinación de las estructuras de las proteínas.

\subsubsection{El descubrimiento, el diseño y el desarrollo}

La fase de descubrimiento de un fármaco dura desde la obtención del mismo hasta la primera aplicación en humanos y se estima que se extiende por aproximadamente 42,6 meses (3,55 años) como promedio, en aquellos países y transnacionales farmacéuticas 
con amplia infraestructura en investigación. En países con un menor nivel de desarrollo, esta fase alcanza entre unos 5 o 6 años.

La fase de desarrollo comprende la etapa de los estudios clínicos y la del registro farmacéutico, y se estima que duren entre 68.6 meses y 30.3 meses cada una. Todo este largo proceso, desde la obtención hasta el registro comprende un total de 11.8 años de investigación, con un costo promedio de 231 millones de dólares por cada nuevo medicamento que sale al mercado.

Por otra parte sólo una de cada 10000 moléculas ensayadas pasa a la fase de desarrollo, una de cada 100000 supera los ensayos clínicos y logra registrarse y sólo 3 de cada 10 nuevos medicamentos registrados recupera su inversión inicial.

Por tal razón, que por cada millón de moléculas tan sólo tres devendrán en medicamento, se hace necesario el diseño racional de fármacos. Aunque invocar a la racionalidad parezca una verdad de Perogrullo, y no solamente en el ahorro de recursos y esfuerzos en cuanto a la industria farmacéutica, es muy importante desentrañar los mecanismos por los cuales se hace efectiva esa racionalidad.

Si se conoce la base biológica de una enfermedad o de una disfunción metabólica, es posible diseñar un medicamento cuando se conoce el proceso en su nivel molecular y se pueden definir los agentes implicados en tal proceso.

Para comprender profundamente el proceso fisiológico, es necesario conocer la estructura tridimensional de la o las molécula involucradas. No siempre es posible hacerlo debido a la dificultad, por ejemplo, de cristalizar los receptores biológicos en estado sólido. Si esto puede resolverse experimentalmente se utilizan básicamente dos métodos para la determinación de estructuras como son la Resonancia Magnética Nuclear y la Cristalografía de Rayos X.

\subsubsection{El farmacóforo}

Independientemente de la vía que se utilice para lograr un nuevo fármaco, el resultado final será una nueva estructura química destinada a interactuar de manera precisa con un blanco molecular, ya sea un receptor de membrana, un canal iónico, una enzima o una proteína transportadora. ¿Qué tiene en común esta nueva molécula con otras conocidas 
y de igual actividad para que el receptor la reconozca y dispare la respuesta farmacológica?

La simple observación de analogías estructurales suele no alcanzar para responder esta pregunta, de manera que se hace necesario un análisis más exhaustivo en donde la asistencia de computadoras cobra un valor preponderante.

Podemos decir entonces que el farmacóforo no es más que el conjunto de grupos químicos, unidos o no entre sí, que todas las moléculas activas sobre un mismo receptor tienen de común entre ellas, y que son esenciales para el reconocimiento por el mismo. Aunque por propia definición de farmacóforo, éste es el mínimo conjunto de requisitos estructurales y electrónicos indispensable para una determinada actividad, ello no significa que su sola presencia en cualquier estructura química sea suficiente para disparar una respuesta farmacológica. En tal sentido puede ocurrir que otras partes de la molécula puedan interaccionar también con el sitio activo del receptor, impidiendo así la actividad del mismo. Por ello la condición de actividad farmacológica debe estar sujeta a otros requisitos como son:

$\checkmark$ El compuesto debe ser metabólicamente estable y capaz de ser transportado hasta el sitio de interacción con el receptor. Un compuesto puede resultar inactivo a pesar de parecer óptimo cuando tiene problemas de biodisponibilidad.

$\checkmark$ El compuesto debe ser capaz de asumir la conformación farmacófora, siendo importante el porcentaje que el mismo representa en el equilibrio conformacional de la molécula. Así, confórmeros que asumen el farmacóforo energéticamente estables presentarán una mayor actividad que aquellos que, debido a su inestabilidad energética sean menos abundantes en el equilibrio y por lo tanto menos disponibles a la hora de la interacción con el receptor.

$\checkmark$ El compuesto no debe presentar en su estructura otras partes que le permitan una interacción parcial con el receptor, pues estaría bloqueando la actividad del compuesto.

Las dos formas de encarar el estudio del farmacóforo tienen que ver con el conocimiento que se tenga o no del receptor. Este se puede conocer del análisis estructural cuando se ha podido cristalizar la biomolécula, como es el caso de muchas proteínas del citoplasma, y posteriormente obtener los corrimientos magnéticos de Resonancia Nuclear o el difractograma de Rayos x de la misma. En cambio eso no 
sucede cuando hablamos de canales iónicos u otros receptores a los cuales no podemos acceder por la vía experimental.

Los estudios para dilucidar el farmacóforo cuando no se conoce la estructura del receptor involucran técnicas computacionales de modelización de estructuras análogas para múltiples moléculas, el análisis conformacional, la determinación de distancias geométricas, el cálculo de potenciales electrostáticos y las técnicas de QSAR tridimensional entre otras.

Actualmente existen bancos de datos de coordenadas atómicas de macromoléculas biológicas, procedentes de cristalografía de rayos $\mathrm{X}$ y de resonancia magnética nuclear. La mayor base de datos de macromoléculas la constituye el banco de datos de proteínas (PDB) de Brookhaven que cuenta en la actualidad con varios miles de estructuras de proteínas y varios cientos de estructuras de ácidos nucleicos.

Periodicamente se cristalizan estructuras de receptores en su unión con el ligando y de esta forma es posible conocer cuáles son los grupos del ligando que interaccionan directamente con el receptor, y cuáles son sus contrapartes en la proteína.

Con estos resultados es posible conocer la naturaleza de la unión, la flexibilidad del receptor, y las interacciones que mantienen al ligando unido al mismo. También se pueden estimar las energías de estabilización de estos complejos, y además, el aporte por separado, de cada una de las regiones del ligando. Mediante este tipo de estudio, es posible definir entonces de manera más precisa y exacta, la naturaleza del farmacóforo. Además, la lectura en computadoras de estos datos del complejo fármaco-receptor, permite la manipulación del ligando y la inserción de otros ligandos en la cavidad de unión, pudiendo analizar la naturaleza de la interacción entre estos nuevos sustratos con el receptor. De esta forma se puede permitir la inserción de estructuras construidas o diseñadas para su ajuste con el receptor, generando nuevas entidades con potencial actividad famacológica ${ }^{41}$.

En las últimas dos décadas han surgido tecnologías novedosas para la búsqueda de nuevos agentes terapéuticos que fueron incorporadas como práctica común a nivel de la industria farmacéutica internacional. Uno es el Screening de Alta Performance o High

\footnotetext{
${ }^{41}$ Julio César Escalona Arranz, Ramón Carrasco Velar y Juan Alexander Padrón García; Diseño racional de fármacos / Editorial Universitaria, Ciudad de La Habana (2008). ISBN 978-959-16-0647-1
} 
Throughput Screening (HTS), que conjuga robótica y microensayos para evaluar biológicamente, mediante ensayos in vitro frente a receptores o enzimas, pequeñas cantidades de compuestos contra un gran número de blancos moleculares.

Otro es el Screening Virtual (SV), un conjunto de técnicas computacionales que permiten, a partir de representaciones de la estructura molecular de los compuestos químicos almacenados en grandes bases de datos, identificar compuestos potencialmente interesantes desde el punto de vista farmacológico. Este último método tiene entre sus atributos la rapidez, ya que el estado de la técnica permite explorar bases de datos de varios millones de estructuras químicas en períodos de tiempo del orden de semanas; una vez que el laboratorio ha desarrollado o adquirido una base de datos y el software necesario para aplicar una metodología de screening, el costo se reduce al tiempo que el proceso demanda al personal especializado. Considerando que existen diversas bases de datos de estructuras químicas de dominio público, como es el caso de Pubchem (que actualmente incluye más de 40 millones de estructuras químicas) o ChemIDplus 7.8, la inversión mínima se reduce al equipo computacional necesario y al software específico. Además no requiere (como el HTS) disponer de cantidades de los compuestos evaluados y puede realizarse incluso sobre estructuras hipotéticas. La adquisición o síntesis del compuesto se realiza con posterioridad a la selección computacional de la base de datos, y solamente se ensayan aquellos compuestos promisorios que son señalados como candidatos a presentar la actividad farmacológica buscada. También es posible encontrar nuevas indicaciones terapéuticas para fármacos ya conocidos y aplicados en clínica, lo cual permite responder a necesidades terapéuticas de la población en tiempos relativamente breves, ya que se puede prescindir, al menos parcialmente, de los ensayos preclínicos de toxicidad aguda y crónica y de los ensayos clínicos orientados a establecer la seguridad del fármaco. Por último responde a la filosofía de las pautas de bioética vigentes a nivel internacional, que proponen utilizar modelos computacionales $\mathrm{y}$ ensayos in vitro previos a la realización de ensayos preclínicos y clínicos in vivo ${ }^{42}$.

\subsubsection{Las correlaciones estructura/actividad}

\footnotetext{
${ }^{42}$ A. Talevi, L. E. Bruno-Blanch; Lat. Am. J. Pharm. 28 (1): 141-50 (2009)
} 
Los métodos que buscan establecer relaciones entre la estructura molecular de un compuesto y su actividad biológica se denominan QSAR (Relaciones Cuantitativas Estructura-Actividad) ${ }^{43}$. Las diversas formulaciones de la Teoría QSAR sugieren modelos matemáticos capaces de estimar propiedades biológicas relevantes, especialmente cuando no se dispone de información experimental medida. Tales estudios asumen que la estructura química de una sustancia es causante de las propiedades que manifiesta. Por tanto, se traduce la estructura molecular en variables numéricas con interpretación física de alguna clase, conocidas como descriptores moleculares, a través de ecuaciones matemáticas obtenidas de diferentes teorías, tales como la Teoría de Grafos Química, la Teoría de la Información, la Mecánica Cuántica, $\operatorname{etc}^{44,45,46}$. Existen miles de descriptores asequibles en la literatura, y uno enfrenta usualmente el problema de seleccionar aquellos que resulten más representativos para la propiedad en consideración.

Los diversos métodos usados en las técnicas de QSAR encuentran los primeros antecedentes en la relación que estableció Hammett, en 1937, entre la constante de ionización del ácido benzoico y las propiedades atractoras o donoras de electrones de distintos sustituyentes para el ácido ${ }^{47}$.

En el análisis de Free Wilson, las relaciones cuantitativas de estructura-actividad correlacionan constantes de inhibición y otras actividades biológicas con rasgos estructurales, dentro de una serie congenérica de compuestos con afinidades de ligandos a su sitio de unión.

Las propiedades moleculares, grupales o atómicas, tales como lipofilicidad, polarizabilidad, electrónicas y estéricas son el tipo de relaciones que estableció Hansch $^{48}$.

CoMFA (Comparative Molecular Field Analysis) es una técnica 3D QSAR basada en bases de datos de moléculas activas conocidas para usar cuando se desconoce la estructura 3D del receptor. En esta técnica se determina la actividad de los compuestos

\footnotetext{
43 C. Hansch, A. Leo; Exploring QSAR. Fundamentals and Applications in Chemistry and Biology, American Chemical Society, Washington, D. C., 1995

${ }^{44}$ A.R. Katritzky y col Chem. Soc. Rev. 24 (1995) 279

${ }^{45}$ R. Todeschini, V. Consonni, Handbook of Molecular Descriptors, Wiley VCH, Weinheim (Germany), 2000

${ }^{46}$ N. Trinajstic, Chemical Graph Theory, CRC Press, Boca Raton (FL), 1992

${ }^{47}$ C. Hansch, P. Maloney, T. Fujita, T. and R. Muir; Nature 194 (1962) 178-180

${ }^{48}$ C. Hansch and A. Leo; Exploring QSAR. Fundamentals and Applications in Chemistry and Biology; American Chemical Society; 1995
} 
y se obtiene la estructura 3D de la molécula por análisis de difracción de rayos X o bien derivando de un diagrama 2D y posterior optimización computacional. El propósito de CoMFA es derivar una correlación entre la actividad biológica de un set de moléculas y sus propiedades geométricas, electrostáticas y de uniones hidrógeno 3D. Esta correlación se deriva de una serie de conformaciones superpuestas, una por cada molécula del conjunto. Se asume que tales conformaciones son las biológicamente activas, cosa que no siempre es cierto, en su modo común de unión.

Se toma cada conformación por vez y se calcula el campo molecular, electrostático y estérico, alrededor de la misma usando un átomo de prueba de carga +1 . El mismo se mide en una grilla tridimensional donde se ubican todas las moléculas activas. El análisis para predecir actividad a partir de los puntos de la grilla se hace con análisis parcial de cuadrados mínimos (PLS). La mayor parte de las aplicaciones está en las interacciones entre proteína-ligando, en lo que respecta a la descripción de constantes de inhibición o de afinidad ${ }^{49}$.

\subsection{El trabajo}

El estudio de compuestos de interés farmacológico permite una muy vasta diversidad de enfoques desde disciplinas en apariencia inconexas como la Informática y la Biología, lo que permite enriquecer de manera cooperativa los resultados que salen de una visión multidisciplinaria y un entrecruzamiento de las herramientas propias de cada una. Desde el campo de la Fisicoquímica podemos aportar con el estudio del sistema en lo que hace a sus propiedades moleculares, electrónicas, vibracionales, magnéticas teniendo como norte el aprovechamiento de esta información para establecer relaciones útiles orientadas a la actividad farmacológica.

En el trabajo encarado en esta tesis se avanza en los primeros pasos en el uso de computadoras con el propósito de su empleo para el estudio de compuestos con viabilidad farmacéutica. Para ello se recorrió un camino de aprendizaje y familiarización con el uso de programas de Modelado Molecular, el uso de software de Optimización de estructuras moleculares y cálculo de propiedades electrónicas. También se calcularon frecuencias vibracionales, corrimientos químicos RMN y

\footnotetext{
${ }^{49}$ H. Kubinyi, (ed.), ‘3D QSAR in Drug Design. Theory, methods and applications', ESCOM, Leiden, 1993
} 
Potenciales electrostáticos. Estas propiedades, además de tener una importancia en sí mismas en lo que significa la validación de métodos computacionales, reviste un singular interés en su uso como descriptores para los antes mencionados análisis de correlación estructura-actividad. Es así que la proyección del trabajo abordado en esta tesis encuentra un horizonte inmediato en el estudio a fondo de un sistema más ambicioso que involucre el receptor del conjunto de moléculas estudiada, tema que seguramente dará lugar a nuevas satisfacciones y, lo que es mejor aún, a nuevos interrogantes. 
Capítulo 2: EL MÉTODO 


\section{EL MÉTODO}

\subsection{La Ecuación de Schrödinger}

La mecánica cuántica explica el doble comportamiento de los electrones como partículas en el sentido físico del término, pero también como ondas. La ecuación de Schrödinger describe la función de onda de tal partícula

$$
\left\{\frac{-\mathrm{h}^{2}}{8 \pi^{2} \mathrm{~m}} \nabla^{2}+\mathrm{V}\right\} \Psi(\overrightarrow{\mathrm{r}}, \mathrm{t})=\frac{\mathrm{ih}}{2 \pi} \frac{\partial}{\partial \mathrm{t}} \Psi *(\overrightarrow{\mathrm{r}}, \mathrm{t})
$$

En esta ecuación, $\Psi$ es la función de onda, $m$ es la masa de la partícula, $h$ es la constante de Planck y $\mathrm{V}$ es el campo de energía potencial en el cual la partícula se mueve $^{50}$. El operador nabla cuadrado $\nabla^{2}$ es el Laplaciano y tiene la forma

$$
\nabla^{2}=\frac{\partial^{2}}{\partial x^{2}} \overrightarrow{\mathrm{i}}+\frac{\partial^{2}}{\partial y^{2}} \overrightarrow{\mathrm{j}}+\frac{\partial^{2}}{\partial z^{2}} \overrightarrow{\mathrm{k}}
$$

El producto de $\Psi$ con su compleja conjugada $\Psi *$ se interpreta como la función de distribución de probabilidad de la partícula, de manera que la normalización de esta función conduce a que $\int \Psi * \Psi \mathrm{d} \tau=1$ y permite asegurar que en términos de probabilidad la partícula está en el espacio tridimensional ${ }^{51}$.

Con el fin de simplificar la notación de éstas y otras ecuaciones íntegro-diferenciales Dirac introdujo una nomenclatura denominada braket, donde cualquier función $f$ se puede escribir $|f\rangle$ y nombrarse ket mientras que el bra sería su compleja conjugada $f^{*}$ y se escribe $\langle f|$, de forma que la normalización de la función de distribución se puede escribir en la notación de Dirac como $\langle\Psi \mid \Psi\rangle=1$.

La ecuación de Schrödinger para una colección de partículas, como es el caso de una molécula, es similar. Para tales sistemas $\Psi$ es función de las coordenadas de todas las partículas y del tiempo.

\footnotetext{
${ }^{50}$ E. Schrödinger; Ann. Physik 79 (1926)

${ }^{51}$ F. L. Pilar; Elementary Quantum Chemistry; McGraw-Hill, Inc., USA 1968
} 
La energía y otras propiedades de la molécula se obtienen resolviendo la ecuación de Schrödinger para condiciones de contorno apropiadas. Hay muchas funciones de onda diferentes que son soluciones de esta ecuación, y corresponden a diferentes estados estacionarios del sistema ${ }^{52}$.

Si V no es función del tiempo, la ecuación de Schrödinger se puede simplificar usando la técnica matemática de separación de variables, y entonces escribimos la función como el producto de una función espacial por una función del tiempo

$$
\Psi(\overrightarrow{\mathrm{r}}, \mathrm{t})=\psi(\overrightarrow{\mathrm{r}}) \tau(\mathrm{t})
$$

Al reemplazar esta nueva función en la ecuación (1), obtenemos dos ecuaciones independientes una de otra. Una de ellas es dependiente del tiempo y la otra no. Para el tipo de problemas que abordamos usamos la ecuación de Schrödinger independiente del tiempo que se escribe

$$
\mathrm{H} \psi(\overrightarrow{\mathrm{r}})=\mathrm{E} \psi(\overrightarrow{\mathrm{r}})
$$

Donde E es la energía de la partícula y $\mathrm{H}$ el operador Hamiltoniano que es

$$
\mathrm{H}=\frac{-\mathrm{h}^{2}}{8 \pi^{2} \mathrm{~m}} \nabla^{2}+\mathrm{V}
$$

Las diferentes soluciones a la ecuación corresponden a los diferentes estados estacionarios de la partícula. Aquélla que proporciona el menor valor de la energía se denomina estado fundamental. Esta ecuación es una descripción no relativista del sistema válida para los casos en los que la velocidad de la partícula no se acerca a la velocidad de la luz, por lo que no la podemos usar para describir el core de electrones en átomos pesados.

\footnotetext{
${ }^{52}$ I. N. Levine; Quantum Chemistry; Allyn and Bacon; Inc., Boston 1974
} 


\subsection{El Hamiltoniano Molecular}

Para un sistema molecular, $\psi$ es una función de las posiciones de los electrones y los núcleos que pertenecen a la molécula, a las que denominamos $\overrightarrow{\mathrm{r}}$ y $\overrightarrow{\mathrm{R}}$ respectivamente. Estos símbolos representan el conjunto de vectores que describe la posición de cada partícula. Para designar un electrón y un núcleo particulares le asignamos el subíndice $\overrightarrow{r_{i}}$ y $\overrightarrow{R_{A}}$.

El Hamiltoniano es la suma de dos términos, uno es la energía cinética del sistema y el otro su energía potencial.

$$
\begin{gathered}
\mathrm{H}=\mathrm{T}+\mathrm{V} \\
\mathrm{H}(\mathrm{r}, \mathrm{R})=\mathrm{T}_{\mathrm{n}}(\mathrm{R})+\mathrm{T}_{\mathrm{e}}(\mathrm{r})+\mathrm{V}_{\mathrm{ee}}(\mathrm{r}, \mathrm{r})+\mathrm{V}_{\mathrm{ne}}(\mathrm{r}, \mathrm{R})+\mathrm{V}_{\mathrm{nn}}(\mathrm{R}, \mathrm{R})
\end{gathered}
$$

La energía cinética es la suma del laplaciano de todas las partículas en la molécula

$$
\mathrm{T}=-\frac{\mathrm{h}^{2}}{8 \pi^{2}} \sum_{\mathrm{k}} \frac{1}{\mathrm{~m}_{\mathrm{k}}}\left(\frac{\partial^{2}}{\partial x_{k}^{2}}+\frac{\partial^{2}}{\partial y_{k}^{2}}+\frac{\partial^{2}}{\partial z_{k}^{2}}\right)
$$

Para un electrón la carga es -e, mientras que para el núcleo es Ze y $\mathrm{Z}$ es el número atómico para el átomo. Entonces, para el sistema molecular si $\mathrm{N}$ es el número de electrones y M el número de núcleos, la energía potencial es la energía de interacción de Coulomb entre las cargas constituyentes de la molécula, que involucran la interacción electrón-núcleo, núcleo-núcleo y electrón-electrón ${ }^{53}$.

$$
\mathrm{V}=\frac{1}{4 \pi \varepsilon_{\mathrm{o}}}\left(-\sum_{\mathrm{i}}^{\mathrm{N}} \sum_{\mathrm{A}}^{\mathrm{M}} \frac{\mathrm{Z}_{\mathrm{A}} \mathrm{e}^{2}}{\mathrm{r}_{\mathrm{iA}}}+\sum_{\mathrm{A}}^{\mathrm{M}} \sum_{\mathrm{B}}^{\mathrm{M}} \frac{\mathrm{Z}_{\mathrm{A}} \mathrm{Z}_{\mathrm{B}} \mathrm{e}^{2}}{\mathrm{R}_{\mathrm{AB}}}+\sum_{\mathrm{i}}^{\mathrm{N}} \sum_{\mathrm{j}}^{\mathrm{N}} \frac{\mathrm{e}^{2}}{\mathrm{r}_{\mathrm{ij}}}\right)
$$

\footnotetext{
${ }^{53}$ Ref 2 , cap. 15
} 
Unidades atómicas

Las ecuaciones fundamentales de la química cuántica se expresan en unidades tales que se eliminan las constantes fundamentales. La unidad atómica de longitud es el radio de Bohr

$$
\mathrm{a}_{\mathrm{o}}=\frac{\mathrm{h}^{2}}{4 \pi^{2} \mathrm{~m}_{\mathrm{o}} \mathrm{e}^{2}}=0.52917725 \stackrel{0}{\mathrm{~A}}
$$

Y las coordenadas se pueden dividir por $a_{o}$ para ser transformadas a bohrs.

Las energías se miden en hartrees, que se define como la energía de repulsión coulómbica entre dos electrones separados por un bohr.

$$
1 \text { hartree }=\frac{\mathrm{e}^{2}}{\mathrm{a}_{\mathrm{o}}}
$$

Las masas están especificadas en relación a la masa del electrón que es la unidad.

Utilizando las unidades atómicas podemos reescribir el hamiltoniano molecular de la forma

$$
\mathrm{H}=-\frac{1}{2} \sum_{\mathrm{A}}^{\mathrm{M}} \frac{\nabla_{\mathrm{A}}^{2}}{\mathrm{~m}_{\mathrm{A}}}-\frac{1}{2} \sum_{\mathrm{i}}^{\mathrm{N}} \nabla_{\mathrm{i}}^{2}-\sum_{\mathrm{A}}^{\mathrm{M}} \sum_{\mathrm{i}}^{\mathrm{N}} \frac{\mathrm{Z}_{\mathrm{A}}}{\mathrm{r}_{\mathrm{iA}}}+\sum_{\mathrm{A}}^{\mathrm{M}-1} \sum_{\mathrm{B}>\mathrm{A}}^{\mathrm{M}} \frac{\mathrm{Z}_{\mathrm{A}} \mathrm{Z}_{\mathrm{B}}}{\mathrm{R}_{\mathrm{AB}}}+\sum_{\mathrm{i}}^{\mathrm{N}-1} \sum_{\mathrm{j}>\mathrm{i}}^{\mathrm{N}} \frac{1}{\mathrm{r}_{\mathrm{ij}}}
$$

El último término es la causa por la cual es imposible resolver de manera exacta la ecuación de Schrödinger, por lo que se hace necesario introducir una serie de aproximaciones apoyadas en dos importantes métodos aplicados a la mecánica cuántica, el método variacional y la teoría de perturbaciones. Antes de explicar estas dos es conveniente introducir una simplificación para el tratamiento de estos sistemas que es la aproximación de Born-Oppenheimer ${ }^{54}$.

\subsection{La aproximación de Born-Oppenheimer}

Esta es la primera de varias aproximaciones usadas en la mecánica cuántica para simplificar la resolución de la ecuación de Schrödinger y consiste en desacoplar el movimiento de los electrones del movimiento de los núcleos, lo cual es razonable ya

\footnotetext{
${ }^{54}$ J. Foresman, A. Fisch; Exploring Chemistry with Electronic Structure Methods; Gaussian, Inc.; USA 1993
} 
que la masa de los núcleos es miles de veces más grande que la de los electrones. Por lo mismo los núcleos se mueven mucho más lentamente que los electrones y los cambios de estos últimos se pueden considerar instantáneos respecto del movimiento nuclear. La distribución electrónica depende así de las posiciones de los núcleos y no de sus velocidades, de tal forma que se puede describir el movimiento de los electrones dentro de un campo de núcleos fijos. Esto nos permite escribir el hamiltoniano de los electrones separado del hamiltoniano nuclear

$$
\mathrm{H}^{\text {elec }}(\mathrm{r}) \Psi^{\text {elec }}(\mathrm{r} ; \mathrm{R})=\mathrm{E}^{\text {elec }}(\mathrm{R}) \Psi^{\text {elec }}(\mathrm{r} ; \mathrm{R})
$$

Se ve así que la energía electrónica depende paramétricamente de las coordenadas del núcleo. Esta energía describe la superficie de energía potencial del sistema y es usada como potencial efectivo cuando se resuelve el hamiltoniano nuclear. La energía electrónica $E^{\text {elec }}$ combinada junto con $V_{n n}(R, R)$ es la energía electrónica total.

El hamiltoniano nuclear describe el movimiento de los núcleos, y como éstos se mueven mucho más lentamente que los electrones, se puede reemplazar el movimiento detallado de estos últimos por su promedio

$$
\begin{aligned}
& H(R)=H(R,\langle r\rangle)=T_{n}(R)+\left\langle H_{\text {elec }}\right\rangle+V_{\text {nn }}(R, R) \\
& H(R)=T_{n}(R)+E_{\text {elec }}(R)+V_{n n}(R, R)
\end{aligned}
$$

La energía electrónica Eelec sumada al potencial de interacción núcleo-núcleo $\mathrm{V}_{\mathrm{nn}}(\mathrm{R}, \mathrm{R})$ proporciona el potencial para calcular la Superficie de Energía Potencial (PES, por sus siglas en inglés)

$$
\mathrm{V}_{\operatorname{PES}}(\mathrm{R})=\mathrm{V}(\mathrm{R})=\mathrm{E}_{\text {elec }}(\mathrm{R})+\mathrm{V}_{\mathrm{nn}}(\mathrm{R}, \mathrm{R})
$$

Entonces la ecuación que describe el hamiltoniano nuclear queda

$$
H(R)=T_{n}(R)+V(R)
$$


Las soluciones a esta ecuación describen los estados traslacionales, rotacionales y vibracionales del sistema molecular. En la superficie de energía potencial se describe el movimiento de los núcleos en función de sus coordenadas $\mathrm{R}$, pero teniendo en cuenta la validez de la aproximación de Born-Oppenheimer no es erróneo pensar la misma en términos de coordenadas de los átomos en una molécula ${ }^{4,55,56}$.

\subsection{El Teorema Variacional}

El principio variacional enuncia que la energía del estado fundamental de cualquier función antisimétrica de las coordenadas electrónicas normalizada $\varphi$, a la que se le llama función de prueba, será siempre mayor que la energía para la función de onda exacta $\psi^{57}$

$$
\mathrm{E}(\varphi)>\mathrm{E}(\psi)
$$

y por tanto, ésta es el límite inferior para cualquier otra calculada con la función de prueba. En este método se define el funcional

$$
\varepsilon[\varphi]=\frac{\langle\varphi|\mathrm{H}| \varphi\rangle}{\langle\varphi \mid \varphi\rangle}
$$

y se ejecuta una variación arbitraria sobre la función de prueba tal que $\delta \varepsilon[\varphi]=0$

De acuerdo al principio de superposición de estados, si se conoce el conjunto de autofunciones de un hamiltoniano, se puede escribir la función que describe el comportamiento del sistema como una combinación lineal de tales autofunciones

$$
\Psi=\sum_{\mathrm{i}} \mathrm{c}_{\mathrm{i}} \psi_{\mathrm{i}}
$$

\footnotetext{
${ }^{55}$ Ref. 5, apéndice A

${ }^{56}$ M. Born, J. R. Oppenheimer; Ann. Phys. 84 (1927)

${ }^{57}$ S. T. Epstein, The Variation Methods in Quantum Chemistry; Academic Press; NY 1974
} 
Se puede escoger una función de prueba que sea una combinación lineal de funciones de un conjunto completo dado $\left\{\chi_{i}\right\}$ conocido

$$
\varphi=\sum_{\mathrm{i}} \mathrm{a}_{\mathrm{i}} \chi_{\mathrm{i}}
$$

Ahora la variación se hará sobre los coeficientes y, de esta manera, el problema a resolver es encontrar el conjunto de coeficientes para esta función que minimicen la energía. Para esto reemplazamos la ecuación (22) en el funcional $\varepsilon[\varphi]$ y derivamos respecto del conjunto de los coeficientes para hacer la ecuación igual a cero. Se obtiene la conocida ecuación secular ${ }^{58}$

$$
\sum_{\mathrm{i}}\left(\mathrm{h}_{\mathrm{ij}}-\varepsilon \mathrm{s}_{\mathrm{ij}}\right) \mathrm{a}_{\mathrm{i}}=0, \quad \mathrm{j}=1,2, \ldots
$$

donde

$$
\mathrm{h}_{\mathrm{ij}}=\left\langle\chi_{\mathrm{i}}|\mathrm{H}| \chi_{\mathrm{j}}\right\rangle
$$

$\mathrm{y}$

$$
\mathrm{s}_{\mathrm{ij}}=\left\langle\chi_{\mathrm{i}} \mid \chi_{\mathrm{j}}\right\rangle
$$

La solución a la ecuación 23 se obtiene encontrando las raíces del determinante secular

$$
\operatorname{det}\left(\mathrm{h}_{\mathrm{ij}}-\varepsilon \mathrm{s}_{\mathrm{ij}}\right)=0
$$

en la práctica se trunca la expansión (22) a un valor determinado debido a la imposibilidad de utilizar las infinitas funciones del conjunto.

En virtud del teorema de Eckart ${ }^{59}$ se cumple que si Eo es el autovalor del sistema en estudio entonces

$$
\varepsilon[\varphi] \geq \mathrm{E}_{\mathrm{o}}
$$

\footnotetext{
${ }^{58}$ Ref. 3, capítulo 8

${ }^{59}$ C.E. Eckart, Phys. Rev. 36 (1930) 878
} 


\subsection{La Teoría de Perturbaciones}

Si el hamiltoniano del sistema es tal que no posee solución exacta

$$
\mathrm{H} \psi_{\mathrm{n}}=\mathrm{E}_{\mathrm{n}} \psi_{\mathrm{n}}
$$

dividimos el hamiltoniano en dos partes

$$
\mathrm{H}=\mathrm{H}_{\mathrm{o}}+\mathrm{V}
$$

donde $\mathrm{H}_{\mathrm{o}}$ es el hamiltoniano con solución exacta y $\mathrm{V}$ es una perturbación aplicada a Ho que tiene un efecto muy pequeño respecto de éste. Esta perturbación se puede expandir en términos de algún parámetro real $\lambda$ de modo que

$$
\mathrm{V}=\lambda \mathrm{H}^{(1)}+\lambda^{2} \mathrm{H}^{(2)}+\ldots \quad=\sum_{\mathrm{i}=1}^{\infty} \lambda^{\mathrm{i}} \mathrm{H}^{(\mathrm{i})}
$$

la perturbación es tal que $\lim _{\lambda \rightarrow 0} \mathrm{H}=\mathrm{H}_{\circ}$

Las soluciones a la ecuación 28 se expresan como potencias de $\lambda$

$$
\begin{aligned}
& \psi_{\mathrm{n}}=\sum_{\mathrm{i}} \lambda^{\mathrm{i}} \psi_{\mathrm{n}}^{\mathrm{i}} \\
& \mathrm{E}_{\mathrm{n}}=\sum_{\mathrm{i}} \lambda^{\mathrm{i}} \mathrm{E}_{\mathrm{n}}^{\mathrm{i}}
\end{aligned}
$$

donde $\psi_{n}^{\mathrm{i}}$ y $\mathrm{E}_{\mathrm{n}}^{\mathrm{i}}$ son la correcciones de orden i a la autofunción y a la energía que describen el n-ésimo estado del sistema perturbado. Como el conjunto de funciones $\left\{\psi_{\mathrm{n}}^{\mathrm{o}}\right\}$ del sistema sin perturbar es conocido y completo se pueden expresar las correcciones a la función perturbada en términos de las no perturbadas

$$
\psi_{\mathrm{n}}^{\mathrm{k}}=\sum_{\mathrm{i}} \mathrm{c}_{\mathrm{in}}^{\mathrm{k}} \psi_{\mathrm{n}}^{\mathrm{o}}
$$


Para resolver las correcciones se reemplazan en la ecuación 28 las ecuaciones 29, 30, 31 y 33; luego se desarrollan e igualan los términos con idéntica potencia en $\lambda$. Para $\lambda^{0}$ se obtiene la ecuación del hamiltoniano sin perturbar, y para cada valor de $\mathrm{k} \geq 1$ se obtienen ecuaciones que serán el punto de partida para los órdenes subsiguientes ${ }^{60}$.

\subsection{El método de Hartree-Fock}

Se define un hamiltoniano monoelectrónico de la forma $\mathcal{H}_{i}^{o}=-\frac{1}{2} \nabla_{\mathrm{i}}^{2}-\sum \frac{\mathrm{Z}}{\mathrm{r}_{\mathrm{i}}}$ que contiene en el primer término la energía cinética del i-ésimo electrón y en el segundo la energía potencial de atracción coulómbica con los núcleos. El hamiltoniano para $\mathrm{N}$ electrones no ineractuantes será $\mathcal{H}^{o}=\sum_{\mathrm{i}=1}^{\mathrm{N}} \mathcal{H}_{i}^{o}$ y el hamiltoniano correcto no relativista que considera la repulsión entre electrones es $\mathcal{H}=\mathcal{H}^{o}+\sum_{\mathrm{i}<\mathrm{j}}^{\mathrm{N}} \frac{1}{\mathrm{r}_{\mathrm{j}}}$

Hartree propuso una función de prueba que es producto de funciones monoelectrónicas

$$
\psi(1,2, \ldots, \mathrm{N})=\prod_{\mathrm{i}=1}^{\mathrm{N}} \phi_{\mathrm{i}}(\mathrm{i})
$$

A estas funciones monoelectrónicas se las denomina orbitales aunque no son las clásicas hidrogenoides y aún están indefinidas. Estas funciones de Hartree no tienen en cuenta el espín electrónico ni el principio de exclusión de Pauli. Una función que describa el comportamiento de los electrones (fermiones) debe ser antisimétrica para el intercambio de las coordenadas. Más adelante veremos como las funciones determinantales de Slater dan cuenta de esto y además incluyen el problema del espín.

Estas funciones de Hartree $^{61}$ pueden usarse para definir un potencial efectivo unielectrónico. Este potencial se puede interpretar, desde una analogía con la física clásica, como la interacción de la carga del i-ésimo electrón con las cargas de los N-1 electrones restantes, y puede entenderse como un potencial promedio que siente un electrón en el campo creado por los otros $\mathrm{j} \neq \mathrm{i}$ electrones

\footnotetext{
${ }^{60}$ Ref. 3, capítulo 9

${ }^{61}$ D. R. Hartree; Proc. Cambridge Phil. Soc. 24 (1928) 89
} 


$$
\mathrm{V}_{\mathrm{i}}^{\mathrm{ef}}=\sum_{\mathrm{j} \neq \mathrm{i}}^{\mathrm{N}}\left\langle\phi_{\mathrm{j}}(\mathrm{j})\left|\frac{1}{\mathrm{r}_{\mathrm{ij}}}\right| \phi_{\mathrm{j}}(\mathrm{j})\right\rangle
$$

Usando este potencial se puede separar la ecuación de onda en términos de las coordenadas electrónicas individuales y resolver $\mathrm{N}$ ecuaciones independientes de la forma

$$
\left(\mathcal{H}_{i}^{o}+\mathrm{V}_{\mathrm{i}}^{\mathrm{ef}}\right) \phi_{\mathrm{i}}(\mathrm{i})=\varepsilon_{\mathrm{i}} \phi_{\mathrm{i}}(\mathrm{i})
$$

donde $\varepsilon_{\mathrm{i}}$ es la energía orbital, y si definimos

$$
\mathcal{H}_{i}^{e f}=\left(\mathcal{H}_{i}^{o}+\mathrm{V}_{\mathrm{i}}^{\text {ef }}\right)
$$

entonces

$$
\mathcal{H}_{i}^{e f} \phi_{\mathrm{i}}(\mathrm{i})=\varepsilon_{\mathrm{i}} \phi_{\mathrm{i}}(\mathrm{i})
$$

Estas ecuaciones se resuelven mediante una técnica iterativa usando un método de aproximaciones sucesivas desde un conjunto de funciones de prueba que se van mejorando en cada paso de iteración. Como las ecuaciones son íntegro-diferenciales se deben usar técnicas numéricas. El proceso se repite hasta que algún conjunto de operadores de Coulomb conduce a operadores de Hartree que satisfacen para todo i que

$$
\begin{aligned}
& \mathcal{H}_{i}^{n} \approx \mathcal{H}_{i}^{n+1}=\mathcal{H}^{S C F} \\
& \phi_{\mathrm{i}}^{\mathrm{n}}(\mathrm{i}) \approx \phi_{\mathrm{i}}^{\mathrm{n}+1}(\mathrm{i})=\phi_{\mathrm{i}}(\mathrm{i})
\end{aligned}
$$

De esta forma los orbitales son tales que las distribuciones de carga que de ellos se generan son las que producen el campo y se dice que los electrones se mueven en un campo autoconsistente (SCF) ${ }^{62}$.

Como dijimos antes es necesario encontrar una función de prueba que se comporte bien para un sistema electrónico. La función antisimétrica al intercambio de coordenadas de dos electrones cualesquiera más simple y que a la vez satisface el principio de exclusión

\footnotetext{
${ }^{62}$ Ref. 2, capítulo 8
} 
es un determinante. Teniendo en cuenta el espín del electrón se definen dos funciones de espín, $\alpha$ y $\beta$, de forma tal que

$$
\begin{aligned}
& \alpha(\uparrow)=1 \quad \alpha(\downarrow)=0 \\
& \beta(\uparrow)=0 \quad \beta(\downarrow)=1
\end{aligned}
$$

Multiplicando una función orbital molecular por $\alpha$ o $\beta$ se incluirá el espín del electrón como parte de la función de onda electrónica completa. El producto del orbital molecular por la función de espín se llama espín orbital. Para $\mathrm{N}$ electrones que ocuparán $\frac{\mathrm{N}}{2}$ orbitales espaciales el determinante se escribe

$$
\phi(\overrightarrow{\mathrm{r}})=\frac{1}{\sqrt{\mathrm{N}} !}\left|\begin{array}{ccccccc}
\varphi_{1}\left(\overrightarrow{\mathrm{r}}_{1}\right) \alpha(1) & \varphi_{1}\left(\overrightarrow{\mathrm{r}}_{\mathrm{r}}\right) \beta(1) & \varphi_{2}\left(\overrightarrow{\mathrm{r}}_{\mathrm{r}}\right) \alpha(1) & \varphi_{2}\left(\overrightarrow{\mathrm{r}}_{\mathrm{r}}\right) \beta(1) & \cdots & \varphi_{\frac{N}{2}}\left(\overrightarrow{\mathrm{r}}_{1}\right) \alpha(1) & \varphi_{\frac{N}{2}}\left(\overrightarrow{\mathrm{r}}_{1}\right) \beta(1) \\
\varphi_{1}\left(\overrightarrow{\mathrm{r}}_{2}\right) \alpha(2) & \varphi_{1}\left(\overrightarrow{\mathrm{r}}_{2}\right) \beta(2) & \varphi_{2}\left(\overrightarrow{\mathrm{r}}_{2}\right) \alpha(2) & \varphi_{2}\left(\overrightarrow{\mathrm{r}}_{2}\right) \beta(2) & \cdots & \varphi_{\frac{N}{2}}\left(\overrightarrow{\mathrm{r}}_{2}\right) \alpha(2) & \varphi_{\frac{N}{2}}\left(\overrightarrow{\mathrm{r}}_{2}\right) \beta(2) \\
\vdots & \vdots & & & & \vdots & \vdots \\
\varphi_{1}\left(\overrightarrow{\mathrm{r}}_{\mathrm{i}}\right) \alpha(\mathrm{i}) & \varphi_{1}\left(\overrightarrow{\mathrm{r}}_{\mathrm{i}}\right) \beta(\mathrm{i}) & \varphi_{2}\left(\overrightarrow{\mathrm{r}}_{\mathrm{i}}\right) \alpha(\mathrm{i}) & \varphi_{2}\left(\overrightarrow{\mathrm{r}}_{\mathrm{i}}\right) \beta(\mathrm{i}) & \cdots & \varphi_{\frac{N}{2}}\left(\overrightarrow{\mathrm{r}}_{\mathrm{i}}\right) \alpha(\mathrm{i}) & \varphi_{\frac{N}{2}}\left(\overrightarrow{\mathrm{r}}_{\mathrm{i}}\right) \beta(\mathrm{i}) \\
\varphi_{1}\left(\overrightarrow{\mathrm{r}}_{\mathrm{j}}\right) \alpha(\mathrm{j}) & \varphi_{1}\left(\overrightarrow{\mathrm{r}}_{\mathrm{j}}\right) \beta(\mathrm{j}) & \varphi_{2}\left(\overrightarrow{\mathrm{r}}_{\mathrm{j}}\right) \alpha(\mathrm{j}) & \varphi_{2}\left(\overrightarrow{\mathrm{r}}_{\mathrm{j}}\right) \beta(\mathrm{j}) & \cdots & \varphi_{\frac{N}{2}}\left(\overrightarrow{\mathrm{r}}_{\mathrm{j}}\right) \alpha(\mathrm{j}) & \varphi_{\frac{N}{2}}\left(\overrightarrow{\mathrm{r}}_{\mathrm{j}}\right) \beta(\mathrm{j}) \\
\vdots & \vdots & & & & \vdots & \vdots \\
\varphi_{1}\left(\overrightarrow{\mathrm{r}}_{\mathrm{N}}\right) \alpha(\mathrm{N}) & \varphi_{1}\left(\overrightarrow{\mathrm{r}}_{\mathrm{N}}\right) \beta(\mathrm{N}) & \varphi_{2}\left(\overrightarrow{\mathrm{r}}_{\mathrm{N}}\right) \alpha(\mathrm{N}) & \varphi_{2}\left(\overrightarrow{\mathrm{r}}_{\mathrm{N}}\right) \beta(\mathrm{N}) & \cdots & \varphi_{\frac{N}{2}}\left(\overrightarrow{\mathrm{r}}_{\mathrm{N}}\right) \alpha(\mathrm{N}) & \varphi_{\frac{N}{2}}\left(\overrightarrow{\mathrm{r}}_{\mathrm{N}}\right) \beta(\mathrm{N})
\end{array}\right|
$$

Cada fila está formada por todas las posibles asignaciones del electrón i a todas las combinaciones de espín-orbital. El factor inicial es de normalización. Intercambiar dos electrones significa intercambiar dos filas del determinante, lo que dará como resultado un cambio en su signo ${ }^{6,63}$.

Reemplazando las funciones de Hartree por las funciones antisimétricas y aplicando el principio variacional se deriva un set de ecuaciones de campo autoconsistente llamadas ecuaciones de Hartree-Fock SCF y que son la base para el cálculo de estructura electrónica de átomos y moléculas.

Los orbitales espaciales que minimizan la función variacional dada por la ecuación (20) se obtienen de resolver las ecuaciones diferenciales

$$
\mathcal{H}_{i}^{e f} \phi_{\mathrm{i}}(\mathrm{i})=\varepsilon_{\mathrm{i}} \phi_{\mathrm{i}}(\mathrm{i})
$$

\footnotetext{
${ }^{63}$ J. C. Slater; Phys. Rev. 35 (1930) 210
} 
donde $\varepsilon_{\mathrm{i}}$ es la energía del i-ésimo orbital y el operador Hartree-Fock en unidades atómicas es

$$
\mathcal{H}_{i}^{e f}=-\frac{1}{2} \nabla_{\mathrm{i}}^{2}-\sum \frac{\mathrm{Z}}{\mathrm{r}_{\mathrm{i}}}+\sum_{\mathrm{j}} 2 \mathrm{~J}_{\mathrm{j}}-\mathrm{K}_{\mathrm{j}}
$$

J y K son operadores bielectrónicos que dan cuenta de las repulsiones entre los electrones, el primero es el operador de Coulomb y el segundo se denomina operador de intercambio y quedan expresados

$$
\begin{aligned}
& J_{j}=\left\langle j\left|\frac{1}{r_{i j}}\right| j\right\rangle \\
& K_{j}=\left\langle j\left|\frac{1}{r_{i j}}\right| i\right\rangle
\end{aligned}
$$

En esta notación simplificamos la función $\phi_{\mathrm{i}}$ representándola con la letra correspondiente.

El operador de Coulomb representa la energía potencial de interacción entre el electrón i con densidad de carga $\left|\phi_{\mathrm{i}}\right|^{2}$ y el resto de los electrones $\mathrm{j} \neq \mathrm{i}$. El operador de intercambio no tiene una interpretación física sencilla pero responde a la necesidad de que la función sea antisimétrica con respecto al intercambio de las coordenadas de los electrones.

La expresión para la energía de Hartree-Fock es

$$
\mathrm{E}_{\mathrm{HF}}=2 \sum_{\mathrm{i}} \varepsilon_{\mathrm{i}}-\sum_{\mathrm{i}} \sum_{\mathrm{j}} 2 \mathrm{~J}_{\mathrm{ij}}-\mathrm{K}_{\mathrm{ij}}+\mathrm{V}_{\mathrm{NN}}
$$

Roothaan propuso en 1951 desarrollar los orbitales espaciales como combinaciones lineales de un conjunto completo de funciones base $f_{\mathrm{k}}$ en lo que se conoce como Método de la expansión o Hartree-Fock-Roothaan ${ }^{64,65,66,67}$.

\footnotetext{
${ }^{64}$ V. Fock; Z. Physik 61 (1930) 126

${ }^{65}$ C. C. J. Roothaan; Rev. Mod. Phys. 23 (1951) 69
} 


$$
\phi_{\mathrm{i}}=\sum_{\mathrm{k}} \mathrm{c}_{\mathrm{ik}} f_{\mathrm{k}}
$$

Aplicando el operador de Hartree-Fock a estas funciones base obtenemos la ecuación

$$
\sum_{\mathrm{k}} \mathrm{c}_{\mathrm{ik}} \mathcal{H}_{i}^{e f} f_{\mathrm{k}}=\varepsilon_{\mathrm{i}} \sum_{\mathrm{k}} \mathrm{c}_{\mathrm{ik}} f_{\mathrm{k}}
$$

y multiplicando por $f_{\mathrm{j}} *$ e integrando obtenemos

$$
\sum_{\mathrm{k}} \mathrm{c}_{\mathrm{ik}}\left(\mathcal{H}_{j k}^{e f}-\varepsilon_{\mathrm{i}} S_{j k}\right)=0
$$

donde

$$
\mathcal{H}_{j k}^{e f}=\left\langle f_{\mathrm{j}}\left|\mathcal{H}^{e f}\right| f_{\mathrm{k}}\right\rangle
$$

y

$$
S_{j k}=\left\langle f_{\mathrm{j}} \mid f_{\mathrm{k}}\right\rangle
$$

Para resolver este sistema de ecuaciones lineales homogéneas de incógnita en los coeficientes $\mathrm{c}_{\mathrm{ik}}$ es necesario que

$$
\operatorname{det}\left(\mathcal{H}_{j k}^{e f}-\varepsilon_{\mathrm{i}} S_{j k}\right)=0
$$

las raíces de esta ecuación secular dan las energías orbitales $\varepsilon_{\mathrm{i}} \mathrm{y}$ deben resolverse por un proceso iterativo, puesto que las integrales $\mathcal{H}_{j \kappa}^{e f}$ dependen de los orbitales $\phi_{\mathrm{i}}$, y a su vez éstos dependen de los coeficientes $\mathrm{c}_{\mathrm{ik}}$ que son desconocidos. En este proceso primero se parte de proponer un conjunto de OM ocupados que sean combinación lineal de otro conjunto de funciones base, y con éstos se calcula $\mathcal{H}_{i}^{e f}$ de acuerdo a la ecuación (48). Luego se calculan los elementos matriz (56)-(57) y se resuelve la ecuación secular (58) para obtener el conjunto inicial de $\varepsilon_{i}$. Éstos se utilizan en la ecuación (55) para mejorar el conjunto de coeficientes y obtener un nuevo conjunto de OM. Se continúa el

\footnotetext{
${ }^{66}$ C. C. J. Roothaan, P. S. Bagus; Methods Comput. Phys. 2 (1963) 47
}

${ }^{67}$ Ref. 2, capítulo 13 
proceso hasta no obtener ninguna mejoría en las energías y coeficientes de una etapa a la siguiente.

\subsection{Las funciones base}

Los cálculos cuánticos moleculares se hicieron, históricamente, usando el método de Combinación Lineal de Orbitales Atómicos-Orbitales Moleculares (LCAO MO). Esto significa que los orbitales moleculares están formados por una combinación lineal de orbitales atómicos

$$
\psi_{\mathrm{i}}=\sum_{\mu=1}^{\mathrm{n}} \mathrm{c}_{\mu \mathrm{i}} \varphi_{\mu}
$$

donde $\psi_{\mathrm{i}}$ es el i-ésimo orbital molecular, $\mathrm{c}_{\mu \mathrm{i}}$ son los coeficientes de la combinación lineal, $\mu$ es el $\mu$-ésimo orbital atómico y n es el número de orbitales atómicos.

Estrictamente hablando, los orbitales atómicos son soluciones de las ecuaciones de Hartree Fock para un átomo, es decir funciones de onda de un solo electrón. Cualquier otra cosa no es realmente un orbital atómico. Algunas cosas son similares, y existe una gran confusión en la terminología usada. El término orbital atómico fue reemplazado, más tarde, por "funciones bases". Al principio, se usaron como funciones bases los orbitales tipo Slater (STO, por sus siglas en inglés) por su similitud con los orbitales atómicos del átomo de hidrógeno. Éstos se describen por una función que depende de coordenadas esféricas ${ }^{68,69,70}$.

$$
\Phi_{\mathrm{i}}(\xi, \mathrm{n}, 1, \mathrm{~m}, \mathrm{r}, \theta, \varphi)=\mathrm{Nr}^{\mathrm{n}-1} \mathrm{e}^{-\mathrm{r} \xi} \mathrm{Y}_{\operatorname{lm}}(\theta, \varphi)
$$

$\mathrm{N}$ es una constante de normalización, $\zeta$ es el llamado exponente. Las variables $\mathrm{r}, \theta$ y $\varphi$ son coordenadas esféricas e $\mathrm{Y}$ es la parte angular de la función de onda. Las letras n, 1 y m simbolizan los números cuánticos principal, momento angular y magnético respectivamente.

\footnotetext{
${ }^{68}$ R. Ahlrichs, P.R.Taylor; J.Chim.Phys. 78 (1981) 315-324

${ }^{69}$ J. Almlof, P.R. Taylor; J. Chem. Phys. 86 (1987) 4070-4077

${ }^{70}$ J. Almlof, T. Helgaker, P.R. Taylor; J. Phys. Chem. 92 (1988) 3029-3033
} 
Las funciones de este tipo no son adecuadas para cálculos rápidos de integrales bielectrónicas, razón por la cual se introducen los Orbitales Tipo Gausianas (GTO, por sus siglas en inglés). Se puede aproximar la forma de la función STO sumando un número de funciones GTO con diferentes coeficientes y exponentes. Aún si se utilizan cuatro o cinco funciones GTO para representar una STO, el cálculo de las integrales es más rápido que para una STO original. La GTO, también llamada gausiana cartesiana, se expresa como

$$
g(\alpha, 1, m, x, y, z)=N e^{-\alpha r^{2}} x^{p} y^{q} z^{t}
$$

Aquí $\mathrm{N}$ es una constante de normalización, $\alpha$ es el exponente, $\mathrm{x}, \mathrm{y}, \mathrm{z}$ son las coordenadas cartesianas y $\mathbf{p}, \mathbf{q}$ y $\mathbf{t}$ son exponentes enteros de las coordenadas cartesianas, no números cuánticos, pero la suma de ellos es igual al número cuántico $\mathbf{L}$. En la literatura más reciente estas funciones se denominan primitivas gaussianas.

La principal diferencia es que el factor preexponencial $r^{n-1}$ desaparece, $\mathrm{y} r$ en la función exponencial está elevada al cuadrado; y la parte angular es la representación en coordenadas cartesianas de los armónicos esféricos. La ausencia de $\mathrm{r}^{\mathrm{n}-1}$ restringe las gausianas primitivas a orbitales $1 \mathrm{~s}, 2 \mathrm{p}, 3 \mathrm{~d}, 4 \mathrm{f} .$. La elección de gausianas en lugar de funciones de Slater obedece a razones prácticas con el propósito de acelerar el cálculo de las integrales. Sin embargo, las combinaciones de funciones gausianas son capaces de aproximar correctamente las propiedades nodales de los orbitales atómicos. La siguiente es una lista de funciones gausianas posibles ${ }^{71,72}$

$$
\begin{aligned}
1 s & =\mathrm{Ne}^{-\alpha \mathrm{r}^{2}} \\
2 p_{x} & =\mathrm{Ne}^{-\alpha \mathrm{r}^{2}} x \\
2 p_{y} & =\mathrm{Ne}^{-\alpha \mathrm{r}^{2}} y \\
2 p_{z} & =\mathrm{Ne}^{-\alpha \mathrm{r}^{2}} z \\
3 d_{x x} & =\mathrm{Ne}^{-\alpha \mathrm{r}^{2}} x^{2} \\
3 d_{x y} & =\mathrm{Ne}^{-\alpha \mathrm{r}^{2}} x y
\end{aligned}
$$

\footnotetext{
${ }^{71}$ J. Andzelm, M. Klobukowski, E. Radzio-Andzelm, Y. Saski, H. Tatewaki; "Gaussian Basis Sets for Molecular Calculations," (S. Huzinaga, Editor), Elsevier, Ámsterdam; 1984

${ }^{72}$ T. Clark, J. Chandrasekhar, G.W. Spitznagel, P.v.R. Schleyer; J. Comput. Chem.; 4 (1983) 294-301
} 


$$
\begin{aligned}
& 3 d_{x z}=\mathrm{Ne}^{-\alpha \mathrm{r}^{2}} x z \\
& 3 d_{y y}=\mathrm{Ne}^{-\alpha \mathrm{r}^{2}} y^{2} \\
& 3 d_{y z}=\mathrm{Ne}^{-\alpha \mathrm{r}^{2}} y z \\
& 3 d_{z z}=\mathrm{Ne}^{-\alpha \mathrm{r}^{2}} z^{2} \\
& 4 f_{x x x}=\mathrm{Ne}^{-\alpha \mathrm{r}^{2}} x^{3} \\
& 4 f_{x x y}=\mathrm{Ne}^{-\alpha \mathrm{r}^{2}} x^{2} y \\
& 4 f_{x y z}=\mathrm{Ne}^{-\alpha \mathrm{r}^{2}} x y z
\end{aligned}
$$

Hay un problema con las funciones tipo-d y las siguientes en orden. Sólo hay cinco orbitales d linealmente independientes y ortogonales, pero hay seis posibles gausianas cartesianas. De esta manera se introduce una función $3 \mathrm{~s}$ ya que

$$
3 d_{x x}+3 d_{y y}+3 d_{z z}=\mathrm{N}\left(x^{2}+y^{2}+z^{2}\right) \mathrm{e}^{-\alpha \mathrm{r}^{2}}=\mathrm{Nr}^{2} \mathrm{e}^{-\alpha \mathrm{r}^{2}}=3 s
$$

Las primitivas gausianas se obtienen de cálculos cuánticos en átomos. Los exponentes se modifican hasta que se alcanza la más baja energía ${ }^{73}$.

Para cálculos moleculares, las funciones gaussianas primitivas deben ser contraídas. La contracción significa una combinación lineal de gaussianas primitivas para ser usadas como funciones base. Estas funciones bases tienen sus coeficientes $y$ exponentes fijos. Las contracciones son, a veces, llamadas Orbitales Tipo Gausianas Contraídos (CGTO, de las siglas en inglés).

Huzinaga derivó en $1965^{74,75}$ los coeficientes y exponentes de una expansión gausiana que minimizan la energía del átomo de hidrógeno. Para representar el orbital 1s se usaron cuatro gausianas tipo-s:

$\psi_{1 \mathrm{~s}}=0.50907 \mathrm{~N}_{1} e^{-0.123317 r^{2}}+0.47449 \mathrm{~N}_{2} e^{-0.47449 r^{2}}+0.13424 \mathrm{~N}_{3} e^{-2.01330 r^{2}}+0.01906 \mathrm{~N}_{4} e^{-13.3615 r^{2}}$

\footnotetext{
${ }^{73}$ E.Clementi, S.J.Chakravorty, G.Corongiu, V.Sonnad; "Independent Electron Models: Hartree-Fock for Many-Electron Atoms"; pp. 47-140, in: "MOTECC-90 Modern Techniques in Computational Chemistry (E.Clementi, Ed.), Escom, Leiden 1990, ISBN-90-72199-07-3

${ }^{74}$ S. Huzinaga; J. Chem. Phys.; 42 (1965) 1293-1302

${ }^{75}$ S. Huzinaga, D. McWilliams, B. Domsky; J. Chem. Phys. 54 (1971) 2283-2284
} 
Estas primitivas pueden agruparse en dos contracciones, la primera con una sola primitiva y la segunda con tres

$$
\begin{gathered}
\varphi_{1}=\mathrm{N}_{1} e^{-0.123317 r^{2}} \\
\varphi_{2}=\mathrm{N}\left(0.47449 \mathrm{~N}_{2} e^{-0.453757 r^{2}}+0.13424 \mathrm{~N}_{3} e^{-2.01330 r^{2}}+0.01906 \mathrm{~N}_{4} e^{-13.3615 r^{2}}\right)
\end{gathered}
$$

En este caso, cuatro primitivas fueron contraídas a dos funciones base. Se expresa esto, frecuentemente, como contracción $(4 s) \rightarrow[2 s]$ o bien $(4 s) /[2 s]$.

No es sencillo resumir la manera en que las contracciones son derivadas. Algunos sets de bases son buenos para calcular energías y geometrías, o dirigidos a propiedades particulares como la polarizabilidad, otros están optimizados sólo para Hartree-Fock y otros adaptados para cálculos con correlación. Algunos son buenos para aniones, otros para cationes y otros para moléculas neutras. A veces es necesario una buena descripción de orbitales internos (core) y otras veces de los electrones de valencia.

Hay dos formas básicas de generar una contracción llamadas "segmentada" una y "general" la otra. Las segmentadas están inconexas, pues dada una primitiva ésta aparece sólo en una contracción. El átomo de hidrógeno de Huzinaga es un ejemplo de esto. Las contracciones generales permiten aparecer a cada primitiva en cada función base.

Las bases segmentadas se estructuran de tal manera que las primitivas más difusas (aquéllas con el exponente más pequeño) se dejan sin contraer (una primitiva por una función base). Las primitivas más compactas (exponentes más grandes) se toman con sus coeficientes de cálculos atómicos HF y se forman una o dos contracciones. Luego las contracciones son renormalizadas.

La ventaja de utilizar funciones contraídas no radica en reducir el número de integrales a calcular, ya que el número de funciones es el mismo. La ventaja está en la reducción del orden del determinante a diagonalizar para efectuar el cálculo. 
Las gausianas cartesianas están agrupadas en capas (shells) que corresponden al mismo valor de número cuántico momento angular. No deben confundirse estas capas con las capas electrónicas. La capa es una colección de gausianas cartesianas con el mismo valor de L. De esta manera, la capa s es una colección de gausianas tipo-s, la capa p es una colección de gausianas tipo-p, la capa d es una colección de gausianas tipo-d y así sucesivamente. Por supuesto carece de sentido combinar, en la misma contracción, primitivas de diferente capa por cuestiones de ortogonalidad ${ }^{76,77,78}$.

Los átomos del segundo y tercer período (del $\mathrm{Li}$ al $\mathrm{Ne}$ y del $\mathrm{Na}$ al $\mathrm{Cl}$ ) tienen los mismos exponentes para gaussianas tipo s y p formalmente asociadas con una capa electrónica dada del átomo aislado. Para los sets de bases en los cuales las funciones tipo-s y tipo-p comparten los mismos exponentes se usa el término capa SP (SP-shell). A veces se usa el término capa L por analogía para la segunda capa electrónica. Esta aproximación es válida en la práctica. Por otra parte, se puede escribir un código eficiente para calcular integrales en tales casos. Vale la pena indicar que la distinción entre orbitales internos y orbitales de valencia es arbitraria y corresponde, más bien, a una etapa anterior a los orbitales de Slater. Las contracciones de primitivas con exponentes grandes están asociadas con orbitales atómicos internos, mientras que las funciones más difusas lo están con orbitales de valencia. Las funciones bases no son usualmente orbitales atómicos, y en muchos casos ni siquiera se asemejan a los orbitales de los átomos aislados. En realidad, mirando los coeficientes de los orbitales moleculares, frecuentemente se observa que aquellas funciones base del "core" contribuyen significativamente al orbital molecular más alto ocupado (HOMO). Esto viene como consecuencia de que las funciones base con un dado centro no son ortogonales unas de otras y las funciones bases del "core" con diferentes centros se solapan en gran medida, cosa que no ocurre con orbitales atómicos verdaderos ${ }^{79}$.

Las primeras contracciones gausianas se obtuvieron de aplicar cuadrados mínimos a orbitales atómicos de Slater. El número de contracciones (no primitivas) usado para representar un simple orbital de Slater (zeta) era una medida de la bondad del conjunto. Para estos tiempos tenemos términos como simple zeta (SZ), doble zeta (DZ), triple zeta

\footnotetext{
${ }^{76}$ J.E. Del Bene; J. Comput. Chem. 10 (1989) 603-615

${ }^{77}$ T.H. Dunning, P.J. Hay; "Gaussian basis sets for molecular calculations", in: "Modern Theoretical Chemistry"; vol. 3. Ed. H.F. Schaefer III, pp. 1-28, Plenum Press, New York; 1977

${ }^{78}$ T.H. Dunning, Jr; J.Chem.Phys. 90 (1989) 1007-1023

${ }^{79}$ P. Durand, J.-C. Barthelat; Theor. Chim. Acta (Berl.) 38 (1975) 283-302
} 
(TZ), cuádruple zeta (QZ), etc. En el conjunto de bases mínimas se usa una sola función base por orbital atómico de Slater. Los conjuntos DZ tienen dos funciones base por orbital, etc. Puesto que los orbitales atómicos de valencia están más afectados a formar parte de enlaces más que los del core, se asignan frecuentemente más funciones base para describir orbitales de valencia. Que más funciones base se usen para describir orbitales de valencia no significa que los orbitales de valencia incorporan más primitivas. A menudo, los orbitales del core son contracciones largas de muchas primitivas para poder representar bien el "máximo" de la función tipo-s a la posición del núcleo. La terminología "zeta" es a menudo aumentada con un número de funciones de polarización que serán descritas más adelante. De esta forma, DZP significa doble zeta más polarización, TZP triple zeta más polarización y así. La nomenclatura TZDP, $\mathrm{TZ2P}, \mathrm{TZ}+2 \mathrm{P}$ se establece para triple zeta más doble polarización. La letra $\mathrm{V}$ denota valencia desdoblada para los conjuntos de bases. DZV representa un conjunto de bases con una sola contracción para los orbitales internos y dos contracciones para los orbitales de valencia ${ }^{80}$.

El conjunto de bases mínimo es el más pequeño posible, y contiene sólo una función por orbital atómico ocupado en el estado fundamental. En realidad, éste siempre incluye todos los orbitales de las subcapas parcialmente ocupadas y las funciones de valencia tipo-p para elementos de los tres primeros períodos de la tabla periódica. De esta manera, para los átomos de Li y Be hay 2 contracciones tipo-s y 1 contracción tipo-p. El conjunto de bases mínimo para el átomo de $\mathrm{S}$ tiene 3 contracciones tipo-s y 2 contracciones tipo-p. Los conjuntos de bases mínimos más usados son los STO-nG, donde $\mathrm{n}$ significa el número de primitivas en la contracción. Estos conjuntos se obtuvieron por ajuste de cuadrados mínimos de la combinación de $\mathrm{n}$ funciones gausianas para un orbital de Slater del mismo tipo con zeta $=1.0$. Para este conjunto se usan contracciones adicionales, de forma que los exponentes de las correspondientes funciones primitivas sean las mismas que para las funciones base que describen los orbitales con el mismo número cuántico principal (por ejemplo, se usan las mismas

\footnotetext{
${ }^{80}$ D. Feller, E.R. Davidson; "Basis set selection for molecular calculations"; Chemical Reviews; 86 (1986) 681-696
} 
primitivas para las funciones $2 \mathrm{~s}$ y $2 \mathrm{p}$ ). Luego, esos exponentes se multiplican por el cuadrado de zeta en el orbital de Slater que mejor describe el conjunto de moléculas ${ }^{81}$.

El STO-3G, el más conocido de los conjuntos de bases mínimos, contiene el mínimo número de funciones base necesario para cada átomo, por ejemplo

$$
\begin{aligned}
& \mathrm{H}: 1 \mathrm{~s} \\
& \mathrm{C}: 1 \mathrm{~s}, 2 \mathrm{~s}, 2 \mathrm{p}_{\mathrm{x}}, 2 \mathrm{p}_{\mathrm{y}}, 2 \mathrm{p}_{\mathrm{z}}
\end{aligned}
$$

El conjunto de valencia desdoblada incrementa el número de funciones base por átomo y tiene dos o más medidas de funciones base por cada orbital de valencia

$$
\begin{aligned}
& \mathrm{H}: 1 \mathrm{~s}, 1 \mathrm{~s}^{\prime} \\
& \mathrm{C}: 1 \mathrm{~s}, 2 \mathrm{~s}, 2 \mathrm{~s}^{\prime}, 2 \mathrm{p}_{\mathrm{x}}, 2 \mathrm{p}_{\mathrm{x}}{ }^{\prime}, 2 \mathrm{p}_{\mathrm{y}}, 2 \mathrm{p}_{\mathrm{y}}{ }^{\prime}, 2 \mathrm{p}_{\mathrm{z},}, 2 \mathrm{p}_{\mathrm{z}}
\end{aligned}
$$

Prima y no prima representan orbitales de diferente tamaño. Doble zeta usa dos medidas de funciones para cada orbital atómico y triple zeta, como 6-311G, utiliza tres medidas de funciones contraídas.

La notación de Pople $^{82,83}$ acentúa la naturaleza de la valencia desdoblada de los conjuntos. Los símbolos $\mathbf{n}$-ijG o $\mathbf{n}$-ijkG significan: $\mathbf{n}$ es el número de primitivas para la capas más internas, $\mathbf{i j}$ o ijk son los números de primitivas para contracciones en la capa de valencia. La notación ij describe sets de calidad de valencia doble zeta y los ijk de valencia triple zeta, Generalmente en las bases de Pople, las contracciones s y p que pertenecen a la misma "capa electrónica" están plegadas dentro de una capa sp. En este caso, el número de primitivas tipo-s y tipo-p es el mismo y tienen idénticos exponentes. Sin embargo, los coeficientes para las contracciones tipo-s y tipo-p son diferentes.

De manera que en las funciones 3-21G las capas internas están descritas por una función que es combinación lineal de tres funciones primitivas y cada orbital de valencia es combinación de dos gausianas, una de ellas combinación lineal de dos primitivas y la otra simple.

\footnotetext{
${ }^{81}$ D. Feller, E.R. Davidson; "Basis Sets for Ab Initio Molecular Orbital Calculations and Intermolecular Interactions"; pp. 1-43, in: "Reviews in Computational Chemistry" (Editors:Kenny B. Lipkowitz and Donald B. Boyd), VCH, New York; 1990

${ }^{82}$ M.M. Francl, J.S. Binkley, M.S. Gordon, D.J. DeFrees, J.A. Pople; J.Chem.Phys. 77 (1982) 3654-3665

${ }^{83}$ M.J. Frisch, J.A. Pople, J.S. Binkley; J. Chem. Phys. 80 (1984) 3265-3269
} 
Las funciones 6-31G las capas internas se representan por una gausiana combinación lineal de seis primitivas y las de valencia por dos gausianas, una combinación lineal de tres funciones primitivas y otra simple.

\subsubsection{Funciones de polarización y difusas}

Las contracciones originales derivadas de cálculos atómicos Hartree-Fock son frecuentemente aumentados con otras funciones. Las más populares son las funciones de polarización y las difusas. Las funciones de polarización son funciones simples que tienen valores de 1 más altos que aquellos que presentan los orbitales atómicos ocupados para el átomo correspondiente. Esto es un poco ambiguo porque depende de los resultados que arroje el uso de tales funciones, por ejemplo las funciones tipo-p no son de polarización para el átomo de litio pero las tipo-d sí lo son para el átomo de azufre. Los exponentes de polarización no pueden derivarse de Hartree-Fock ya que los orbitales no están poblados. Éstos se pueden estimar por cálculos de correlación o, en la práctica utilizando reglas bien establecidas u optimización explícita.

La importancia de las funciones de polarización radica en su aplicación al enlace químico. Se incorporan como gausianas sin contraer. Esto significa un costo computacional grande ya que se están introduciendo 5 o 6 funciones base si son tipo-d o 7 o 10 si son del tipo-f. El número de funciones debe ser especificado. Las bases de Pople 6-31G* usan 6 funciones tipo-d, mientras que las 6-311G** usan 5.

Los conjuntos de bases se aumentan también frecuentemente con las llamadas funciones difusas. Estas gausianas tienen exponentes muy pequeños y decaen lentamente con la distancia desde el núcleo. Las funciones difusas son generalmente tipo-s o tipo-p. Son necesarias para el cálculo de aniones y de uniones débiles, como puente de hidrógeno, y son usadas para el cálculo de propiedades como la polarizabilidad o los momentos dipolares. La notación es $\mathbf{n}-\mathbf{i j}+\mathbf{G}$ o $\mathbf{n}-\mathbf{i j k} \mathbf{k}+\mathbf{G}$ donde una función difusa tipo-s y una tipo-p con los mismos exponentes se agregaron al set estándar para átomos pesados. Las $\mathbf{n}-\mathbf{i j}++\mathbf{G}$ o $\mathbf{n}-\mathbf{i j k} \mathbf{k}++\mathbf{G}$ se obtienen agregando una difusa tipo-s y una tipo-p para los pesados y una tipo-s para el hidrógeno.

Los conjuntos con funciones difusas son importantes para sistemas con electrones relativamente lejos del núcleo, que pueden ser moléculas con pares libres, aniones y 
otros sistemas con carga negativa significativa, estados excitados, sistemas con bajos potenciales de ionización, descripción de acidez absoluta. Estas funciones son versiones de mayor dimensión de las de tipo s y p. Permiten a los orbitales ocupar amplias regiones del espacio. El conjunto $6-31+\mathrm{G}(\mathrm{d})$ agrega funciones difusas a los átomos más pesados que $\mathrm{H}$ y He, y 6-31++G(d) incorpora al hidrógeno.

Conjunto base de alto momento angular

Estos conjuntos suman múltiples funciones de polarización por átomo y son útiles para describir interacción de electrones en los métodos de correlación electrónica. Las bases $6-311++G(3 d f, 3 p d)$ tienen tres funciones $d y$ una $f$ para átomos pesados y tres funciones p y una d para hidrógeno como funciones de polarización ${ }^{84,85}$.

\subsection{Teoría del Funcional de la Densidad}

Los métodos de la mecánica cuántica utilizaron, desde sus orígenes, funciones de onda para el cálculo de la energía electrónica del estado fundamental de un sistema atómico o molecular. Si el sistema en cuestión posee $\mathrm{N}$ electrones el problema hasta acá es $3 \mathrm{~N}$ dimensional. El propósito de la Teoría del Funcional de la Densidad es reducir la dimensionalidad del problema calculando la energía electrónica a partir, no de la función de onda sino de la densidad electrónica. Así el problema se reduce a uno tridimensional.

Para un sistema de $\mathrm{N}$ electrones el potencial externo determina completamente el hamiltoniano del sistema, y por tanto la energía, función de onda y demás propiedades. Hohenberg y $\mathrm{Kohn}^{86}$ demostraron que existe una relación entre la densidad electrónica y el potencial externo de manera que la densidad se puede constituir en la variable fundamental del problema determinando, a partir de ésta, todas las propiedades del mismo. La expresión de la energía para un sistema de electrones que interactúan queda definida como

\footnotetext{
${ }^{84}$ R.C. Raffenetti; J. Chem. Phys, 58 (1973) 4452-4458

${ }^{85}$ K. Jankowski, R. Becherer, P. Scharf, H. Schiffer, R. Ahlrichs; J. Chem. Phys. 82 (1985) 1413-1419

${ }^{86}$ P. Hohenberg and W. Kohn; Phys. Rev.; 136 (1964) B864
} 


$$
E[\rho(r)]=T[\rho(r)]+\int v(r) \rho(r) d r+V_{\text {ee }}[\rho(r)]
$$

donde $V_{\text {ee }}$ será la energía de repulsión entre los electrones y $T[\rho(r)]$ el funcional que describe la energía cinética. Ambos funcionales son desconocidos.

Fueron Kohn y Sham ${ }^{87}$ quienes desarrollaron el formalismo para expresar de manera práctica el teorema de Hohenberg-Kohn. Consideraron un sistema de referencia con $\mathrm{N}$ electrones no interactuantes que sienten sólo la acción del potencial externo con densidad igual a la del sistema de electrones interactuantes, donde la energía queda definida como

$$
E_{s}[\rho(r)]=T_{s}[\rho(r)]+\int v(r) \rho(r) d r
$$

Se puede dar una forma más útil a la ecuación que expresa la energía teniendo en cuenta la interacción sumando y restando términos idénticos sin cambiar la igualdad

$$
E[\rho(r)]=T[\rho(r)]+\int v(r) \rho(r) d r+V_{\text {ee }}[\rho(r)]+T_{s}[\rho(r)]-T_{s}[\rho(r)]+J[\rho(r)]-J[\rho(r)]
$$

Donde $J[\rho(r)]$ es la parte clásica de la interacción electrón-electrón. Reordenando la ecuación anterior

$$
E[\rho(r)]=T_{s}[\rho(r)]+J[\rho(r)]+\int v(r) \rho(r) d r+E_{x c}[(\rho)]
$$

donde

$$
E_{x c}[\rho(r)]=V_{\text {ee }}[\rho(r)]-J[\rho(r)]+T[\rho(r)]-T_{s}[\rho(r)]
$$

y se la denomina energía de intercambio y correlación y contiene la contribución de la parte no clásica de la interacción electrón-electrón y el error que resulta de reemplazar el funcional de la energía cinética de los electrones cuando interactúan $\mathrm{T}[\rho(\mathrm{r})]$, por el funcional de la energía cinética de los electrones no interactuantes $\mathrm{T}_{\mathrm{s}}[\rho(\mathrm{r})]$.

\footnotetext{
${ }^{87}$ W. Kohn, L.J. Sham; Phys. Rev..; 140 (1965) A113
} 
La densidad electrónica para el estado fundamental puede expresarse en función de un conjunto de orbitales base auxiliar $\{\phi\}$, orbitales de Kohn-Sham

$$
\rho(\mathrm{r})=\sum_{\mathrm{i}=1}^{\mathrm{N}} \phi_{\mathrm{i}}(\mathrm{r}) \phi_{\mathrm{i}}^{*}(\mathrm{r})
$$

Aplicando el principio variacional a la energía electrónica $E[\rho(r)]$ se derivan las ecuaciones de Kohn-Sham y se resuelven mediante un proceso autoconsistente similar al usado para resolver las ecuaciones de Hartree-Fock.

\subsubsection{Aproximación local de la Densidad}

En el método de la aproximación local de la densidad (LDA por sus siglas en inglés) se suelen separar las contribuciones a la $E_{x c}[\rho(r)]$ en dos: una que contempla sólo el intercambio y otra únicamente la correlación, de forma tal que $E_{x c}[\rho(r)]=E_{x}[\rho(r)]+E_{c}[\rho(r)] \frac{\partial^{2} \Omega}{\partial v^{2}}$. La forma más sencilla de expresarla es aquella en la que las ecuaciones funcionales sólo dependen de la densidad electrónica ${ }^{88}$, como es el ejemplo de la energía de intercambio

$$
E_{x}[\rho(r)]=c \int \rho(r)^{4 / 3} d r
$$

La forma más general de expresarla es en función de la dependencia de los funcionales con el espín, así

$$
\mathrm{Ex}_{\mathrm{x}}[\rho(\mathrm{r})]=\int \rho(\mathrm{r}) \varepsilon_{\mathrm{x}}[\rho(\mathrm{r}), \xi] \mathrm{dr}
$$

donde $\varepsilon_{x}[\rho(r), \xi]$ es la energía de intercambio por electrón y $\xi=\frac{\rho(r)_{\alpha}-\rho(r)_{\beta}}{\rho(r)}$ es la polarización del espín y $\rho(\mathrm{r})_{\alpha}$ y $\rho(\mathrm{r})_{\beta}$ son las densidades de espín correspondientes. Para sistemas de capa cerrada $\rho(r)_{\alpha}=\rho(r)_{\beta}$ y se la llama simplemente aproximación

\footnotetext{
${ }^{88}$ P.A.M. Dirac; Proc. Cambridge Philos. Soc.; 26 (1930) 376
} 
local de la densidad (LDA), en cambio para sistemas de capa abierta las densidades de espín son diferentes y se la llama aproximación local de la densidad de espín (LSDA).

Uno de los funcionales más populares para expresar la correlación es el desarrollado por Vosko, Wilk y Nusair ${ }^{89}$, conocido como VWN que se escribe

$$
\mathrm{E}_{\mathrm{VWN}}^{\mathrm{C}}[\rho(\mathrm{r})]=\frac{\mathrm{A}}{2}\left\{\ln \frac{\mathrm{x}}{\mathrm{X}(\mathrm{x})}+\frac{2 \mathrm{~b}}{\mathrm{Q}} \tan ^{-1} \frac{\mathrm{Q}}{2 \mathrm{x}-\mathrm{b}}-\frac{\mathrm{bx} \mathrm{x}_{\mathrm{o}}}{\mathrm{X}(\mathrm{x})}\left[\ln \frac{\left(\mathrm{x}-\mathrm{x}_{\mathrm{o}}\right)}{\mathrm{X}(\mathrm{x})}+\frac{2\left(\mathrm{~b}+2 \mathrm{x}_{\circ}\right)}{\mathrm{Q}} \tan ^{-1} \frac{\mathrm{Q}}{2 \mathrm{x}+\mathrm{b}}\right]\right\}
$$

\subsubsection{Aproximación generalizada del gradiente}

En el método de aproximación generalizada del gradiente (GGA, por sus siglas en inglés) los funcionales de correlación y de intercambio dependen, además de la densidad, del gradiente de la densidad. Esto conduce a una mejora en el cálculo de geometrías, las frecuencias y las densidades de carga, pero principalmente en las energías de enlace. Entre los funcionales más conocidos que hacen uso de esta aproximación se encuentran los propuestos por Axel D. Becke $e^{90,91,92,93,94, ~} 95$, uno de ellos es el de Becke $88^{96}$ (B) expresado por la ecuación

$$
\mathrm{E}_{\mathrm{B} 88}^{\mathrm{x}}=\mathrm{E}_{\mathrm{LDA}}^{\mathrm{x}}[\rho(\mathrm{r})]\left[1-\frac{\beta}{2^{1 / 3} \mathrm{~A}_{\mathrm{x}}} \frac{\mathrm{x}^{2}}{1+6 \beta \mathrm{xsenh}^{-1}(\mathrm{x})}\right]
$$

donde $A_{x}$ y $\beta$ son constantes y $x=2^{1 / 3} \frac{|\nabla \rho|}{\rho^{4 / 3}}$ y el de Perdew-Wang ${ }^{97}(\mathrm{PW})$ dado por la ecuación

$$
\mathrm{E}_{\mathrm{PW}}^{\mathrm{x}}=\mathrm{E}_{\mathrm{LDA}}^{\mathrm{x}}[\rho(\mathrm{r})]\left[1+0.0864 \frac{\mathrm{s}^{2}}{\mathrm{~m}}+\mathrm{bs}^{4}+\mathrm{cs}^{6}\right]
$$

\footnotetext{
${ }^{89}$ S.J. Vosko, L. Wilk and M. Nusair; Can. J. Phys.; 58 (1980) 1200

${ }^{90}$ A. D. Becke, J. Chem. Phys.; 84 (1986) 4524

${ }^{91}$ A. D. Becke, J. Chem. Phys.; 96 (1992) 2155

92 A. D. Becke, J. Chem. Phys.; 97 (1992) 9173

${ }^{93}$ A. D. Becke, J. Chem. Phys.; 98 (1993) 5648

${ }^{94}$ A. D. Becke, J. Chem. Phys.; 104 (1996) 1040

${ }^{95}$ A. D. Becke, J. Chem. Phys.; 107 (1997) 8544

${ }^{96}$ A. D. Becke, Phys. Chem. A; 38 (1988) 3098

${ }^{97}$ J. P. Perdew, Y. Wang; Phys. Rev. A; 38 (1986) 8800
} 
para $s=\frac{|\nabla \rho|}{\left(24 \pi^{2}\right)^{1 / 3} \rho^{4 / 3}}$ y m,b y c son constantes.

Algunos funcionales muy usados son Perdew-Wang 91 (PW91), Becke-Perdew (BP), Perdew-Burke-Ernzerhof (PBE). Para la correlación, algunos de los funcionales más utilizados son los de Perdew-Wang 86 (PW86) y Lee-Yang-Parr (LYP).

Estos funcionales contienen algún parámetro ajustado a fin de reproducir las energías de una serie de átomos o alguna integral de corte que prueba en donde falla dicha integral. El funcional PW91 es ab initio puro.

\subsubsection{Métodos híbridos del Funcional de la Densidad}

Los métodos híbridos de los funcionales de la densidad (H-GGA) combinan el intercambio y la correlación de métodos GGA convencionales con un porcentaje del intercambio de Hartree-Fock. Mediante las energías de atomización, los potenciales de ionización, las afinidades protónicas, las energías atómicas totales y otros datos experimentales de un conjunto representativo de moléculas pequeñas se ajustan los porcentajes y se optimizan los factores de peso para cada componente ${ }^{98}$.

El funcional híbrido más popular es el funcional B3LYP que está compuesto por el funcional de intercambio exacto Hartree Fock $\left(\mathrm{E}_{\mathrm{HF}}^{\mathrm{x}}\right)$ y uno de intercambio con aproximación local $\left(\mathrm{E}_{\mathrm{LDA}}^{\mathrm{x}}\right)$; un funcional GGA (Becke88) de intercambio y dos funcionales de correlación, uno de aproximación local $\left(\mathrm{E}_{\mathrm{LDA}}^{\mathrm{c}}\right)$ y otro GGA de LeeYang-Parr $\left(\mathrm{E}_{\mathrm{LYP}}^{\mathrm{c}}\right)$, de esta forma la expresión que queda es

$$
\mathrm{E}_{\mathrm{B} 3 \mathrm{LYP}}^{\mathrm{xc}}=\mathrm{a} \mathrm{E}_{\mathrm{HF}}^{\mathrm{x}}+(1-\mathrm{a}) \mathrm{E}_{\mathrm{LDA}}^{\mathrm{x}}+\mathrm{bE}_{\mathrm{B} 88}^{\mathrm{x}}+(1-\mathrm{c}) \mathrm{E}_{\mathrm{LDA}}^{\mathrm{c}}+\mathrm{cE}_{\mathrm{LYP}}^{\mathrm{c}}
$$

Los mejores valores para los coeficientes son $\mathrm{a}=0.2, \mathrm{~b}=0.72 \mathrm{y} \mathrm{c}=0.81 \mathrm{y}$ se determinan por ajuste con datos experimentales para optimizar energías de disociación. La ventaja de este método radica en la precisión de los cálculos a costo computacional bajo, ya que da geometrías y energías de enlace tan buenas como los métodos de la teoría de perturbaciones de segundo orden pero con tiemos de cálculos más bajos.

\footnotetext{
${ }^{98}$ S.F. Sousa, P.A. Fernandes, and M.J. Ramos; J. Phys. Chem. A; 111 (2007) 10439-10452
} 


\subsection{Métodos semiempíricos}

El costo computacional para resolver las ecuaciones de Hartree-Fock-Roothaan aumenta con la cuarta potencia de las funciones base utilizadas, de manera que a veces se hace necesario reducir el tiempo de cálculo si el problema así lo amerita. O bien para tener una primera aproximación de resultados a modo de ensayo que nos permita decidir si descartamos o no una vía de cálculo.

En los métodos semiempíricos se reduce el costo computacional disminuyendo el número de integrales bielectrónicas con las que se construye la matriz de Fock.

El primer paso consiste en considerar sólo los electrones de valencia y modelar las funciones de los electrones internos reduciendo la carga nuclear. En general se usan para estos electrones orbitales de Slater y funciones s y p.

La aproximación común a casi todos los métodos semiempíricos es la del solapamiento diferencial nulo ZDO (Zero Differential Overlap), en la cual se desprecian todos los productos de funciones base que dependen de las mismas coordenadas electrónicas cuando están en átomos diferentes. Si el orbital atómico sobre el centro A es $\phi_{\mathrm{A}} \mathrm{y}$ el orbital atómico sobre el centro B es $\phi_{\mathrm{B}}$, entonces $\phi_{\mathrm{A}} \phi_{\mathrm{B}}=0$, y por tanto la matriz de solapamiento $S$ será la matriz unidad. Bajo esta aproximación se anulan también las integrales monoelectrónicas que involucran tres centros y las bielectrónicas de tres y cuatro centros. Las integrales restantes se ajustan de forma paramétrica con valores obtenidos de datos experimentales. Los diferentes tipos de métodos quedan definidos por el número de integrales que desprecian y por el tipo de parametrización hecha.

En el método NDDO $^{99}$ (Neglect of Diatomic Differential Overlap) se usan las aproximaciones antes mencionadas y la carga nuclear reducida debido a los electrones internos. En el método INDO ${ }^{100}$ (Intermediate Neglect of Differential Overlap) le suma a lo descartado en NDDO todas las integrales bielectrónicas que no son del tipo de Coulomb. En el modelo CNDO ${ }^{101,102}$ (Complete Neglect of Differential Overlap) se desprecian además las integrales bielectrónicas de Coulomb.

\footnotetext{
99 J.J.P Stewart; Reviews in Computacional Chemistry; VHC Publishers INC. 1990

100 J.A. Pople, D.L. Beveridge, P.A. Dobosh; J. Chem. Phys.; 47 (1967) 2026

101 J.A. Pople, D.P. Santry, G.A. Segal; J. Chem. Phys.; 43 (1965) S129

102 J.A. Pople, G.A. Segal; J. Chem. Phys.; 43 (1965) S136
} 


\subsubsection{El método AM1}

Algunos errores sistemáticos con MNDO como la sobreestimación de la repulsión entre dos átomos separados 2-3 $\AA$ daban como resultado valores altos de energías de activación. El problema estaba en que el modelo del potencial núcleo-núcleo es demasiado repulsivo para MNDO. El modelo de Austin (AM1, por Austin Model) corrigió el potencial de repulsión de MNDO agregando funciones gausianas y reparametrizando. De manera que la expresión corregida del potencial es

$$
\mathrm{V}_{\mathrm{nn}}^{\mathrm{AM} 1}(\mathrm{~A}, \mathrm{~B})=\mathrm{V}_{\mathrm{nn}}^{\mathrm{MNDO}}(\mathrm{A}, \mathrm{B})+\frac{\mathrm{Z}_{\mathrm{A}}{ }^{\prime} \mathrm{Z}_{\mathrm{B}}{ }^{\prime}}{\mathrm{R}_{\mathrm{AB}}} \sum_{k}\left(a_{k B} e^{-b_{k A}\left(R_{A B}-c_{k A}\right)^{2}}+a_{k B} e^{-b_{k A}\left(R_{A B}-c_{k B}\right)^{2}}\right)
$$

Donde $\mathrm{k}$ toma valores entre 2 y 4 según el átomo. Al igual que en MNDO los parámetros se obtienen de espectros atómicos y las constantes ak, bk y ck son constantes que se obtienen de ajustes de datos El método AM1 predice la fuerza de los enlaces de puentes de hidrógeno con una buena aproximación y las energías de activación dan mejor que con MNDO. Como contrapartida los enlaces peróxidos son más cortos en cerca de $1.7 \AA$ y predice la conformación gauche en etanol más estable que la trans ${ }^{103}$.

\footnotetext{
${ }^{103}$ F. Jensen; Introduction to Computacional Chemistry, Second Edition 2007 John Wiley \& Sons Ltd; cap. 3
} 
Capítulo 3: EL SISTEMA 


\section{EL SISTEMA, SU CONTEXTO Y SU ESTUDIO}

\subsection{Los compuestos y su proteína}

Los microtúbulos (MT) son polímeros filamentosos que forman parte del citoesqueleto de las células eucariotas, de forma cilíndrica de $25 \mathrm{~nm}$ de diámetro externo y $15 \mathrm{~nm}$ de diámetro interno aproximadamente. Los microtúbulos desempeñan en la célula diferentes funciones como la movilidad celular por estar en las cilias y los flagelos, el transporte de vesículas desde el retículo endoplasmático al aparato de Golgi y a lo largo del axón en células nerviosas. También participa en la formación del huso mitótico durante la segregación de los cromosomas en la división celular. Por esta última función, las proteínas que constituyen los microtúbulos son el blanco de numerosas drogas antiprolifelativas como la colchicina y el taxol ${ }^{104}$.

Los microtúbulos están formados por la unión no covalente de hetrodímeros de $\alpha$-tubulina y $\beta$-tubulina que se ensamblan en forma ordenada y paralela, lo que confiere al microtúbulo su forma de cilindro y una polaridad intrínseca con un extremo $(+) \mathrm{o}$ distal de crecimiento rápido y otro extremo (-) o proximal de crecimiento más lento (Figura 1).

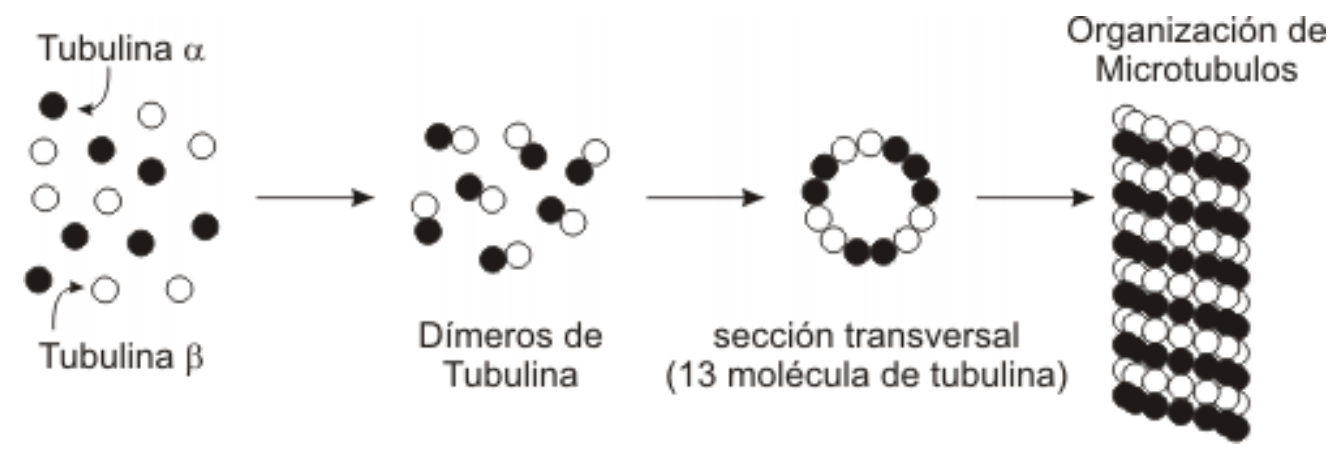

104 (a) E. K. Rowinsky, R. C. Donehower; Pharmacol. Ther. 52 (1991) 35. (b) E. Hamel; Med. Res. Rev. 16 (1996) 207. (c) Q. Shi, K. Chen, S. L. Morris-Natschke, K. H. Lee; Curr. Pharm. Des. 4 (1998) 219. (d) A. Jordan, J. A. Hadfield, N. J. Lawrence, A. T. McGown; Med. Res. Rev. 18 (1998) 259. (e) Q. Li, H. Sham, S. Rosenberg; Annu. Rep. Med. Chem. 34 (1999) 139. (f) E. von Angerer; Expert Opin. Ther. Pat. 9 (1999) 1069 


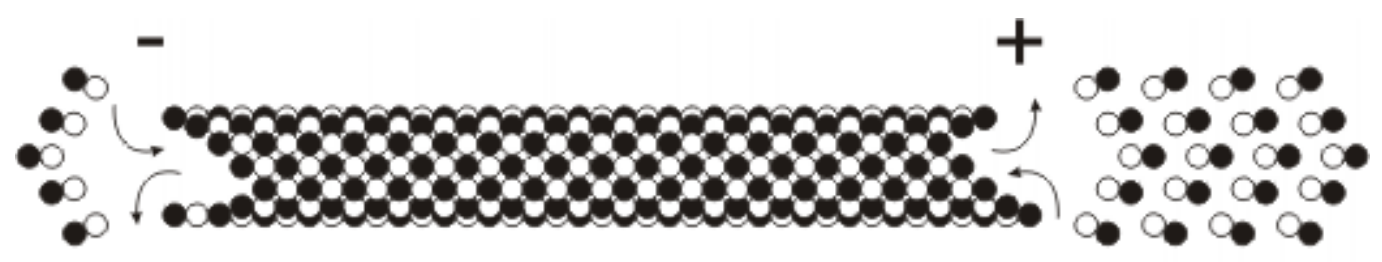

Dímeros de Tubulina

Figura 3.1

Las tubulinas son una superfamilia de proteínas constituidas por las $\alpha$ y $\beta$ que forman los heterodímeros de los microtúbulos y las $\gamma$ que forman los núcleos de polimerización ubicadas en el centrosoma. Las $\alpha$ y $\beta$ tubulinas son una familia de proteínas de cerca de 450 residuos y se encuentran muy conservadas en la evolución. Estas proteínas globulares forman los microtúbulos cuando los dímeros se unen al nucleótido guanosin trifosfato (GTP). Las dos subunidades se unen a GTP, pero sólo la subunidad $\beta$ tiene actividad GTPasa hidrolizando irreversiblemente el GTP a GDP (Figura 2). Esta hidrólisis modula la adición de nuevos dímeros. El crecimiento de los microtúbulos ocurre como un proceso denominado inestabilidad dinámica en el cual se alternan fases de crecimiento lento y despolimerización rápida o catástrofe. La elongación neta del microtúbulo se da en el extremo $(+)$.

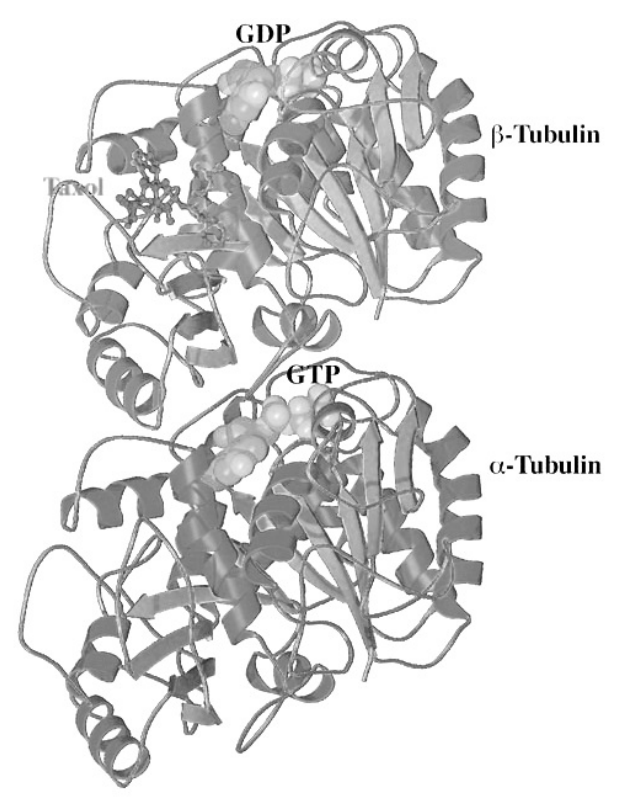

Figura 3.2 
Existen tres clases principales de agentes antimitóticos, cada una con su propio sitio de unión a la tubulina, que actúan interrumpiendo la dinámica de esta proteína. Una clase es la conformada por los compuestos que se unen al sitio del taxano (taxol y epotilone) y actúan impidiendo la depolimerización de tubulina, y de esa forma estabilizan los microtúbulos. Otra clase es la de los compuestos que se unen al sitio del alcaloide vinca (vincristina, dolastatina y criptoficina); y la tercera conformada por los compuestos que se ligan al sitio de la colchicina (colchicina y combretastatina) ${ }^{1}$.

Estos últimos, los derivados análogos de combretastatina configuran uno de los grupos más extensamente estudiados desde el descubrimiento de la combretastatina A-4 (Figura 3), dentro de los numerosos agentes antimitóticos que inhiben la polimerización de la tubulina interactuando con el sitio de la colchicina (Figura 3) ${ }^{105}$.

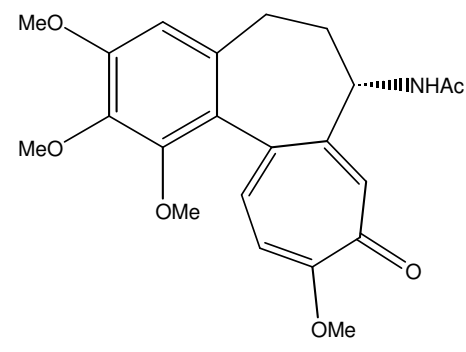

colchicina<smiles>COc1ccc(/C=C\c2cc(OC)c(OC)c(OC)c2)cc1O</smiles>

combretastatina A-4

Figura 3.3

En los últimos años se prepararon numerosos análogos de combretastatina A-4 con el fin de mejorar la solubilidad, la estabilidad y el índice terapéutico. La presencia del doble enlace cis entre los dos anillos A y B, que los obliga a mantenerse no coplanares dentro de una cierta distancia, parece tener una importancia clave en la actividad citotóxica $^{2,106,107}$. Esto dio lugar al comienzo del estudio de derivados neoflavonoides que adoptan también una conformación en la cual los anillos son no coplanares. De entre estos numerosos compuestos, Christian Bailly y sus colaboradores sintetizaron y evaluaron la actividad biológica de nuevos derivados de 4-arilcumarinas, análogos de

${ }^{105}$ (a) G. R. Pettit, G. M. Cragg, S. B. Singh; J. Nat. Prod. 50 (1987) 386-391. (b) G. R. Pettit, S. B. Singh, M. R. Boyd, E. Hamel, R. K. Pettit, J. M. Schmidt, F. Hogan; J. Med. Chem. 38 (1995) 16661672. (c) G. R. Pettit; J. Nat. Prod. 59 (1996) 812-821

${ }^{106}$ K. Gaukroger, J. A. Hadfield, L. A. Hepworth, N. J. Lawrence, A. T. McGown; J. Org. Chem. 66 (2001) 8135-8138 and references therein

${ }^{107}$ C. M. Lin, S. B. Singh, P. S. Chu, R. O. Dempcy, J. M. Schmidt, G. R. Pettit, E. Hamel; Mol. Pharmacol. 34 (1988) 200-208 
combretastatinas. Dos de ellos mostraron inhibir el ensamble de tubulina, y además los mismos son los que presentan citotoxicidad ${ }^{108}$.

En esta tesis se estudiaron nueve de estos nuevos compuestos (Figura 4) y la combretastatina A-4. Se efectuaron cálculos de Dinámica Molecular (DM) de los diez compuestos y se generó un espacio conformacional de 25 geometrías para cada una de las diez moléculas. Se optimizaron las geometrías de todo el conjunto completo del espacio conformacional con un método local de la Teoría del Funcional de la Densidad usando el paquete de programas Gaussian03 ${ }^{109}$, y luego con otro método de funcionales dependientes de la densidad y de su gradiente se optimizaron los confórmeros de más baja energía hasta $2 \mathrm{kcal} / \mathrm{mol}$ por encima del de energía menor. Posteriormente se realizó el cálculo de frecuencias vibracionales al mismo nivel de teoría con el doble propósito de determinar los puntos estacionarios en la superficie de energía potencial y asignar los modos normales de vibración. También se llevaron a cabo los cálculos de los tensores magnéticos de acuerdo al método sugerido por Chesseman y sus colaboradores ${ }^{110}$ usando el $^{2}$ método GIAO (Gauge-Including-Atomic-Orbitals) ${ }^{111}$ tal como está implementado en el paquete de programas Gaussian03. Finalmente se calcularon los potenciales electrostáticos sobre los confórmeros de más baja energía con el objetivo de determinar las zonas del entorno molecular que son relevantes en la interacción droga-receptor.

\footnotetext{
${ }^{108}$ C. Bailly, C. Bal, P. Barbier, S. Combes, J. P. Finet, M. P. Hildebrand, V. Peyrot, N. Wattez; J. Med. Chem. 46 (2003) 5437-5444

109 M.J. Frisch, G.W. Trucks, H.B. Schlegel, G.E. Scuseria, M.A. Robb, J.R. Cheeseman, V.G. Zakrzewski, J.A. Montgomery, Jr., R.E. Stratmann, J.C. Burant, S. Dapprich, J.M. Millam, A.D. Daniels, K.N. Kudin, M.C. Strain, O. Farkas, J. Tomasi, V. Barone, M. Cossi, R. Cammi, B. Mennucci, C. Pomelli, C. Adamo, S. Clifford, J. Ochterski, G.A. Petersson, P.Y. Ayala, Q. Cui, K. Morokuma, D.K. Malick, A.D. Rabuck, K. Raghavachari, J.B. Foresman, J. Cioslowski, J.V. Ortiz, A.G. Baboul, B.B. Stefanov, G. Liu, A. Liashenko, P. Piskorz, I. Komaromi, R. Gomperts, R.L. Martin, D.J. Fox, T. Keith, M.A. Al-Laham, C.Y. Peng, A.Nanayakkara, C. Gonzalez, M. Challacombe, P.M.W. Gill, B. Johnson, W. Chen, M.W. Wong, J.L. Andres, C. Gonzalez, M. Head-Gordon, E.S. Replogle, J.A. Pople, Gaussian 03, Revision A.; Gaussian, Inc., Pittsburgh PA, 2003

${ }_{110}$ J.R. Cheeseman, G.W. Trucks, T.A. Keith, M.J. Frisch, J. Chem. Phys. 1996; 104: 5497

${ }^{111}$ R. Ditchfield. Mol. Phys. 1974; 27: 789
} 


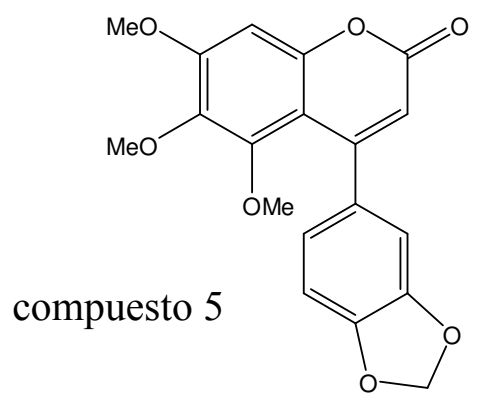<smiles>[2H]c1cc(-c2cc(=O)oc3cc(OC)c(Br)c(Br)c23)cc(Br)c1O</smiles>

Figura 3.4

\begin{tabular}{c|c|c|c|c} 
compuesto & $\mathbf{R}_{\mathbf{1}}$ & $\mathbf{R}_{\mathbf{2}}$ & $\mathbf{R}_{\mathbf{3}}$ & $\mathbf{R}_{\mathbf{4}}$ \\
\hline $\mathbf{1}$ & $\mathrm{OMe}$ & $\mathrm{H}$ & $\mathrm{OH}$ & $\mathrm{H}$ \\
\hline $\mathbf{2}$ & $\mathrm{OMe}$ & $\mathrm{H}$ & $\mathrm{OH}$ & $\mathrm{OMe}$ \\
\hline $\mathbf{3}$ & $\mathrm{OMe}$ & $\mathrm{H}$ & $\mathrm{OMe}$ & $\mathrm{OH}$ \\
\hline $\mathbf{4}$ & $\mathrm{OMe}$ & $\mathrm{OMe}$ & $\mathrm{OH}$ & $\mathrm{OMe}$ \\
\hline $\mathbf{6}$ & $\mathrm{H}$ & $\mathrm{H}$ & $\mathrm{OH}$ & $\mathrm{H}$ \\
\hline $\mathbf{7}$ & $\mathrm{H}$ & $\mathrm{H}$ & $\mathrm{OH}$ & $\mathrm{OMe}$ \\
\hline $\mathbf{8}$ & $\mathrm{H}$ & $\mathrm{H}$ & $\mathrm{OMe}$ & $\mathrm{OH}$ \\
\hline $\mathbf{9}$ & $\mathrm{H}$ & $\mathrm{OMe}$ & $\mathrm{OH}$ & $\mathrm{OMe}$
\end{tabular}

4-(4'-hidroxifenil)-5,6,7 trimetoxicromen-2-ona $\equiv$ compuesto 1

4-(4'-hidroxi-3' -metoxifenil)-5,6,7-trimetoxicromen-2-ona $\equiv$ compuesto 2

4-(3'-hidroxi-4' -methoxifenil)-5,6,7-trimetoxicromen-2-ona $\equiv$ compuesto 3

4-(4'-hidroxi-3', 5' -dimetoxifenil)-5,6,7-trimetoxicromen-2-ona $\equiv$ compuesto 4

4-(3', 4'-Metilenedioxifenyl)-5,6,7-trimetoxicromen-2-ona $\equiv$ compuesto 5

4-(4'-hidroxifenil)-5,7-dimetoxicromen-2-ona $\equiv$ compuesto 6

4-(4'-hidroxi-3' -metoxifenil)-5,7-dimetoxicromen-2-ona $\equiv$ compuesto 7

4-(3'-hidroxi-4'-metoxifenil)-5,7-dimetoxicromen-2-ona $\equiv$ compuesto 8

4-(4'-hidroxi-3', 5'-dimethoxifenil)-5,7-dimetoxicromen-2-ona $\equiv$ compuesto 9

Las diferentes distribuciones espaciales de los átomos generadas cuando se producen rotaciones alrededor de un enlace sencillo se denominan conformaciones. La existencia de numerosos isómeros conformacionales en la mayoría de los sistemas moleculares y la relación entre las conformaciones y diferentes propiedades de los compuestos dio lugar al estudio detallado de las mismas. A este tipo de estudio se lo conoce como Análisis Conformacional. Una de las aplicaciones más importantes del análisis conformacional se orienta a la búsqueda de relaciones entre la flexibilidad de la 
molécula y su función biológica, de enorme importancia en el campo del diseño de fármacos. El diseño basado en la estructura del fármaco y las simulaciones de dinámica molecular hacen uso de este tipo de análisis para identificar potenciales fármacos que encajen en un sitio de unión tridimensional conocido, por ejemplo por técnicas cristalográficas, de RMN o de modelado molecular.

El potencial de interacción entre los átomos de un sistema molecular en una simulación de Dinámica Molecular define, junto a la topología, el modelo molecular. Este potencial de interacción se conoce como el campo de fuerzas y debe ser lo suficientemente simple como para permitir el cálculo en tiempos razonables, pero a la vez dar una descripción realista del sistema. Debido a que incorporar todos los tipos de interacción no es posible, el campo de fuerzas es necesariamente aproximado.

Para describir estos campos de fuerzas se suelen usar potenciales efectivos que deben ser parametrizados para cada sistema atómico-molecular particular. Tanto la selección de la forma del potencial como de los parámetros particulares es una tarea ardua en la formulación del modelo. Lo usual es dividir los potenciales entre potenciales para átomos ligados y potenciales para átomos no-ligados.

Las interacciones entre átomos ligados incluyen energías de enlace covalentes, ángulos de enlace y diedros propios e impropios. Para los átomos no ligados cuentan las energías de naturaleza eléctrica y las interacciones de Van der Waals expresadas en general por su forma más clásica que es el potencial de Lennard-Jones. La expresión general es

$\mathrm{E}=\sum_{\text {enlaces }} \frac{\mathrm{k}_{\mathrm{r}}}{2}\left(\mathrm{r}-\mathrm{r}_{0}\right)^{2}+\sum_{\text {ángulos }} \frac{\mathrm{k}_{\theta}^{\prime}}{2}\left(\theta-\theta_{0}\right)^{2}+\sum_{\text {diedros }} \mathrm{k}_{\phi}{ }^{\prime \prime}\left[1+\cos \left(\mathrm{n} \phi-\phi_{0}\right)\right]+\sum_{\text {pares }} \frac{\mathrm{q}_{\mathrm{i}} \mathrm{q}_{\mathrm{j}}}{\mathrm{r}}+\sum_{\text {pares }}\left(\frac{\mathrm{C}^{12}}{\mathrm{r}^{12}}-\frac{\mathrm{C}^{6}}{\mathrm{r}^{6}}\right)$

El primer término describe la vibración entre dos átomos ligados a través del enlace como un movimiento armónico simple, donde $\mathrm{r}_{0}$ es la distancia de equilibrio entre los dos átomos 


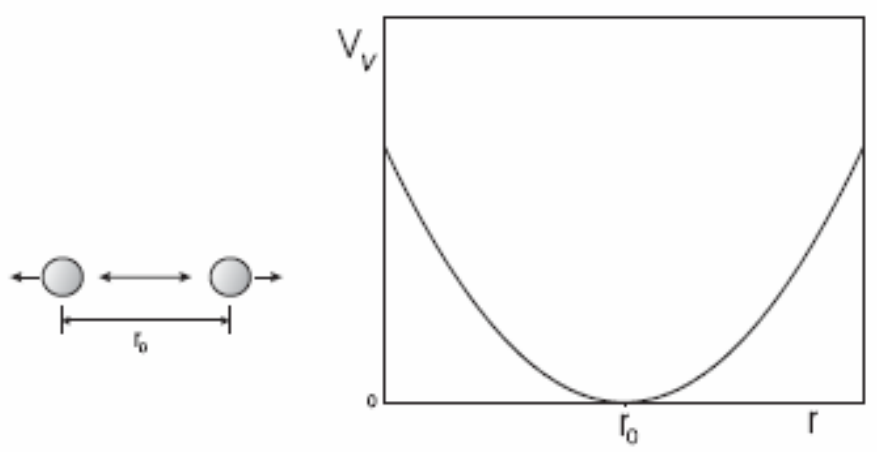

El segundo término se describe de forma similar al primero con un potencial armónico que flexiona el ángulo alrededor de $\theta_{0}$ que es el ángulo de enlace del equilibrio.
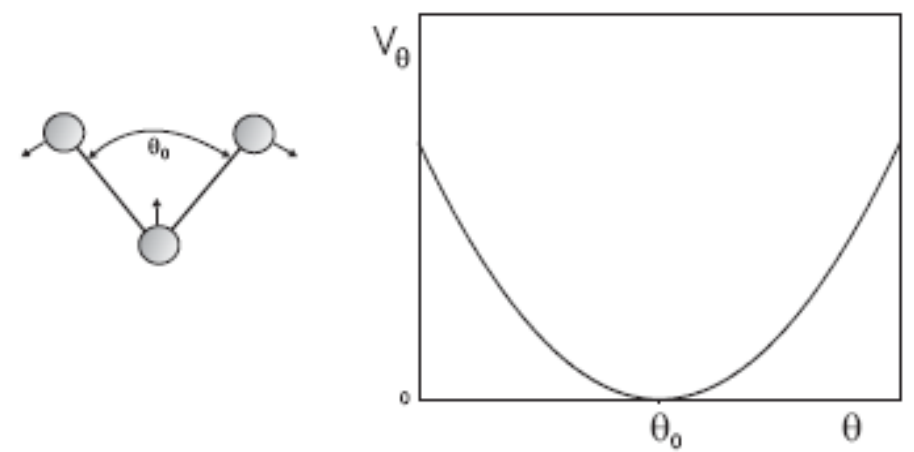

El tercer término es más complejo de modelar y depende de la naturaleza de los ángulos de torsión característicos en la molécula. El cuarto es un término coulómbico y plantea como desafío para su modelado la interacción entre cargas cercanas como así también establecer un radio de corte que ponga un coto al alcance de la interacción, pero a la vez que tal corte no sea abrupto. El último término requiere un trabajo dedicado para el establecimiento de los coeficientes de Lennard-Jones ya que dependen de los tipos de átomos involucrados.

\subsection{La Dinámica Molecular}

Una característica de los sistemas moleculares a temperatura ambiente es su movimiento. La simulaciones de Dinámica Molécular (DM), a diferencia del método Monte Carlo, son deterministas. Los valores de las futuras velocidades y posiciones se calculan en base a los valores presentes. Los átomos se mueven de acuerdo a las leyes de la mecánica newtoniana. Una simulación DM se lleva a cabo integrando las ecuaciones de movimiento de Newton sobre el tiempo para el sistema molecular. 


$$
\mathrm{F}_{\mathrm{i}}(\mathrm{t})=\mathrm{m}_{\mathrm{i}} \mathrm{a}_{\mathrm{i}}(\mathrm{t})=\mathrm{m}_{\mathrm{i}} \frac{\partial^{2} \mathrm{r}_{\mathrm{i}}(\mathrm{t})}{\partial \mathrm{t}^{2}} \quad \mathrm{i}=1,2 \ldots \mathrm{N}(\mathrm{N}=\text { número de átomos })
$$

Donde $F_{i}(t)$ es la fuerza sobre el átomo i al tiempo $t$

$\mathrm{a}_{\mathrm{i}}(\mathrm{t})$ es la aceleración del átomo $\mathbf{i}$ al tiempo $\mathbf{t}$

$\mathrm{r}_{\mathrm{i}}(\mathrm{t})$ es la posición del átomo $\mathbf{i}$ al tiempo $\mathbf{t}$

La fuerza sobre el átomo $\mathbf{i}$ al tiempo $\mathbf{t}$ se resuelve fácilmente como el gradiente negativo de la función energía potencial

$$
\mathrm{F}_{\mathrm{i}}(\mathrm{t})=-\frac{d \mathrm{E}\left(\mathrm{r}_{1}, \mathrm{r}_{2}, \ldots \mathrm{r}_{\mathrm{N}}\right)}{d \mathrm{r}_{\mathrm{i}}}
$$

Una variedad de algoritmos son usados para resolver las ecuaciones de movimiento. El más común de estos es el algoritmo de Verlet, que establece los vectores de posición utilizando las fuerzas y las posiciones previas de los átomos

$$
r_{i}(t+\Delta t)=2 r_{i}(t)-r_{i}(t-\Delta t)+\frac{F_{i}(t)}{m_{i}}\left(\Delta t^{2}\right)+O\left(\Delta t^{4}\right)
$$

donde el último es un término de corrección de cuarto orden. Los vectores de velocidad se calculan con una fórmula de distancia central

$$
v_{i}(t)=\frac{r_{i}(t+\Delta t)-r_{i}(t-\Delta t)}{2 \Delta t}+O\left(\Delta t^{3}\right)
$$

Una simulación de estas características se desarrolla en un ensamble microcanónico (NVE), con el número de partículas, el volumen y la energía total constantes. El paso de tiempo de integración es, para sistemas biomoleculares, del orden de los femtosegundos $\left(1 \mathrm{fs}=1.0 \times 10^{-15} \mathrm{~s}\right)$. Estos tiempos pequeños son necesarios para asegurar la estabilidad numérica al integrar las ecuaciones, pero además deben ser lo suficientemente largos como para observar el fenómeno deseado. Las ecuaciones de movimiento para sistemas con $3 \mathrm{~N}$ grados de libertad se deben integrar iterativamente durante $10^{5}$ pasos de tiempo para generar una trayectoria de 100 picosegundos $\left(1 \mathrm{ps}=1.0 \times 10^{-12} \mathrm{~s}\right)$. Con frecuencia, los grados de libertad internos, en particular los modos de bond stretching están fijos en una simulación DM. La metodología de restricción más usada es SHAKE, que aplica 
fuerzas adicionales para mantener las longitudes de enlace fijas a los valores del equilibrio. En principio, todas las propiedades dinámicas y de equilibrio se pueden calcular con una trayectoria DM. Como en Monte Carlo, las propiedades derivadas como la capacidad calorífica, convergen más lentamente que las promediadas como la energía interna. A diferencia de Monte Carlo, los cálculos MD son promedios en el tiempo mientras que los primeros son promedios de conjuntos. La hipótesis ergódica establece que un promedio en los conjuntos es equivalente a uno en el tiempo dentro de los límites de una muestra adecuada y tiempo suficiente.

La Dinámica Molecular es una poderosa herramienta a la hora de estudiar los movimientos que ocurren durante la aproximación de un ligando al sitio de unión de una macromolécula, o la actividad enzimática o el reconocimiento molecular.

\subsubsection{Resultados de la Dinámica Molecular}

En este trabajo se empleó el paquete de software Hyperchem para llevar adelante las simulaciones de DM sin restricciones. El algoritmo que emplea es en sustancia similar al de Verlet con una pequeña modificación en la expresión de la velocidad en donde la velocidad a tiempo $t$ es un promedio entre $v_{i}\left(t+\frac{1}{2}\right)$ y $v_{i}\left(t-\frac{1}{2}\right)$.

Las simulaciones para cada una de las arilcumarinas y la combretastatina A-4 se llevaron a cabo con un intervalo de tiempo $\Delta \mathrm{t}$ de 1.0 fs. Estos valores pequeños para el intervalo de tiempo permiten integrar adecuadamente el movimiento de más alta frecuencia, el estiramiento, que es del orden de varios picosegundos. Se utilizó un campo de fuerzas de la Mecánica Molecular MM+ tal como está disponible en el programa.

El constructor molecular del software ubica a los átomos y moléculas cerca del cero de energía, que corresponde a $0 \mathrm{~K}$ para la temperatura de simulación. Es necesario entonces calentar hasta alcanzar la temperatura a la que se mantendrá la simulación, en este caso $900 \mathrm{~K}$. Lo más conveniente es hacerlo de a incrementos pequeños de temperatura lo cual permite al sistema alcanzar el equilibrio en cada paso, lo que da como beneficio un menor tiempo total hasta alcanzar las condiciones de simulación.

Debido a que las velocidades resultantes del calentamiento no simulan el tipo de movimiento de un sistema real en el equilibrio, es necesario dejar transcurrir un tiempo 
de equilibración. Para generar las velocidades características se deja interactuar a los átomos unos con otros mediante las ecuaciones de movimiento. Las velocidades para la simulación isotérmica estarán correctamente escaladas luego de un "baño de relajación", en donde el factor es

$$
\lambda=\left[1+\frac{\Delta \mathrm{t}}{\tau}\left(\frac{\mathrm{T}_{0}}{\mathrm{~T}}-1\right)\right]^{\frac{1}{2}}
$$

y $\tau$ es el tiempo de relajación. Este algoritmo se conoce como termostato de Berendsen $^{112}$. En el actual trabajo el tiempo de relajación se fijó en 0.5 ps y la temperatura de la simulación en $900 \mathrm{~K}$.

En el siguiente script se detallan las condiciones para la simulación tomando como ejemplo el del compuesto 1

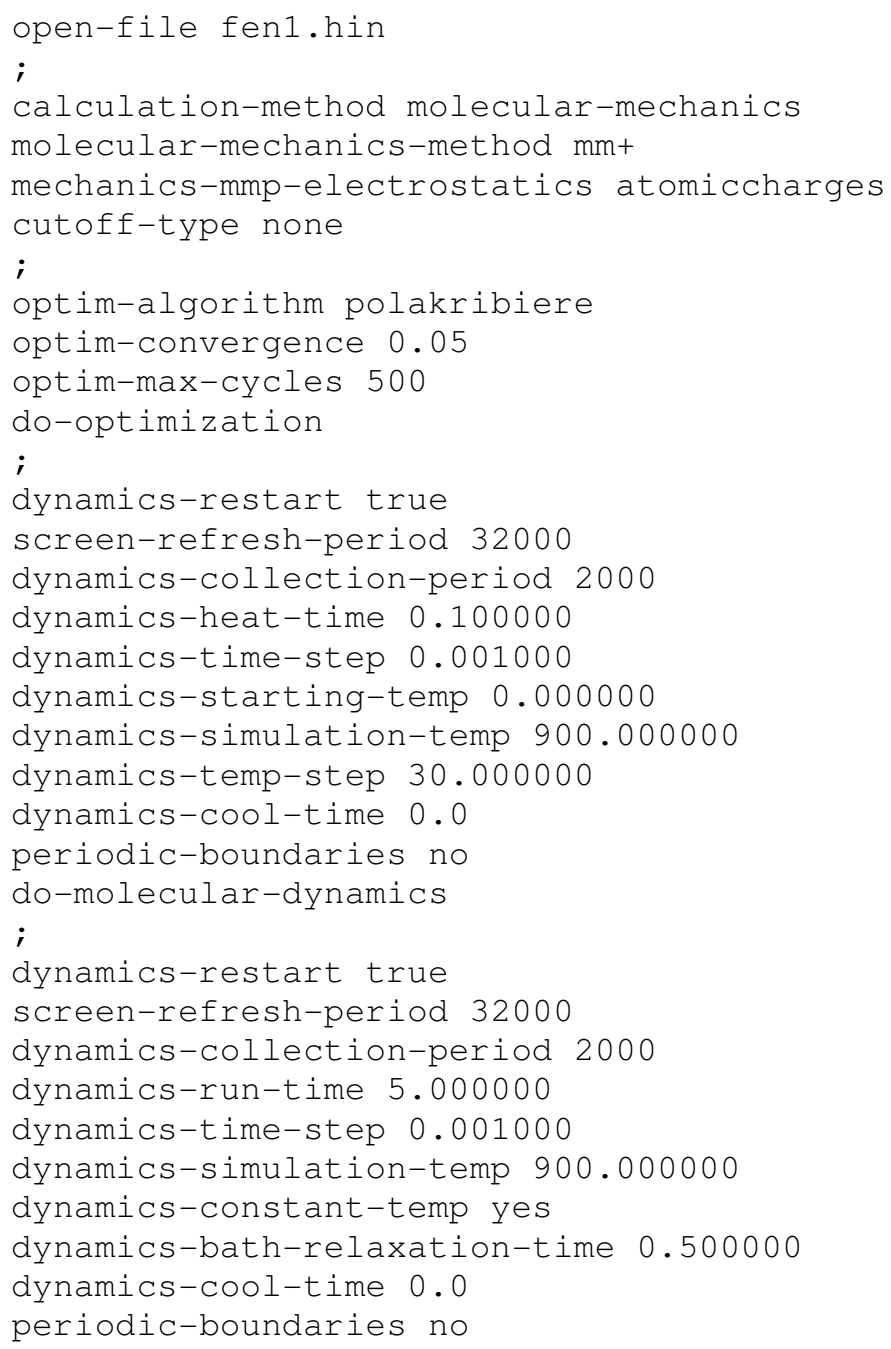

112 H. J. C. Berendsen, J. P. M. Postma, W. F. van Gunsteren, A. DiNola and J. R. Haak, J. Chem. Phys. 81 (1984) 3684-3690. 


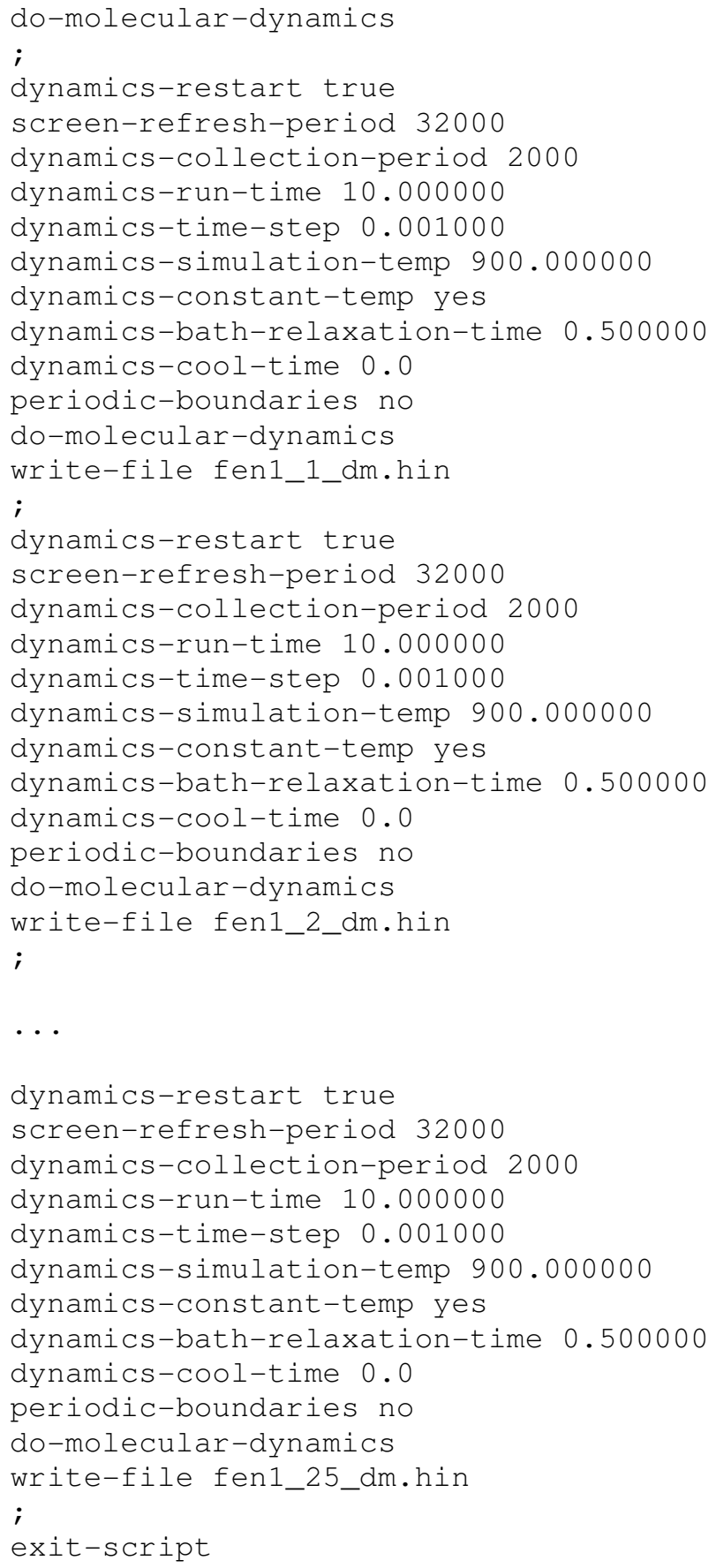

Cada geometría guardada de la DM fue optimizada con el método semiempírico AM1 tal como está disponible en el programa utilizando también un script detallado a continuación

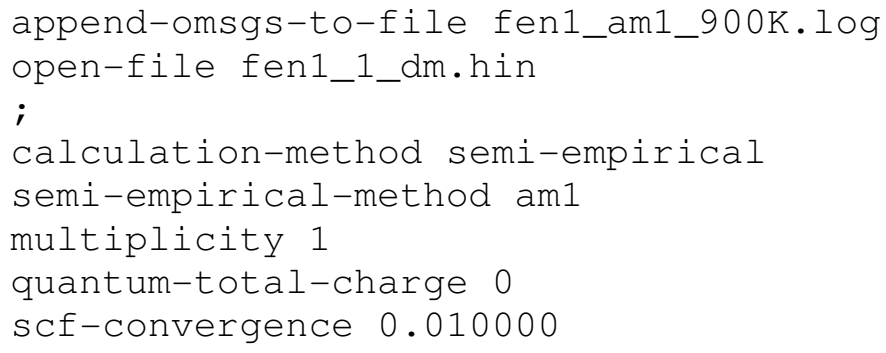




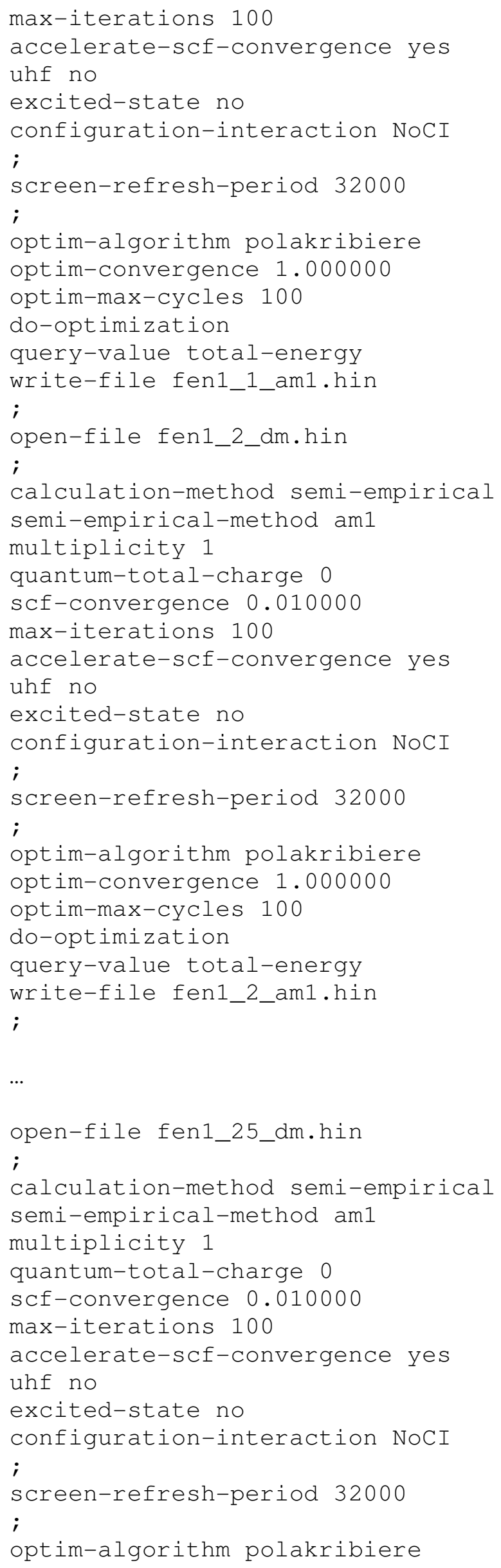


optim-convergence 1.000000

optim-max-cycles 100

do-optimization

query-value total-energy

write-file fen1_25_am1.hin

;

exit-script

De esta forma obtuvimos 25 geometrías de partida para optimizar con funcionales de la densidad SVWN (Slater, Vosko, Wilk y Nusair) que dependen sólo de la densidad electrónica (LSDA) y usando un conjunto de funciones base $3-21 \mathrm{G}^{* *}$. Posteriormente las geometrías obtenidas de esta manera se optimizaron usando el funcional híbrido B3LYP (Becke, Lee, Yang y Parr) que depende además de la densidad de su gradiente (GGA) y un conjunto de funciones base $6-31+\mathrm{G}^{* *}$. Como explicamos antes, en las funciones 6-31G las capas internas se representan por una función combinación lineal de seis primitivas y las de valencia por dos funciones, una combinación lineal de tres funciones primitivas y otra simple.

En el sistema que se estudió, la contracción para estas funciones es

$\mathrm{H} \quad(4 \mathrm{~s}, 1 \mathrm{p}) \rightarrow[2 \mathrm{~s}, 1 \mathrm{p}]$

$\mathrm{C}, \mathrm{O} \quad(10 \mathrm{~s}, 4 \mathrm{p}, 1 \mathrm{~d}) \rightarrow[3 \mathrm{~s}, 2 \mathrm{p}, 1 \mathrm{~d}]$

Esto significa que para el átomo de carbono y para el átomo de oxígeno se usaron 10 funciones s y con 6 de ellas (los orbitales internos 1s) se construyó una función combinación lineal de estas seis, con las otras cuatro (orbitales de valencia 2s) se construyeron dos funciones base, una de ellas combinación lineal de tres primitivas y otra simple. El orbital d quedó como función simple de polarización.

Para el átomo de hidrógeno que no tiene orbitales internos se usaron 4 orbitales s para construir dos funciones, una combinación lineal de tres primitivas y otra simple. El orbital p queda como función simple de polarización.

En las siguientes tablas de la 3a1 a la 3a10 se muestran las energías ordenadas de menor a mayor de todos los confórmeros de las diez moléculas numerados del 1 al 25 para los resultados de la dinámica y la optimización con AM1 en $\mathrm{kcal} / \mathrm{mol}$, y de las optimizaciones DFT en unidades atómicas (hartrees). En la columna 1 (DM+AM1) se muestran las energías resultantes de la DM llevada a cabo con el programa disponible en el paquete de HyperChem de las 25 conformaciones y posteriormente las geometrías optimizadas con AM1. En la columna 3 (SVWN/3-21G**) se listan las energías de las conformaciones generadas por el cálculo DFT local y en la quinta columna (B3LYP/6- 
$31+\mathrm{G}^{* *}$ ) se listan las energías de los confórmeros que finalmente resultan de un cálculo DFT con gradiente corregido por correlación. En esta columna, como es de esperar, se reduce el número de confórmeros ya que el método y las bases usadas incrementan la precisión para optimizar las energías calculadas. Finalmente la última columna de las tablas muestra la diferencia de energía entre los confórmeros en kcal/mol. 


\section{Compuesto 1}

\begin{tabular}{|c|c|c|c|c|c|c|}
\hline $\mathbf{D M}+\mathbf{A M 1}$ & $n^{0} \operatorname{conf}$ & SVWN/3-21G* & $n^{0} \operatorname{conf}$ & B3LYP/6-31+G** & $n^{0} \operatorname{conf}$ & $\Delta \mathbf{E}$ \\
\hline-102509.2 & 17 & -1134.557351 & 14 & -1146.91361 & 5 & 0 \\
\hline-102509.0 & 1 & -1134.557351 & 10 & -1146.91361 & 23 & 0 \\
\hline-102508.7 & 16 & -1134.557349 & 22 & -1146.91354 & 16 & 0.044 \\
\hline-102508.0 & 2 & -1134.557232 & 15 & -1146.910965 & 15 & 1.660 \\
\hline-102507.9 & 6 & -1134.557231 & 12 & -1146.910955 & 18 & 1.666 \\
\hline-102507.9 & 12 & -1134.557056 & 5 & -1146.909391 & 19 & 2.648 \\
\hline-102507.8 & 11 & -1134.557056 & 25 & -1146.909391 & 20 & 2.648 \\
\hline-102507.8 & 13 & -1134.557056 & 11 & -1146.909391 & 9 & 2.648 \\
\hline-102507.6 & 8 & -1134.556867 & 16 & -1146.909391 & 22 & 2.648 \\
\hline-102507.4 & 19 & -1134.556867 & 1 & -1146.909391 & 14 & 2.648 \\
\hline-102507.3 & 5 & -1134.556867 & 17 & -1146.909391 & 7 & 2.648 \\
\hline-102507.3 & 24 & -1134.556867 & 13 & & & \\
\hline-102507.2 & 23 & -1134.556867 & 8 & & & \\
\hline-102506.6 & 4 & -1134.556732 & 19 & & & \\
\hline-102506.5 & 7 & -1134.556732 & 2 & & & \\
\hline-102506.2 & 15 & -1134.556269 & 20 & & & \\
\hline-102506.2 & 21 & -1134.555962 & 23 & & & \\
\hline-102505.8 & 20 & -1134.555961 & 4 & & & \\
\hline-102505.8 & 25 & -1134.555961 & 3 & & & \\
\hline-102505.7 & 22 & -1134.555961 & 6 & & & \\
\hline-102504.9 & 9 & -1134.555961 & 21 & & & \\
\hline-102504.9 & 14 & -1134.555651 & 18 & & & \\
\hline-102504.8 & 10 & -1134.55555 & 7 & & & \\
\hline-102504.7 & 18 & -1134.55555 & 24 & & & \\
\hline-102504.5 & 3 & -1134.555375 & 9 & & & \\
\hline
\end{tabular}

Tabla 3a1 


\section{Compuesto 2}

\begin{tabular}{|c|c|c|c|c|c|c|}
\hline DM+AM1 & $n^{0} \operatorname{conf}$ & SVWN/3-21G* & $n^{0} \operatorname{conf}$ & B3LYP/6-31+G** & $n^{0} \operatorname{conf}$ & $\Delta \mathbf{E}$ \\
\hline-113481.6 & 7 & -1247.900904 & 10 & -1261.444467 & 22 & 0 \\
\hline-113481.3 & 17 & -1247.900319 & 22 & -1261.443869 & 7 & 0.375 \\
\hline-113481.3 & 22 & -1247.899918 & 3 & -1261.442046 & 3 & 1.520 \\
\hline-113480.6 & 2 & -1247.899425 & 8 & -1261.441227 & 15 & 2.033 \\
\hline-113480.2 & 5 & -1247.899174 & 15 & -1261.440324 & 10 & 2.600 \\
\hline-113479.8 & 20 & -1247.898736 & 7 & -1261.439806 & 8 & 2.925 \\
\hline-113479.5 & 14 & -1247.898736 & 2 & -1261.439806 & 23 & 2.925 \\
\hline-113479.4 & 3 & -1247.898736 & 5 & -1261.43702 & 19 & 4.673 \\
\hline-113479 & 10 & -1247.898087 & 20 & -1261.436468 & 12 & 5.020 \\
\hline-113478.6 & 15 & -1247.897825 & 17 & -1261.434594 & 14 & 6.195 \\
\hline-113478.3 & 25 & -1247.897468 & 23 & -1261.432905 & 18 & 7.256 \\
\hline-113477.7 & 4 & -1247.888152 & 4 & -1261.432465 & 1 & 7.531 \\
\hline-113477.7 & 18 & -1247.887436 & 19 & -1261.432465 & 6 & 7.531 \\
\hline-113477.5 & 13 & -1247.887011 & 18 & -1261.432391 & 24 & 7.578 \\
\hline-113477 & 21 & -1247.886335 & 13 & -1261.432391 & 11 & 7.578 \\
\hline-113476.7 & 11 & -1247.886302 & 24 & -1261.432391 & 13 & 7.578 \\
\hline-113476.3 & 8 & -1247.886257 & 1 & -1261.430884 & 25 & 8.524 \\
\hline-113476 & 24 & -1247.88607 & 21 & -1261.428628 & 9 & 9.940 \\
\hline-113475.8 & 12 & -1247.885788 & 14 & & & \\
\hline-113474.4 & 6 & -1247.885668 & 12 & & & \\
\hline-113474.4 & 23 & -1247.88488 & 6 & & & \\
\hline-113474 & 19 & -1247.884482 & 25 & & & \\
\hline-113473.6 & 1 & -1247.884331 & 11 & & & \\
\hline-113473.3 & 16 & -1247.883972 & 9 & & & \\
\hline-113472.2 & 9 & -1247.88199 & 16 & & & \\
\hline
\end{tabular}

Tabla 3a2 


\section{Compuesto 3}

\begin{tabular}{c|c|c|c|c|c|c} 
DM+AM1 & $\mathbf{n}^{\mathbf{0}}$ conf & $\mathbf{S V W N / 3 - 2 1 G}$ & $\mathbf{n}^{\mathbf{0}} \mathbf{c o n f}$ & $\mathbf{B 3 L Y P / 6 - 3 1 + G * *}$ & $\mathbf{n}^{\mathbf{o}} \mathbf{c o n f}$ & $\boldsymbol{\Delta E}$ \\
\hline-113481.6 & 17 & -1247.898871 & 10 & -1261.444002 & 1 & 0 \\
\hline-113481.4 & 10 & -1247.897894 & 11 & -1261.444002 & 8 & $6.28 \mathrm{E}-06$ \\
\hline-113480.5 & 22 & -1247.897889 & 13 & -1261.444002 & 5 & $1.88 \mathrm{E}-05$ \\
\hline-113479.5 & 13 & -1247.897566 & 5 & -1261.443692 & 25 & 0.195 \\
\hline-113479.4 & 5 & -1247.897566 & 7 & -1261.443692 & 17 & 0.195 \\
\hline-113479.3 & 4 & -1247.897256 & 25 & -1261.441781 & 10 & 1.394 \\
\hline-113478.3 & 9 & -1247.897256 & 4 & -1261.441245 & 11 & 1.730 \\
\hline-113477.8 & 8 & -1247.897255 & 23 & -1261.437783 & 13 & 3.903 \\
\hline-113477.6 & 3 & -1247.896653 & 8 & -1261.437252 & 16 & 4.236 \\
\hline-113477.5 & 23 & -1247.896653 & 18 & -1261.436367 & 9 & 4.791 \\
\hline-113477.3 & 21 & -1247.896378 & 1 & -1261.434904 & 19 & 5.709 \\
\hline-113477.2 & 7 & -1247.896291 & 17 & -1261.434823 & 15 & 5.760 \\
\hline-113477.2 & 12 & -1247.896291 & 22 & -1261.434823 & 3 & 5.760 \\
\hline-113477.1 & 24 & -1247.892556 & 9 & -1261.433986 & 20 & 6.286 \\
\hline-113476.8 & 1 & -1247.889282 & 15 & -1261.433119 & 6 & 6.830 \\
\hline-113476.6 & 15 & -1247.886726 & 2 & -1261.431897 & 21 & 7.596 \\
\hline-113476.2 & 11 & -1247.886726 & 12 & -1261.431291 & 2 & 7.977 \\
\hline-113475.9 & 25 & -1247.886661 & 21 & -1261.428201 & 14 & 9.916 \\
\hline-113475.6 & 19 & -1247.886506 & 3 & -1261.427228 & 24 & 10.526 \\
\hline-113475.3 & 16 & -1247.885688 & 20 & & & \\
\hline-113475.1 & 14 & -1247.885309 & 19 & & & \\
\hline-113475.1 & 20 & -1247.885252 & 14 & & & \\
\hline-113474.6 & 6 & -1247.885041 & 24 & & & \\
\hline-113473.2 & 18 & -1247.884528 & 6 & & & \\
\hline-113472.7 & 2 & -1247.884422 & 16 & & & \\
\hline
\end{tabular}

Tabla 3a3 


\section{Compuesto 4}

\begin{tabular}{|c|c|c|c|c|c|c|}
\hline DM+AM1 & $n^{0} \operatorname{conf}$ & SVWN/3-21G* & $n^{0}$ conf & B3LYP/6-31+G** & $n^{0} \operatorname{conf}$ & $\Delta \mathbf{E}$ \\
\hline-124452.1 & 9 & -1361.232969 & 15 & -1375.967175 & 4 & 0 \\
\hline-124450.3 & 19 & -1361.230978 & 6 & -1375.967174 & 24 & 0.000 \\
\hline-124450.2 & 8 & -1361.230115 & 22 & -1375.967174 & 2 & 0.000 \\
\hline-124450 & 5 & -1361.229817 & 23 & -1375.967098 & 20 & 0.048 \\
\hline-124450 & 22 & -1361.229472 & 19 & -1375.967098 & 18 & 0.048 \\
\hline-124449.9 & 7 & -1361.228745 & 11 & -1375.967097 & 21 & 0.048 \\
\hline-124449.8 & 15 & -1361.228658 & 25 & -1375.966117 & 22 & 0.664 \\
\hline-124449.6 & 16 & -1361.227888 & 18 & -1375.965709 & 25 & 0.920 \\
\hline-124449.6 & 18 & -1361.227854 & 13 & -1375.965709 & 23 & 0.920 \\
\hline-124449.5 & 2 & -1361.227853 & 14 & -1375.965552 & 7 & 1.018 \\
\hline-124449.4 & 12 & -1361.227628 & 24 & -1375.965552 & 13 & 1.018 \\
\hline-124449.4 & 14 & -1361.227628 & 2 & -1375.965552 & 14 & 1.018 \\
\hline-124449.4 & 23 & -1361.227544 & 10 & -1375.965166 & 9 & 1.261 \\
\hline-124449.2 & 21 & -1361.227544 & 12 & -1375.965166 & 17 & 1.261 \\
\hline-124449.1 & 13 & -1361.22746 & 8 & -1375.964751 & 8 & 1.521 \\
\hline-124448.7 & 1 & -1361.227416 & 5 & -1375.964583 & 10 & 1.626 \\
\hline-124448.6 & 10 & -1361.227144 & 17 & -1375.964583 & 12 & 1.626 \\
\hline-124448.4 & 3 & -1361.227144 & 9 & -1375.964064 & 16 & 1.952 \\
\hline-124448.2 & 24 & -1361.227085 & 7 & -1375.963163 & 19 & 2.517 \\
\hline-124448 & 17 & -1361.227037 & 20 & -1375.963162 & 6 & 2.518 \\
\hline-124448 & 25 & -1361.22703 & 16 & -1375.962964 & 11 & 2.642 \\
\hline-124447.5 & 6 & -1361.226819 & 21 & -1375.962964 & 5 & 2.643 \\
\hline-124447 & 20 & -1361.226519 & 4 & -1375.962963 & 1 & 2.643 \\
\hline-124446.3 & 4 & -1361.226167 & 1 & -1375.961611 & 15 & 3.491 \\
\hline-124445.6 & 11 & -1361.225707 & 3 & -1375.959935 & 3 & 4.543 \\
\hline
\end{tabular}

Tabla 3a4 


\section{Compuesto 5}

\begin{tabular}{c|c|c|c|c|c|c} 
DM+AM1 & $\mathbf{n}^{\mathbf{0}}$ conf & $\mathbf{S V W N / 3 - 2 1 G}$ & $\mathbf{n}^{\mathbf{o}}$ conf & $\mathbf{B 3 L Y P / 6 - 3 1 + G * *}$ & $\mathbf{n}^{\mathbf{o}}$ conf & $\boldsymbol{\Delta} \mathbf{E}$ \\
\hline-112829.5 & 15 & -1246.670706 & 5 & -1260.221535 & 7 & 0 \\
\hline-112829.4 & 5 & -1246.669582 & 24 & -1260.220857 & 5 & 0.426 \\
\hline-112828 & 18 & -1246.669503 & 14 & -1260.220857 & 1 & 0.426 \\
\hline-112827.8 & 10 & -1246.669363 & 25 & -1260.220857 & 16 & 0.426 \\
\hline-112827.5 & 21 & -1246.669363 & 20 & -1260.218937 & 9 & 1.631 \\
\hline-112827.3 & 12 & -1246.669363 & 3 & -1260.218937 & 25 & 1.631 \\
\hline-112827 & 24 & -1246.668944 & 7 & -1260.218349 & 8 & 2.000 \\
\hline-112827 & 25 & -1246.668883 & 8 & -1260.217453 & 11 & 2.561 \\
\hline-112826.9 & 2 & -1246.668807 & 2 & -1260.216704 & 4 & 3.031 \\
\hline-112826.9 & 4 & -1246.668806 & 17 & -1260.216704 & 18 & 3.031 \\
\hline-112826.8 & 22 & -1246.668785 & 18 & -1260.216704 & 2 & 3.031 \\
\hline-112826.6 & 19 & -1246.668401 & 12 & -1260.216704 & 21 & 3.031 \\
\hline-112826.4 & 8 & -1246.6684 & 10 & -1260.216704 & 24 & 3.031 \\
\hline-112826.4 & 16 & -1246.6684 & 23 & -1260.214312 & 13 & 4.533 \\
\hline-112825.8 & 11 & -1246.6684 & 15 & & & \\
\hline-112825.8 & 13 & -1246.6684 & 19 & & & \\
\hline-112825.7 & 14 & -1246.668265 & 4 & & & \\
\hline-112825.5 & 3 & -1246.667808 & 22 & & & \\
\hline-112825.3 & 20 & -1246.66763 & 9 & & & \\
\hline-112825 & 1 & -1246.667595 & 13 & & & \\
\hline-112824.8 & 9 & -1246.667548 & 11 & & & \\
\hline-112824.5 & 7 & -1246.667358 & 16 & & & \\
\hline-112823 & 23 & -1246.667358 & 6 & & & \\
\hline-112822 & 6 & -1246.667058 & 21 & & & \\
\hline-112821.6 & 17 & -1246.66621 & 1 & & & \\
\hline & & & & & & \\
\hline
\end{tabular}

Tabla $3 a 5$ 


\section{Compuesto 6}

\begin{tabular}{c|c|c|c|c|c|c} 
DM+AM1 & $\mathbf{n}^{\mathbf{0}} \mathbf{c o n f}$ & $\mathbf{S V W N / 3 - 2 1 G}$ & $\mathbf{n}^{\mathbf{0}} \mathbf{c o n f}$ & $\mathbf{B 3 L Y P / 6 - 3 1 + G * *}$ & $\mathbf{n}^{\mathbf{0}} \mathbf{c o n f}$ & $\boldsymbol{\Delta} \mathbf{E}$ \\
\hline-91542.29 & 17 & -1021.232288 & 15 & -1032.400193 & 15 & 0 \\
\hline-91541.25 & 16 & -1021.232288 & 18 & -1032.400193 & 3 & $1.26 \mathrm{E}-05$ \\
\hline-91540.88 & 23 & -1021.232288 & 22 & -1032.39989 & 6 & 0.190 \\
\hline-91540.63 & 6 & -1021.232288 & 17 & -1032.39783 & 11 & 1.483 \\
\hline-91540.35 & 25 & -1021.23182 & 6 & -1032.397491 & 16 & 1.696 \\
\hline-91540.13 & 4 & -1021.229906 & 2 & -1032.395127 & 25 & 3.179 \\
\hline-91539.8 & 22 & -1021.22986 & 11 & -1032.395124 & 2 & 3.181 \\
\hline-91539.34 & 8 & -1021.22986 & 4 & -1032.393866 & 12 & 3.970 \\
\hline-91539.15 & 1 & -1021.22986 & 8 & -1032.393866 & 5 & 3.971 \\
\hline-91539.13 & 15 & -1021.229859 & 23 & -1032.393862 & 10 & 3.973 \\
\hline-91538.96 & 10 & -1021.229446 & 25 & & & \\
\hline-91538.94 & 18 & -1021.229446 & 7 & & & \\
\hline-91538.82 & 5 & -1021.229446 & 19 & & & \\
\hline-91538.59 & 24 & -1021.229313 & 16 & & & \\
\hline-91537.94 & 11 & -1021.229313 & 24 & & & \\
\hline-91537.88 & 21 & -1021.229313 & 1 & & & \\
\hline-91537.7 & 7 & -1021.229313 & 9 & & & \\
\hline-91537.54 & 14 & -1021.229287 & 3 & & & \\
\hline-91537.18 & 9 & -1021.228793 & 14 & & & \\
\hline-91537.18 & 19 & -1021.228793 & 21 & & & \\
\hline-91536.99 & 2 & -1021.22865 & 12 & & & \\
\hline-91536.63 & 20 & -1021.228128 & 5 & & & \\
\hline-91536.45 & 13 & -1021.228128 & 20 & & & \\
\hline-91535.85 & 3 & -1021.228128 & 13 & & & \\
\hline-91535.3 & 12 & -1021.22802 & 10 & & & \\
\hline
\end{tabular}

Tabla $3 a 6$ 


\section{Compuesto 7}

\begin{tabular}{|c|c|c|c|c|c|c|}
\hline DM+AM1 & $n^{0} \operatorname{conf}$ & SVWN/3-21G* & $n^{0} \operatorname{conf}$ & B3LYP/6-31+G** & $n^{0} \operatorname{conf}$ & $\Delta \mathbf{E}$ \\
\hline-102514 & 16 & -1134.575899 & 14 & -1146.930828 & 5 & 0 \\
\hline-102513.8 & 11 & -1134.574192 & 5 & -1146.928445 & 19 & 1.495 \\
\hline-102513.4 & 13 & -1134.574192 & 25 & -1146.92811 & 2 & 1.706 \\
\hline-102513.2 & 19 & -1134.571769 & 19 & -1146.926378 & 14 & 2.792 \\
\hline-102512.9 & 5 & -1134.571769 & 20 & -1146.924112 & 9 & 4.214 \\
\hline-102512.1 & 8 & -1134.571623 & 2 & -1146.923297 & 4 & 4.726 \\
\hline-102511.9 & 2 & -1134.571623 & 11 & -1146.923194 & 21 & 4.790 \\
\hline-102511.1 & 23 & -1134.571623 & 13 & -1146.921359 & 8 & 5.942 \\
\hline-102510.8 & 4 & -1134.571623 & 16 & -1146.921048 & 7 & 6.137 \\
\hline-102510.7 & 20 & -1134.570135 & 9 & -1146.918966 & 10 & 7.444 \\
\hline-102510.3 & 9 & -1134.561557 & 4 & -1146.918645 & 15 & 7.645 \\
\hline-102509.8 & 25 & -1134.561557 & 12 & -1146.917421 & 6 & 8.413 \\
\hline-102509.7 & 15 & -1134.561046 & 6 & -1146.916177 & 17 & 9.194 \\
\hline-102509.5 & 14 & -1134.560989 & 7 & -1146.914824 & 22 & 10.043 \\
\hline-102509 & 7 & -1134.560834 & 21 & & & \\
\hline-102508.4 & 18 & -1134.560817 & 8 & & & \\
\hline-102507.7 & 1 & -1134.560817 & 23 & & & \\
\hline-102507.5 & 10 & -1134.558613 & 15 & & & \\
\hline-102507.3 & 21 & -1134.558377 & 17 & & & \\
\hline-102507 & 3 & -1134.558377 & 1 & & & \\
\hline-102507 & 6 & -1134.558335 & 10 & & & \\
\hline-102507 & 22 & -1134.557848 & 22 & & & \\
\hline-102506.4 & 24 & -1134.557116 & 24 & & & \\
\hline-102505.7 & 12 & -1134.557116 & 18 & & & \\
\hline-102504.3 & 17 & -1134.557116 & 3 & & & \\
\hline
\end{tabular}

Tabla 3a7 


\section{Compuesto 8}

\begin{tabular}{|c|c|c|c|c|c|c|}
\hline DM+AM1 & $n^{0} \operatorname{conf}$ & SVWN/3-21G* & $n^{0}$ conf & B3LYP/6-31+G** & $n^{0} \operatorname{conf}$ & $\Delta \mathbf{E}$ \\
\hline-102514 & 8 & -1134.572382 & 3 & -1146.930848 & 16 & 0 \\
\hline-102513.1 & 13 & -1134.572382 & 15 & -1146.930118 & 3 & 0.458 \\
\hline-102512.6 & 4 & -1134.570965 & 24 & -1146.928531 & 24 & 1.454 \\
\hline-102511.9 & 3 & -1134.570965 & 2 & -1146.927722 & 8 & 1.961 \\
\hline-102511.5 & 15 & -1134.570965 & 6 & -1146.925311 & 5 & 3.474 \\
\hline-102511.5 & 17 & -1134.570803 & 5 & -1146.92406 & 14 & 4.259 \\
\hline-102511 & 22 & -1134.569977 & 8 & -1146.923205 & 10 & 4.796 \\
\hline-102510.9 & 20 & -1134.569977 & 13 & -1146.921792 & 9 & 5.683 \\
\hline-102510.9 & 24 & -1134.569977 & 17 & -1146.921612 & 4 & 5.796 \\
\hline-102510.5 & 9 & -1134.56997 & 16 & -1146.921197 & 1 & 6.056 \\
\hline-102510.4 & 12 & -1134.56997 & 19 & -1146.92119 & 12 & 6.060 \\
\hline-102510 & 2 & -1134.56997 & 20 & -1146.918986 & 25 & 7.443 \\
\hline-102509.9 & 5 & -1134.568834 & 14 & -1146.917592 & 18 & 8.318 \\
\hline-102509.4 & 16 & -1134.561995 & 9 & -1146.915625 & 21 & 9.552 \\
\hline-102509.3 & 11 & -1134.561335 & 4 & -1146.914529 & 7 & 10.241 \\
\hline-102509.3 & 25 & -1134.561066 & 12 & & & \\
\hline-102508.9 & 6 & -1134.561066 & 22 & & & \\
\hline-102508.9 & 14 & -1134.560605 & 10 & & & \\
\hline-102508.9 & 23 & -1134.559464 & 21 & & & \\
\hline-102508.3 & 1 & -1134.559318 & 25 & & & \\
\hline-102507.4 & 7 & -1134.558706 & 23 & & & \\
\hline-102507.4 & 10 & -1134.558432 & 1 & & & \\
\hline-102507.2 & 18 & -1134.558432 & 11 & & & \\
\hline-102506.1 & 19 & -1134.557996 & 18 & & & \\
\hline-102505.9 & 21 & -1134.557382 & 7 & & & \\
\hline
\end{tabular}

Tabla $3 a 8$ 


\section{Compuesto 9}

\begin{tabular}{c|c|c|c|c|c|c} 
DM+AM1 & $\mathbf{n}^{\mathbf{0}}$ conf & $\mathbf{S V W N / 3 - 2 1 G}$ & $\mathbf{n}^{\mathbf{0}} \mathbf{c o n f}$ & $\mathbf{B 3 L Y P / 6 - 3 1 + G ^ { * * }}$ & $\mathbf{n}^{\mathbf{o}} \mathbf{c o n f}$ & $\boldsymbol{\Delta} \mathbf{E}$ \\
\hline-113484.4 & 1 & -1247.906175 & 24 & -1261.453657 & 10 & 0 \\
\hline-113484.4 & 15 & -1247.905643 & 2 & -1261.45348 & 14 & 0.111 \\
\hline-113483.4 & 7 & -1247.904676 & 23 & -1261.452818 & 1 & 0.527 \\
\hline-113482.8 & 14 & -1247.904562 & 1 & -1261.451766 & 7 & 1.187 \\
\hline-113482.7 & 18 & -1247.903903 & 7 & -1261.451404 & 6 & 1.414 \\
\hline-113482.6 & 10 & -1247.903902 & 17 & -1261.45117 & 11 & 1.561 \\
\hline-113482.6 & 16 & -1247.903313 & 3 & -1261.450692 & 9 & 1.861 \\
\hline-113481.7 & 21 & -1247.903313 & 19 & -1261.449368 & 16 & 2.691 \\
\hline-113481.6 & 13 & -1247.903296 & 9 & -1261.448709 & 3 & 3.105 \\
\hline-113481.4 & 11 & -1247.902319 & 4 & -1261.447986 & 24 & 3.559 \\
\hline-113481.3 & 12 & -1247.902109 & 15 & -1261.447512 & 4 & 3.856 \\
\hline-113480.8 & 19 & -1247.902109 & 10 & -1261.447373 & 5 & 3.944 \\
\hline-113480.7 & 17 & -1247.902044 & 13 & -1261.446611 & 23 & 4.421 \\
\hline-113480.2 & 3 & -1247.902044 & 5 & -1261.44566 & 12 & 5.019 \\
\hline-113480 & 24 & -1247.901779 & 18 & -1261.445266 & 22 & 5.266 \\
\hline-113479.8 & 23 & -1247.901779 & 25 & & & \\
\hline-113479.8 & 25 & -1247.901779 & 14 & & & \\
\hline-113479.6 & 2 & -1247.901289 & 16 & & & \\
\hline-113478.9 & 22 & -1247.901123 & 8 & & & \\
\hline-113478.7 & 6 & -1247.900528 & 22 & & & \\
\hline-113478.6 & 8 & -1247.900113 & 12 & & & \\
\hline-113478.6 & 20 & -1247.899592 & 20 & & & \\
\hline-113477.8 & 5 & -1247.899592 & 6 & & & \\
\hline-113475 & 4 & -1247.899139 & 21 & & & \\
\hline-113473.2 & 9 & -1247.899139 & 11 & & & \\
\hline & & & & & & \\
\hline
\end{tabular}

Tabla 3a9 


\section{Combretastatina A-4}

\begin{tabular}{c|c|c|c|c|c|c} 
DM+AM1 & $\mathbf{n}^{\mathbf{0}}$ conf & $\mathbf{S V W N / 3 - 2 1 G *}$ & $\mathbf{n}^{\mathbf{0}}$ conf & $\mathbf{B} \mathbf{B} \mathbf{L Y P} / \mathbf{6 - 3 1 + G} *$ & $\mathbf{n}^{\mathbf{0}}$ conf & $\boldsymbol{\Delta} \mathbf{E}$ \\
\hline-96393.96 & 17 & -1062.496471 & 17 & -1074.071626 & 13 & 0 \\
\hline-96393.77 & 23 & -1062.495921 & 24 & -1074.071467 & 2 & 0.100 \\
\hline-96393.7 & 25 & -1062.495313 & 3 & -1074.071444 & 4 & 0.114 \\
\hline-96393.36 & 1 & -1062.495313 & 5 & -1074.070608 & 22 & 0.639 \\
\hline-96393.31 & 21 & -1062.494407 & 22 & -1074.070543 & 3 & 0.680 \\
\hline-96392.99 & 16 & -1062.493731 & 13 & -1074.070019 & 23 & 1.008 \\
\hline-96392.88 & 13 & -1062.49328 & 14 & -1074.069889 & 14 & 1.090 \\
\hline-96391.88 & 14 & -1062.49328 & 16 & -1074.069589 & 11 & 1.278 \\
\hline-96391.79 & 4 & -1062.493147 & 1 & -1074.06847 & 1 & 1.980 \\
\hline-96391.05 & 7 & -1062.489698 & 2 & -1074.068417 & 24 & 2.013 \\
\hline-96391.02 & 12 & -1062.48945 & 25 & -1074.068027 & 17 & 2.258 \\
\hline-96390.94 & 6 & -1062.48945 & 4 & -1074.067313 & 21 & 2.707 \\
\hline-96390.41 & 24 & -1062.487913 & 21 & -1074.065165 & 20 & 4.054 \\
\hline-96389.99 & 18 & -1062.486635 & 18 & -1074.063418 & 15 & 5.151 \\
\hline-96389.85 & 11 & -1062.486427 & 23 & -1074.063133 & 19 & 5.330 \\
\hline-96389.59 & 5 & -1062.485972 & 11 & -1074.062774 & 9 & 5.555 \\
\hline-96389.41 & 22 & -1062.483465 & 15 & -1074.062723 & 8 & 5.587 \\
\hline-96389.23 & 9 & -1062.483069 & 10 & -1074.062181 & 10 & 5.927 \\
\hline-96388.97 & 10 & -1062.482414 & 19 & -1074.060671 & 7 & 6.874 \\
\hline-96388.81 & 2 & -1062.482128 & 20 & -1074.06059 & 6 & 6.925 \\
\hline-96388.44 & 8 & -1062.478517 & 8 & -1074.059141 & 18 & 7.834 \\
\hline-96387.7 & 15 & -1062.476952 & 12 & -1074.058624 & 12 & 8.159 \\
\hline-96387.45 & 3 & -1062.476077 & 7 & -1074.058518 & 5 & 8.225 \\
\hline-96387.27 & 20 & -1062.47581 & 6 & & & \\
\hline-96384.69 & 19 & -1062.475741 & 9 & & & \\
\hline
\end{tabular}

Tabla 3a10 


\subsection{La optimización de la geometría}

El camino por el cual la energía de un sistema molecular toma diferentes valores, como consecuencia de pequeños cambios en su estructura, se conoce como Superficie de Energía Potencial (PES por sus siglas en inglés). Una PES es una relación matemática que vincula la estructura de la molécula con la energía resultante. Para moléculas diatómicas esta energía varía según la dirección del enlace con la longitud del mismo, y la relación se puede expresar en un gráfico bidimensional como se muestra en la Figura 1

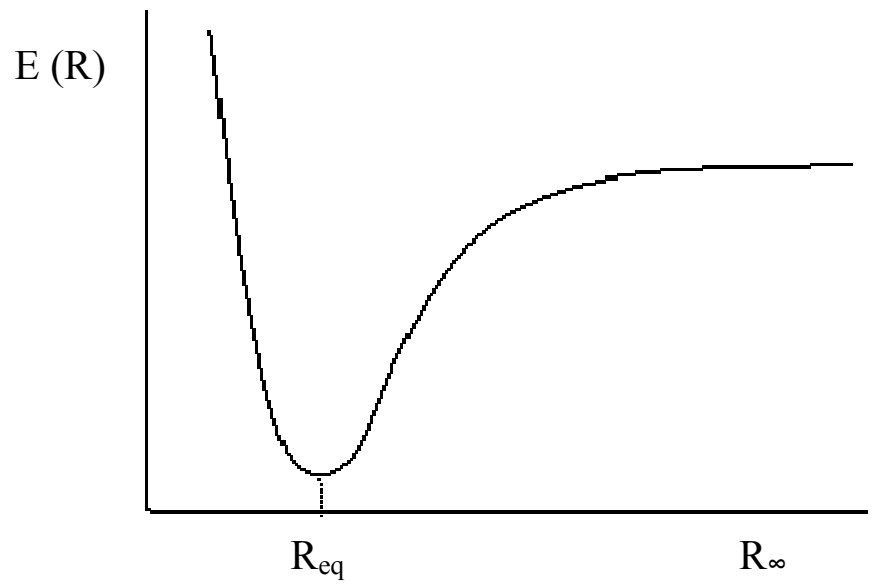

Figura 3.3.1

En sistemas poliatómicos la superficie de energía tiene tantas dimensiones como grados de libertad la molécula, de manera que sólo es posible representarla en un gráfico si consideramos únicamente dos grados de libertad del sistema, usualmente una distancia característica y un ángulo representativo como funciones de la energía.

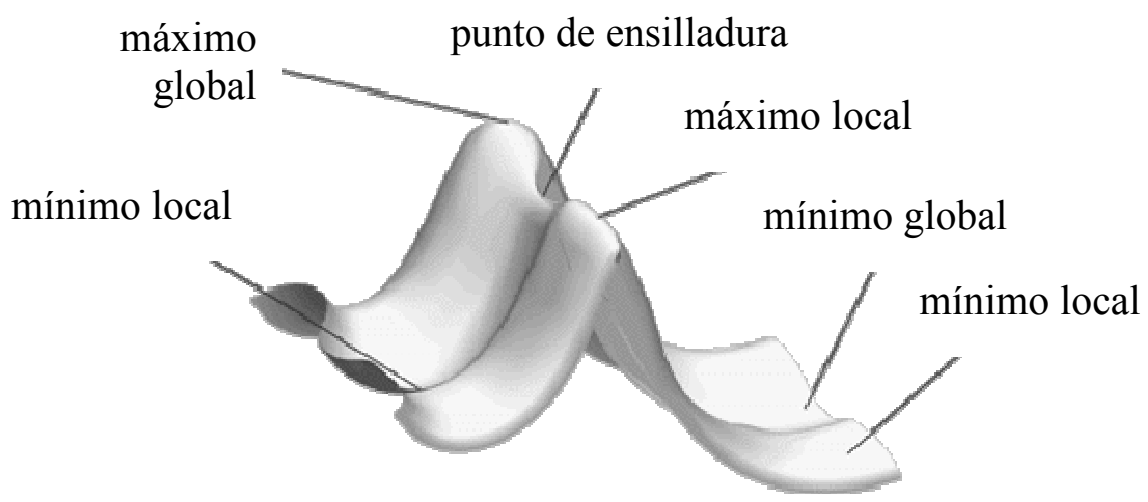


En esta superficie existen tres mínimos. Un mínimo es el fondo de un valle en la superficie de energía, y moverse en cualquier dirección desde ese punto significa ir hacia un incremento de energía. Un mínimo puede ser local o global. El primero lo es en una región limitada de la superficie y el segundo es el más bajo de todos los puntos. Los mínimos se corresponden con estructuras de equilibrio del sistema. Si el sistema es una molécula simple los mínimos describen las diferentes conformaciones de isómeros estructurales. Si el sistema es de varios componentes, éstos describen reactivos y productos.

Los picos corresponden a máximos en la energía potencial. El máximo es tal que moverse desde ese punto significa ir hacia energías menores. Cuando un punto es un máximo en una dirección y un mínimo en la otra dirección estamos en presencia de un punto de ensilladura (saddle point en inglés) de primer orden. Estos puntos son de especial interés para el análisis de estados de transición en un camino de reacción.

La optimización de geometría consiste en explorar la superficie de energía potencial en búsqueda de estructuras de equilibrio del sistema molecular. Los diferentes métodos para la búsqueda de mínimos están basados en los valores que toma la energía y su gradiente respecto de las coordenadas atómicas en estos puntos críticos. En los mínimos y en los puntos de ensilladura la primera derivada de la energía, el gradiente, es cero. Como el gradiente es la fuerza con signo diferente, ésta en estos puntos también es cero y los puntos se llaman puntos estacionarios. Las optimizaciones, también llamadas minimizaciones deben encontrar estos puntos estacionarios.

Un cálculo de optimización comienza con las coordenadas de una estructura especificadas como entrada y se computa la energía y el gradiente en ese punto. Luego determina en cuánto y en qué dirección realiza el siguiente paso. El gradiente indica la dirección en la que la energía decrece más rápidamente. La mayoría de los algoritmos de optimización también estiman el valor de la segunda derivada de la energía con respecto a las coordenadas atómicas, actualizando la matriz de las constantes de fuerza o Hessiano. Estas constantes de fuerza especifican la curvatura en el punto y provee información adicional útil para determinar el siguiente paso.

Una optimización concluye cuando converge. La convergencia está sujeta al criterio utilizado. El usado en Gaussian es el siguiente:

Las fuerzas deben ser cero. Específicamente el componente máximo de la fuerza debe estar debajo de un valor umbral de 0.00045 .

La raíz cuadrática media de las fuerzas debe ser cero. Umbral 0.0003 . 
El desplazamiento calculado para el paso siguiente debe ser cero. Umbral de 0.0018 .

* La raíz cuadrática media de los desplazamientos para el paso siguiente debe ser cero. Esto es menor de 0.0012. Todos los valores anteriores en unidades atómicas.

La existencia de cuatro criterios de convergencia evita la localización prematura de los mínimos. En una zona de valle achatado y ancho las fuerzas son cercanas a cero pero el desplazamiento siguiente no es pequeño. Al contrario en un mínimo empinado los desplazamientos son pequeños pero no las fuerzas.

La superficie de energía potencial depende de las coordenadas de la molécula, de su geometría. Un mínimo en la superficie corresponde a un punto crítico donde la primera derivada del potencial es cero y la segunda derivada es positiva. Para simplificar expresamos el potencial como función de una sola coordenada $\mathrm{V}=\mathrm{V}(x)$, entonces se debe cumplir que

$$
\frac{\partial \mathrm{V}(x)}{\partial x}=0 \quad \mathrm{y} \quad \frac{\partial^{2} \mathrm{~V}(x)}{\partial x^{2}}>0
$$

El valor negativo del gradiente (la primera derivada) es la fuerza que actúa sobre cada átomo del sistema y un protocolo de minimización buscará mover los átomos modificando la fuerza que opera sobre estos y provocar el descenso de la energía buscando que se anule el gradiente. Cada paso de optimización parte de una determinada energía y se dirige hacia un descenso de $\mathrm{V}(x)$ por un camino perpendicular a la superficie. Entre los protocolos para la optimización hay métodos de gradiente y métodos de segunda derivada. De los primeros los más conocidos son:

\section{Descenso por la máxima pendiente (Steepest Descent)}

Se mueve sobre la superficie en dirección paralela a la fuerza neta con un determinado tamaño de paso. Si la energía en el nuevo punto disminuye se aumenta el tamaño de paso, si la energía aumenta el paso se hace menor.

\section{Gradiente conjugado}


Es un protocolo con memoria de los pasos previos efectuados y converge más rápidamente que el steepest descent. Entre éstos están Fletcher-Reeves y Polak-Ribiere. Estos métodos truncan la expresión de la energía potencial en la segunda derivada y el de Newton-Raphson ${ }^{113}$ las calcula, siendo por tanto el de más costo computacional.

\subsection{Análisis vibracional: los conceptos}

Dada una molécula diatómica $\mathrm{AB}$ en un sistema de coordenadas cartesianas donde por conveniencia colocamos la misma sobre el eje $\mathrm{z}$ y el centro de masa coincide con el centro del sistema de coordenadas, las vibraciones moleculares se pueden interpretar en términos de los cambios en la distancia entre A y B

$$
\xi=\left(Z_{A}^{\prime}-Z_{B}^{\prime}\right)-\left(Z_{A}-Z_{B}\right)
$$

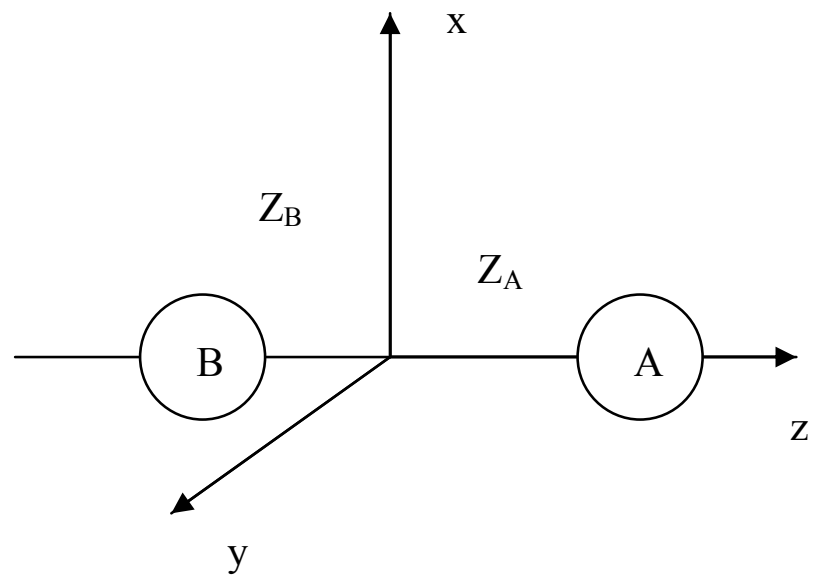

Si bien la Mecánica Clásica interpreta y calcula correctamente las frecuencias de las vibraciones moleculares en la zona infrarroja del espectro electromagnético, la Mecánica Cuántica permite profundizar en otros aspectos del fenómeno vibracional más allá de las frecuencias.

El modelo más sencillo es el del oscilador armónico simple unidimensional.

La función de onda para una molécula diatómica $\mathrm{AB}$, para la cual se puede aplicar esta simplificación es

\footnotetext{
113 J. Foresman, A. Fisch; Exploring Chemistry with Electronic Structure Methods; Gaussian, Inc.; USA
} 1993 


$$
\frac{\partial^{2} \psi}{\partial \xi^{2}}+\frac{8 \pi^{2} \mu}{h^{2}}(\mathrm{E}-\mathrm{V}) \psi=0
$$

en donde $E$ es la energía vibracional total y $\mu=\frac{m_{A} m_{B}}{m_{A}+m_{B}}$ la masa reducida del sistema V es la energía potencial dada por

$$
\mathrm{V}=\frac{1}{2} f \xi^{2}
$$

siendo $f$ la constante de fuerza en términos de la ley de Hooke.

Las soluciones para la ecuación (1) son

$$
\mathrm{E}=\left(\mathrm{n}+\frac{1}{2}\right) \frac{\mathrm{h}}{2 \pi} \sqrt{\frac{f}{\mu}}
$$

con $\mathrm{n}$ un número cuántico que toma valores $1,2,3 \ldots$

Por tanto un cambio en el estado vibracional de la molécula implica que

$$
\Delta \mathrm{E}=\frac{\mathrm{h}}{2 \pi} \sqrt{\frac{f}{\mu}}
$$

y puesto que $\Delta \mathrm{E}=\mathrm{h} v$, la frecuencia asociada al cambio vibracional es

$$
v=\frac{1}{2 \pi} \sqrt{\frac{f}{\mu}}
$$

\subsubsection{Coordenadas internas}

Las componentes del movimiento molecular son tres, la traslación, la rotación y la vibración. Una molécula poliatómica no lineal de $\mathrm{N}$ átomos requiere en el espacio de coordenadas tridimensional de tres de estas coordenadas para especificar la posición de cada átomo $\mathrm{y}$, por tanto de $3 \mathrm{~N}$ coordenadas para ubicar la molécula completa. Si describimos el movimiento del sistema a partir de su centro de masa, las coordenadas para la traslación serán 3 y 3 también las coordenadas para la rotación. Si la molécula es poliatómica lineal las coordenadas para la rotación se reducen a 2. De esta manera quedan para el movimiento vibracional 3N-6 coordenadas para las moléculas 
poliatómicas no lineales y $3 \mathrm{~N}-5$ para las poliatómicas lineales. A estas $3 \mathrm{~N}-6$ o $3 \mathrm{~N}-5$ coordenadas se las conoce como grados de libertad.

Las coordenadas internas están relacionadas a los cambios en las posiciones relativas de los átomos dentro de las moléculas. Las coordenadas internas se denotan como $r_{i}$ donde el subíndice i identifica cada coordenada interna, y la velocidad de cambio de $\mathrm{r}_{\mathrm{i}}$ con el tiempo se escribe $\dot{\mathrm{r}}_{\mathrm{i}}$. En el paquete de programas Gaussian, las coordenadas se ponderan las masas y son éstas las coordenadas que se introducen en la matriz de las constantes de fuerza

$$
\mathrm{q}_{1}=\sqrt{\mathrm{M}_{1}} \xi_{1}, \quad \mathrm{q}_{2}=\sqrt{\mathrm{M}_{2}} \xi_{2}, \quad \mathrm{q}_{\mathrm{i}}=\sqrt{\mathrm{M}_{\mathrm{i}}} \xi_{\mathrm{i}}
$$

La matriz de las constantes de fuerza se denomina el Hessiano y se expresa como

$$
f_{\mathrm{ij}}=\frac{\partial^{2} \mathrm{~V}}{\partial \xi_{\mathrm{i}} \xi_{\mathrm{j}}}
$$

Si las coordenadas i y $\mathrm{j}$ son iguales, la constante de fuerza es la principal y si son diferentes se llama de interacción. En Gaussian el Hessiano queda ponderado por la masa por la expresión

$$
f_{\mathrm{ij}}^{\mathrm{MWC}}=\frac{f_{\mathrm{ij}}}{\sqrt{\mathrm{M}_{\mathrm{i}} \mathrm{M}_{\mathrm{j}}}}=\frac{\partial^{2} \mathrm{~V}}{\partial \mathrm{q}_{\mathrm{i}} \partial \mathrm{q}_{\mathrm{j}}}
$$

Luego se diagonaliza el Hessiano para dar un conjunto de $3 \mathrm{~N}$ autovectores y $3 \mathrm{~N}$ autovalores. Los autovectores son los modos normales y se descartan. Serán calculados otra vez después de haber separado los modos de rotación y de traslación. Los autovalores son las frecuencias fundamentales de la molécula que son convertidas por el programa en $\mathrm{cm}^{-1}$.

Los modos para la rotación y la traslación son cercanos a cero.

Si la optimización conduce a un estado de transición o a un punto de ensilladura de orden mayor habrá algunas frecuencias imaginarias que se listan con valores negativos antes de los modos de frecuencia cero.

El siguiente paso en Gaussian es trasladar el centro de masa al origen y determinar los momentos (elementos diagonales de la matriz) y productos de inercia (elementos no diagonales) con el propósito de encontrar la matriz que diagonalice el tensor momento 
de inercia. Utilizando esta matriz se pueden encontrar los vectores que corresponden a las rotaciones y a las traslaciones, y una vez que éstos se encuentran sabemos que el resto de los modos son los de vibración.

El centro de masa se calcula de la forma convencional

$$
\mathrm{R}=\frac{\sum \mathrm{m}_{\mathrm{i}} \mathrm{r}_{\mathrm{i}}}{\sum \mathrm{m}_{\mathrm{i}}} \text {, suma sobre todos los átomos } \mathrm{i}
$$

Se calculan luego los productos y momentos del tensor de inercia I

$$
\mathbf{I}=\left(\begin{array}{lll}
I_{x x} & I_{x y} & I_{x z} \\
I_{y x} & I_{y y} & I_{y z} \\
I_{z x} & I_{z y} & I_{z z}
\end{array}\right)
$$

Cada uno de los elementos se calcula

$$
\begin{aligned}
& \mathrm{I}_{\mathrm{xx}}=\sum \mathrm{M}\left(\mathrm{y}^{2}+\mathrm{z}^{2}\right), \quad \mathrm{I}_{\mathrm{yy}}=\sum \mathrm{M}\left(\mathrm{x}^{2}+\mathrm{z}^{2}\right), \quad \mathrm{I}_{\mathrm{zz}}=\sum \mathrm{M}\left(\mathrm{x}^{2}+\mathrm{y}^{2}\right) \\
& \mathrm{I}_{\mathrm{xy}}=-\sum \mathrm{M}(\mathrm{xy}), \mathrm{I}_{\mathrm{xz}}=-\sum \mathrm{M}(\mathrm{xz}), \mathrm{I}_{\mathrm{yx}}=-\sum \mathrm{M}(\mathrm{yx}) \\
& \mathrm{I}_{\mathrm{yz}}=-\sum \mathrm{M}(\mathrm{yz}), \mathrm{I}_{\mathrm{zx}}=-\sum \mathrm{M}(\mathrm{zx}), \mathrm{I}_{\mathrm{zy}}=-\sum \mathrm{M}(\mathrm{zy})
\end{aligned}
$$

La matriz simétrica I se diagonaliza y da como resultado los momentos principales de inercia. Los autovectores del tensor momento de inercia se usan para generar los vectores correspondientes a la traslación y rotación de la molécula en el próximo paso.

Luego de diagonalizar I, Gaussian genera la transformación D de coordenadas cartesianas ponderadas por centro de masa a un conjunto de $3 \mathrm{~N}$ coordenadas donde la rotación y la traslación están separadas quedando $3 \mathrm{~N}-6$ o $3 \mathrm{~N}-5$ coordenadas internas para el análisis vibracional.

Los tres vectores de dimensión $3 \mathrm{~N}$ que corresponden a la traslación se generan en coordenadas cartesianas por simplicidad. Estos vectores tienen un módulo $\sqrt{\mathrm{m}_{\mathrm{j}}}$ veces el valor del eje de coordenadas correspondiente siendo $\mathrm{m}_{\mathrm{j}}$ la masa del átomo $\mathrm{j}$.

Tomemos como ejemplo el agua,

Los tres vectores traslacionales son

$\mathrm{D}_{1}=(1,0,0,4,0,0,1,0,0)$

$\mathrm{D}_{2}=(0,1,0,0,4,0,0,1,0)$

$\mathrm{D}_{3}=(0,0,1,0,0,4,0,0,1)$ 
Es más complejo generar los vectores de rotación, que se definen

$$
\begin{aligned}
& \mathrm{D}_{4 \mathrm{j}, \mathrm{i}}=\left(\left(\mathrm{P}_{\mathrm{y}}\right)_{\mathrm{i}} \mathrm{X}_{\mathrm{j}, 3}-\left(\mathrm{P}_{\mathrm{z}}\right)_{\mathrm{i}} \mathrm{X}_{\mathrm{j}, 2}=\sqrt{\mathrm{m}_{\mathrm{i}}}\right. \\
& \mathrm{D}_{5 \mathrm{j}, \mathrm{i}}=\left(\left(\mathrm{P}_{\mathrm{z}}\right)_{\mathrm{i}} \mathrm{X}_{\mathrm{j}, 1}-\left(\mathrm{P}_{\mathrm{x}}\right)_{\mathrm{i}} \mathrm{X}_{\mathrm{j}, 3}=\sqrt{\mathrm{m}_{\mathrm{i}}}\right. \\
& \mathrm{D}_{6 \mathrm{j}, \mathrm{i}}=\left(\left(\mathrm{P}_{\mathrm{x}}\right)_{\mathrm{i}} \mathrm{X}_{\mathrm{j}, 2}-\left(\mathrm{P}_{\mathrm{y}}\right)_{\mathrm{i}} \mathrm{X}_{\mathrm{j}, 1}=\sqrt{\mathrm{m}_{\mathrm{i}}}\right.
\end{aligned}
$$

Donde $\mathrm{j}=\mathrm{x}, \mathrm{y}, \mathrm{z}$ y $\mathrm{P}$ es el producto escalar de las coordenadas de los átomos con respecto al centro de masas $(\mathrm{R})$ y la correspondiente fila de la matriz $(\mathrm{X})$ usada para diagonalizar el tensor de inercia (I)

El siguiente paso es normalizar estos vectores. Si la molécula es lineal se elimina cualquier vector que no corresponda a modos normales de traslación o rotación. Se toma el producto escalar de cada vector con sí mismo. Si vale cero o cercano a ese valor se elimina ya que no es un modo normal verdadero. Si no es así, el vector se normaliza usando la inversa de la raíz cuadrada del producto escalar. En este punto Gaussian verifica que la suma de modos traslacionales más rotacionales sea la esperada, 3 para cada átomo, 6 para moléculas no lineales y 5 para moléculas lineales.

Luego se generan los vectores vibracionales ortogonales a los de rotación y traslación. Con este resultado se obtiene una matriz de transformación $\mathbf{D}$, la cual transforma las coordenadas cartesianas ponderadas por centro de masa a coordenadas internas de vibración.

Posteriormente, en un paso subsiguiente, el programa transforma el Hessiano que estaba en coordenadas cartesianas ponderadas a uno nuevo en coordenadas internas. Aunque se usa el total de las $3 \mathrm{~N}$ coordenadas, sólo las correspondientes a las vibraciones se diagonalizan

$$
f_{\mathrm{ij}}^{\mathrm{INT}}=\mathrm{D}^{\dagger} f_{\mathrm{ij}}^{\mathrm{MWC}} \mathrm{D}
$$

La submatriz cuadrada de $f_{\mathrm{ij}}^{\mathrm{INT}}$ de dimensión $3 \mathrm{~N}-6$ o $3 \mathrm{~N}-5$ que corresponde a los modos vibracionales representa las coordenadas internas de las constantes de fuerza. Esta matriz se diagonaliza para dar $3 \mathrm{~N}-6$ o $3 \mathrm{~N}-5$ autovalores $\lambda_{\mathrm{i}}=4 \pi^{2} v_{\mathrm{i}}^{2}$ y la misma cantidad de autovectores. Se llama la matriz transformación $\mathbf{L}$ a aquélla cuyos elementos son los autovectores 1 y $\boldsymbol{\Lambda}$ es la matriz diagonal con autovalores $\lambda_{i}$ 


$$
\boldsymbol{\Lambda}=\mathrm{L}^{\dagger} f_{\mathrm{ij}}^{\mathrm{INT}} \mathrm{L}
$$

Luego de esto, los autovalores se convierten a frecuencias en unidades de $\mathrm{cm}^{-1}$. Para ello se pasa de frecuencia a número de onda $\tilde{v}_{\mathrm{i}}=v_{\mathrm{i}} / c$ donde $c$ es la velocidad de la luz. Resolviendo la ecuación de autovalores tenemos

$$
\tilde{v}_{\mathrm{i}}=\sqrt{\frac{\lambda_{\mathrm{i}}}{4 \pi^{2} c^{2}}}
$$

Este paso termina con la aplicación de todos los factores de conversión necesarios para imprimir el valor de la frecuencia en $\mathrm{cm}^{-1}$, y es de una molécula a un mol, de hartrees a joules, de masa en unidades atómicas a masa en kilogramos. Para autovalores negativos se calcula el número de onda con el valor absoluto de $\lambda_{\mathrm{i}} \mathrm{y}$ después se multiplica por -1 , de esta manera las frecuencias negativas en realidad estarán expresando valores imaginarios.

El último paso del programa consiste en el cálculo de la masa reducida, las constantes de fuerza y los desplazamientos cartesianos. Si combinamos la ecuación tal con la obtenemos

$$
\mathrm{L}^{\dagger} \mathrm{D}^{\dagger} f^{\mathrm{MWC}} \mathrm{LD}=\boldsymbol{\Lambda}=\mathrm{I}^{\mathrm{WMC} \dagger} f^{W M C} \mathrm{I}^{\mathrm{WMC}}
$$

En realidad, Gaussian no calcula directamente $\mathbf{I}=$ DL la matriz que diagonaliza $f$ sino que lo hace indirectamente a través de $\mathrm{I}^{\mathrm{CART}}=\mathbf{M D L}$, donde $\mathbf{M}$ es la matriz diagonal definida como

$$
\mathbf{M}=\sqrt{\frac{1}{\mathrm{~m}_{\mathrm{i}}}}
$$

Los elementos individuales de $\mathrm{I}^{\mathrm{CART}}$ son

$$
l_{\mathrm{ki}}^{\mathrm{CART}}=\sum_{\mathrm{j}}^{3 \mathrm{~N}} \frac{\mathrm{D}_{\mathrm{kj}} \mathrm{L}_{\mathrm{ji}}}{\sqrt{\mathrm{m}_{\mathrm{j}}}}
$$

Los vectores columna son los modos normales en coordenadas cartesianas. Éstas primero se normalizan para convertirlas en desplazamientos $\mathrm{y}$, luego, se usan para 
calcular diferentes propiedades espectroscópicas como intensidades en infrarrojo, actividades Raman o propiedades de dipolo.

Cada uno de los $3 \mathrm{~N}$ elementos de $\mathrm{I}^{\mathrm{CART}}$ se escala por un factor de normalización $\mathcal{N}_{i}$ para un modo de vibración determinado

$$
\mathcal{N}_{i}=\sqrt{\frac{1}{\sum_{\mathrm{k}}^{3 \mathrm{~N}}\left(l_{\mathrm{ki}}^{\mathrm{CART}}\right)^{2}}}
$$

La masa reducida para un modo particular se calcula de manera similar

$$
\mu_{\mathrm{i}}=\frac{1}{\sum_{\mathrm{k}}^{3 \mathrm{~N}}\left(l_{\mathrm{ki}}^{\mathrm{CART}}\right)^{2}}=\frac{1}{\sum_{\mathrm{k}}^{3 \mathrm{~N}}\left(\frac{l_{\mathrm{ki}}^{\mathrm{MWC}}}{\sqrt{m_{j}}}\right)^{2}}=\frac{1}{\sum_{\mathrm{k}}^{3 \mathrm{~N}} \frac{\left(l_{\mathrm{ki}}^{\mathrm{MWC}}\right)^{2}}{m_{j}}}=\frac{1}{\mathcal{N}_{i}^{2}}
$$

Resulta conveniente clasificar las coordenadas internas dentro de seis categorías, aunque no hay un acuerdo preciso en torno de esto, sino más bien una convención asumida por el uso más general. A continuación describimos estas coordenadas también con su nombre en inglés por ser como más se conocen.

\section{Estiramiento de enlace (bond stretching)}

En estas coordenadas el vector desplazamiento, que se representa como una flecha por encima de uno de los átomos del enlace con dirección paralela a la longitud del enlace, muestra el cambio en la longitud del enlace. Este modo suele representar con la letra griega $v(n u)$.

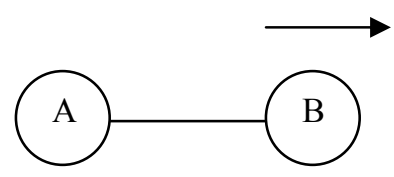

\section{Flexión del ángulo de enlace (angle bending)}

Estas coordenadas cambian el ángulo entre dos uniones. Los vectores desplazamientos son perpendiculares a la línea de unión en el enlace y la coordenada de flexión se 
representa con la letra $\delta$ (delta) y para el ángulo entre los átomos $\mathrm{B} \mathrm{A} \mathrm{C}$ se escribe $\delta$ (BAC).
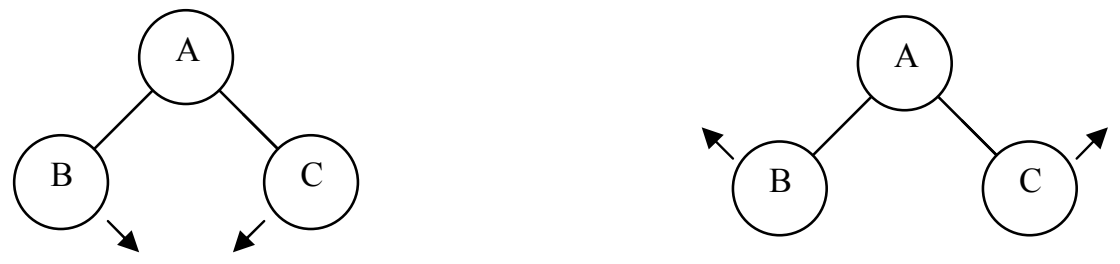

\section{Balanceo (rocking)}

Esta coordenada es un caso particular de la anterior. Se puede dar como un cambio de ángulo entre dos uniones o bien entre una unión y otros dos átomos y, en ambos casos, los desplazamientos son en el plano. Los vectores desplazamiento de dibujan como doble flecha y el símbolo de la coordenada es $\rho$ (rho). Para el primer caso se escribe $\rho$ (AC) y para el segundo $\rho\left(\mathrm{AC}_{2}\right)$.
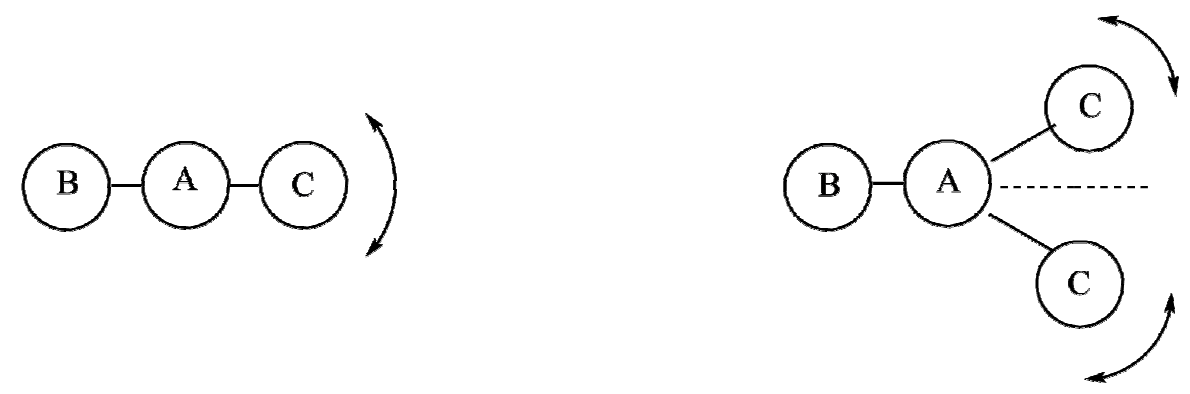

\section{Cabeceo (wagging)}

Se define esta coordenada como un cambio en el ángulo entre un enlace y un plano

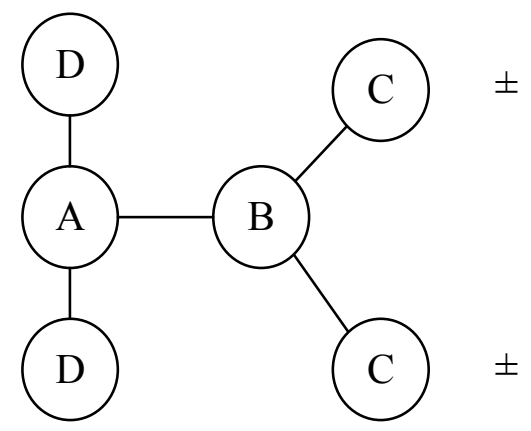


Los átomos A B C y D son coplanares en la configuración de equilibrio. Los átomos C se mueven en una dirección perpendicular a este plano. El signo + indica los desplazamientos por encima del plano, y el signo - indica el movimiento hacia abajo del plano.

\section{Torsión (twisting)}

En esta vibración cambia el ángulo entre dos planos formados por cuatro átomos no coplanares. En este caso entre el plano que forman los átomos A B y C y el plano que forman los átomos B C y D. se indica esta coordenada con la letra $\tau$ (tau).

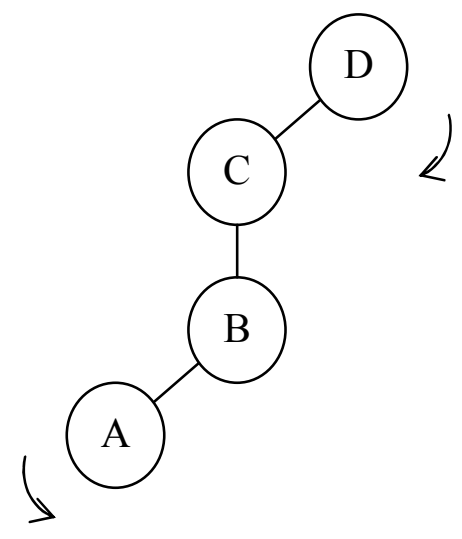

\section{Deformación fuera del plano (out of plane deformation)}

En esta vibración el movimiento de un átomo rompe un plano molecular, que en general es un plano de simetría. Este movimiento se indica con la letra $\pi$ (pi). Por ejemplo, el movimiento del átomo de boro en el trifluoruro de boro rompe el plano de simetría $\sigma_{\mathrm{h}}$.

\subsubsection{Vibraciones de grupos característicos}

Las frecuencias de vibración de grupos funcionales característicos tienen lugar cuando la vibración involucra enlaces múltiples o átomos de masa muy diferentes. De manera que los grupos $-\mathrm{CN},-\mathrm{NO}_{2},-\mathrm{OH},-\mathrm{CH}_{2-},-\mathrm{CH}_{3},-\mathrm{CO}$ y $-\mathrm{NH}_{2}$ en diferentes moléculas tienen frecuencias normales alrededor de un valor determinado, propio para cada grupo. 
Para el grupo metileno $\left(-\mathrm{CH}_{2}-\right)$ las coordenadas internas se describen abajo con las frecuencias aproximadas de cada modo

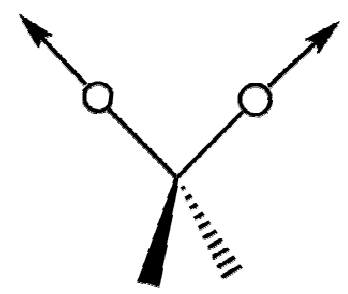

estiramiento simétrico $3300 \mathrm{~cm}^{-1}$

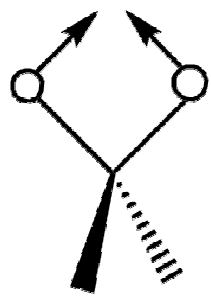

scissors $1600 \mathrm{~cm}^{-1}$

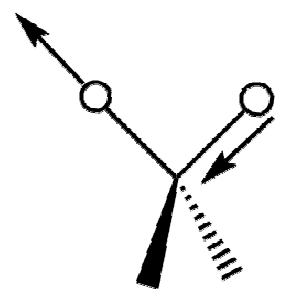

estiramiento asimétrico $3400 \mathrm{~cm}^{-1}$

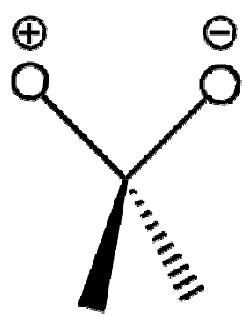

twisting

$1250 \mathrm{~cm}^{-1}$

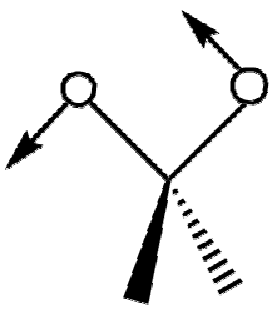

rocking $900 \mathrm{~cm}^{-1}$

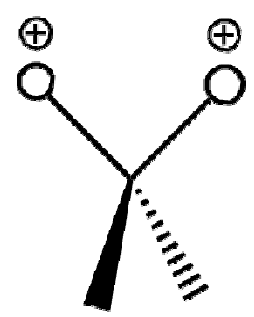

wagging

$1370 \mathrm{~cm}^{-1}$

Para el grupo metilo $\left(-\mathrm{CH}_{3}\right)$ las coordenadas internas se describen abajo con las frecuencias aproximadas de cada modo

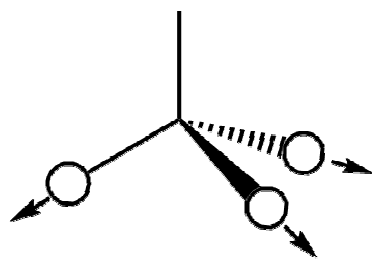

estiramiento simétrico $3000 \mathrm{~cm}^{-1}$

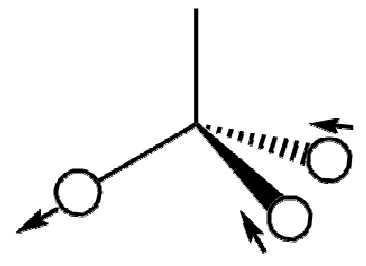

estiramiento asimétrico $3100 \mathrm{~cm}^{-1}$

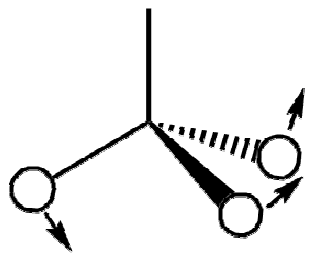

rocking $1000 \mathrm{~cm}^{-1}$

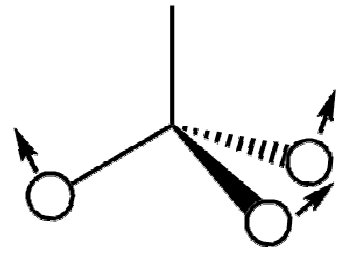

flexión simétrica

$1300 \mathrm{~cm}^{-1}$

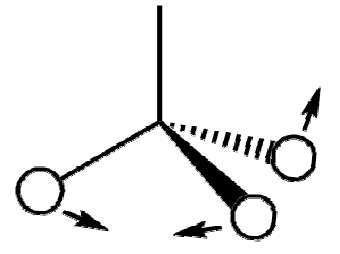

flexión asimétrica $1400 \mathrm{~cm}^{-1}$ 


\subsection{Análisis vibracional: los resultados}

\subsubsection{Cálculo de frecuencias e intensidades infrarrojas}

Para realizar el análisis vibracional se seleccionaron las conformaciones derivadas de la optimización B3LYP/6-31+G** que cumplen la condición de tener energías hasta 2.0 $\mathrm{kcal} / \mathrm{mol}$ por encima del confórmero más estable, asumiendo que son las conformaciones que más contribuyen a temperatura ambiente y que aquellas que están por encima poco aportan. Los cálculos derivados del análisis vibracional de los confórmeros de más baja energía fueron promediadas de acuerdo a la distribución estadística de Maxwell-Boltzmann para una temperatura de $300 \mathrm{~K}$

$$
\langle\mathrm{A}\rangle=\frac{\sum \mathrm{A}_{\mathrm{i}} \mathrm{e}^{-\mathrm{E}_{\mathrm{i}} / \mathrm{RT}}}{\sum \mathrm{e}^{-\mathrm{E}_{\mathrm{i}} / \mathrm{RT}}}
$$

donde $\mathrm{E}$ es la energía del i-ésimo confórmero y A la propiedad correspondiente según se trate de la frecuencia o de la intensidad. Las frecuencias IR y las intensidades calculadas más relevantes se muestran en la siguientes tablas de la $3 \mathrm{~b} 1$ a la $3 \mathrm{~b} 10$ para la combretastatina A-4 y las nueve moléculas derivadas de fenilcumarina. Cabe aclarar que surgieron conformaciones con idéntica energía. Las geometrías que colapsaban a la misma se contabilizaron como una sola, y aquéllas que eran imágenes especulares (rotámeros) se contabilizaron como dos conformaciones, dando cuenta de ello en el promedio de Boltzmann con multiplicidad $m=2$.

$$
\langle\mathrm{A}\rangle=\frac{\sum \mathrm{mA}_{\mathrm{i}} \mathrm{e}^{-\mathrm{E}_{\mathrm{i}} / \mathrm{RT}}}{\sum \mathrm{me}^{-\mathrm{E}_{\mathrm{i}} / \mathrm{RT}}}
$$

En las tablas se informan treinta frecuencias de cada molécula y son aquéllas que presentan la mayor intensidad ordenadas en valores decrecientes de frecuencia en la segunda columna $\left(v\right.$ en $\mathrm{cm}^{-1}$ ). En la tercera columna están las intensidades (I en unidades arbitrarias). En la primera columna se muestra el número de modo de la vibración y en la cuarta columna las asignaciones correspondientes a cada modo. La abreviación est significa un estiramiento o stretching, bend una flexión de ángulo, ip si es en el plano y op si es fuera del plano. Entre paréntesis se precisa en qué parte de la molécula ocurre la vibración (ver Figura 3 para la notación). 


\section{Compuesto 1}

\begin{tabular}{|c|c|c|c|}
\hline modo & v & $\mathbf{I}$ & asignaciones \\
\hline 114 & 3826.81 & 81 & est $\mathrm{O}-\mathrm{H}$ \\
\hline 101 & 3034.68 & 43 & est sim CH3 (anillo A) \\
\hline 100 & 3031.75 & 68 & est $\operatorname{sim} \mathrm{CH} 3$ (anillo $\mathrm{A}$ ) \\
\hline 99 & 3028.80 & 61 & est $\operatorname{sim} \mathrm{CH} 3$ (anillo $\mathrm{A})$ \\
\hline 98 & 1797.50 & 864 & est $\mathrm{C}=\mathrm{O}$ \\
\hline 97 & 1659.00 & 98 & est $\mathrm{C}=\mathrm{C}$ (fenilo) \\
\hline 96 & 1641.74 & 369 & est $\mathrm{C}=\mathrm{C}$ (anillo $\mathrm{A}$ ) \\
\hline 95 & 1637.60 & 98 & est $\mathrm{C}=\mathrm{C}($ anillos $)$ \\
\hline 94 & 1624.73 & 55 & est $\mathrm{C}=\mathrm{C}$ (anillos) + bend $\mathrm{C}-\mathrm{O}-\mathrm{H}$ \\
\hline 93 & 1578.26 & 115 & est $\mathrm{C}=\mathrm{C}$ (anillos) \\
\hline 92 & 1548.48 & 93 & bend ip C-C-H (fenilo) \\
\hline 91 & 1521.98 & 45 & est $\mathrm{C}-\mathrm{O}($ metoxi $\mathrm{A})+$ flex $\operatorname{sim} \mathrm{CH} 3$ \\
\hline 89 & 1507.70 & 49 & flex $\operatorname{asim} \mathrm{CH} 3(\mathrm{~A})$ \\
\hline 84 & 1487.84 & 48 & flex asim CH3 (A) \\
\hline 80 & 1437.30 & 119 & flex sim CH3 (A) \\
\hline 79 & 1386.90 & 392 & bend ip C-C-H (heteroanillo) \\
\hline 76 & 1333.55 & 51 & est $\mathrm{C}=\mathrm{C}(\mathrm{A})+$ bend ip $\mathrm{C}-\mathrm{C}-\mathrm{H}$ (fenilo) \\
\hline 75 & 1325.87 & 43 & bend ip C-C-H (fenilo) \\
\hline 74 & 1290.79 & 151 & est C-O $(\mathrm{OH})$ \\
\hline 72 & 1261.43 & 99 & est O-C (metilo A) + bend ip C-C-H (A) \\
\hline 71 & 1236.09 & 70 & rock $\mathrm{CH} 3(\mathrm{~A})+$ bend ip $\mathrm{C}-\mathrm{C}-\mathrm{H}(\mathrm{A})$ \\
\hline 70 & 1222.35 & 99 & rock $\mathrm{CH} 3(\mathrm{~A})$ \\
\hline 66 & 1186.62 & 113 & bend ip C-O-H \\
\hline 65 & 1181.98 & 246 & rock $\mathrm{CH} 3(\mathrm{~A})+$ bend ip $\mathrm{C}-\mathrm{C}-\mathrm{H}(\mathrm{A})$ \\
\hline 61 & 1160.37 & 47 & est $\mathrm{O}-\mathrm{C}($ metilo $\mathrm{A})+\operatorname{rock} \mathrm{CH} 3(\mathrm{~A})$ \\
\hline 60 & 1130.49 & 99 & est C-O (hetero) + bend ip C-C-H (fenilo) \\
\hline 59 & 1128.10 & 89 & bend ip C-O-H + bend ip C-C-H (fenilo) \\
\hline 58 & 1063.65 & 142 & est O-C (metilos A) \\
\hline 56 & 1027.99 & 45 & est O-C (metilos A) + bend ip C-C-H (fenilo) \\
\hline 23 & 347.99 & 79 & bend op C-O-H \\
\hline
\end{tabular}

Tabla 3b1 


\section{Compuesto 2}

\begin{tabular}{|c|c|c|c|}
\hline modo & v & I & asignaciones \\
\hline 126 & 3773.08 & 120 & est $\mathrm{O}-\mathrm{H}$ \\
\hline 111 & 3030.20 & 71 & est sim CH3 (anillo A) \\
\hline 110 & 3028.90 & 61 & est sim CH3 (anillo A) \\
\hline 108 & 1798.02 & 872 & est $\mathrm{C}=\mathrm{O}$ \\
\hline 106 & 1642.95 & 98 & est $\mathrm{C}=\mathrm{C}$ (anillos) \\
\hline 105 & 1641.05 & 279 & est $\mathrm{C}=\mathrm{C}$ (anillos) \\
\hline 104 & 1628.26 & 143 & est $\mathrm{C}=\mathrm{C}$ (anillos) \\
\hline 103 & 1578.54 & 112 & est $\mathrm{C}=\mathrm{C}$ (anillos) \\
\hline 102 & 1550.73 & 245 & bend C-C-H (fenilo) \\
\hline 100 & 1511.10 & 48 & flex asim $\mathrm{CH} 3$ \\
\hline 98 & 1507.81 & 52 & flex asim $\mathrm{CH} 3$ \\
\hline 87 & 1437.22 & 101 & flex sim CH3 \\
\hline 86 & 1408.04 & 64 & bend ip C-O-H \\
\hline 85 & 1382.54 & 361 & est C-O (metoxi A) + bend ip C-O-H + flex sim $\mathrm{CH} 3$ \\
\hline 84 & 1374.03 & 60 & bend ip C-C-H (het) + bend ip C-C-H (anillo A) \\
\hline 83 & 1332.38 & 83 & est $\mathrm{C}=\mathrm{C}($ anillo $\mathrm{A})$ \\
\hline 82 & 1312.82 & 52 & est $\mathrm{C}=\mathrm{C}$ (fenilo) + bend ip C-C-H (fenilo) \\
\hline 81 & 1309.59 & 172 & resp anillo (fenilo) + bend ip C-C-H \\
\hline 80 & 1280.28 & 101 & est $\mathrm{C}-\mathrm{O}(\mathrm{OH})+$ bend ip C-C-H \\
\hline 79 & 1263.67 & 139 & est C-O (metoxi A) + bend ip C-C-H \\
\hline 78 & 1244.68 & 50 & bend ip C-C-H \\
\hline 77 & 1231.81 & 183 & rock $\mathrm{CH} 3(\mathrm{~A})+$ bend ip $\mathrm{C}-\mathrm{C}-\mathrm{H}$ \\
\hline 76 & 1229.04 & 87 & rock $\mathrm{CH} 3+$ bend ip $\mathrm{C}-\mathrm{C}-\mathrm{H}+$ bend ip $\mathrm{C}-\mathrm{O}-\mathrm{H}$ \\
\hline 71 & 1182.02 & 153 & est C-O (het) + bend ip C-C-H \\
\hline 66 & 1156.85 & 60 & def anillo \\
\hline 65 & 1146.52 & 56 & bend ip C-C-H (fenilo) \\
\hline 64 & 1127.65 & 152 & est C-O (het) + est O-C (metilo) + bend ip C-C-H (fenilo) \\
\hline 63 & 1064.24 & 150 & est O-C (metilos A) \\
\hline 61 & 1029.30 & 61 & est O-C (metilos A) \\
\hline 33 & 468.14 & 51 & bend op C-O-H \\
\hline
\end{tabular}

Tabla 3b2 


\section{Compuesto 3}

\begin{tabular}{|c|c|c|c|}
\hline $\operatorname{modo}$ & v & I & asignaciones \\
\hline 126 & 3779.06 & 120 & est $\mathrm{O}-\mathrm{H}$ \\
\hline 112 & 3034.66 & 45 & est sim $\mathrm{CH} 3$ (anillo $\mathrm{A})$ \\
\hline 111 & 3031.19 & 68 & est sim CH3 (anillo A) \\
\hline 110 & 3028.49 & 60 & est sim CH3 (anillo A) \\
\hline 109 & 3025.29 & 65 & est sim CH3 (fenilo) \\
\hline 108 & 1797.71 & 867 & est $\mathrm{C}=\mathrm{O}$ \\
\hline 106 & 1641.59 & 352 & est $\mathrm{C}=\mathrm{C}$ (anillo $\mathrm{A}$ ) \\
\hline 105 & 1636.51 & 84 & est $\mathrm{C}=\mathrm{C}$ (anillos) \\
\hline 104 & 1623.52 & 87 & est $\mathrm{C}=\mathrm{C}$ (anillos) \\
\hline 103 & 1579.01 & 121 & est $\mathrm{C}=\mathrm{C}$ (anillos) \\
\hline 102 & 1548.03 & 221 & bend ip C-C-H (fenilo) \\
\hline 101 & 1522.02 & 43 & est $\mathrm{C}-\mathrm{O}($ metoxi $\mathrm{A})+$ flex $\mathrm{CH} 3(\mathrm{~A})$ \\
\hline 98 & 1507.53 & 43 & flex asim CH3 (A) \\
\hline 87 & 1437.63 & 119 & flex sim CH3 (A) \\
\hline 86 & 1391.03 & 400 & bend ip C-C-H (hetero) \\
\hline 84 & 1365.08 & 40 & est $\mathrm{C}=\mathrm{C}($ fenilo $)+$ bend ip $\mathrm{C}-\mathrm{O}-\mathrm{H}$ \\
\hline 83 & 1332.65 & 83 & est $\mathrm{C}=\mathrm{C}($ anillo $\mathrm{A})$ \\
\hline 81 & 1310.76 & 203 & est $\mathrm{C}-\mathrm{O}(\mathrm{OH})+$ bend ip $\mathrm{C}-\mathrm{C}-\mathrm{H}$ \\
\hline 80 & 1277.09 & 173 & bend ip C-C-H + bend ip C-O-H \\
\hline 79 & 1263.64 & 129 & est $\mathrm{C}-\mathrm{O}$ (metoxi A) + bend ip C-C-H \\
\hline 78 & 1242.14 & 43 & bend ip C-C-H \\
\hline 77 & 1232.73 & 97 & rock $\mathrm{CH} 3+$ bend ip $\mathrm{C}-\mathrm{C}-\mathrm{H}+$ bend ip $\mathrm{C}-\mathrm{O}-\mathrm{H}$ \\
\hline 76 & 1228.58 & 109 & rock $\mathrm{CH} 3+$ bend ip $\mathrm{C}-\mathrm{C}-\mathrm{H}+$ bend ip $\mathrm{C}-\mathrm{O}-\mathrm{H}$ \\
\hline 75 & 1217.35 & 48 & rock $\mathrm{CH} 3(\mathrm{~A})$ \\
\hline 71 & 1181.76 & 148 & est C-O (het) + bend ip C-C-H \\
\hline 66 & 1161.04 & 110 & bend ip C-C-H (fenilo) \\
\hline 64 & 1128.48 & 166 & est C-O (het) + est O-C (metilo) + bend ip C-C-H \\
\hline 63 & 1065.32 & 161 & est O-C (metilo) \\
\hline 61 & 1029.91 & 75 & est O-C (metilo) \\
\hline 31 & 445.50 & 82 & bend op C-O-H \\
\hline
\end{tabular}

Tabla $3 b 3$ 


\section{Compuesto 4}

\begin{tabular}{|c|c|c|c|}
\hline modo & v & $\mathbf{I}$ & asignaciones \\
\hline 138 & 3773.34 & 127 & est O-H \\
\hline 122 & 3030.25 & 69 & est sim CH3 (anillo A) \\
\hline 121 & 3028.65 & 64 & est sim CH3 (anillo A) \\
\hline 119 & 3018.46 & 53 & est sim CH3 (fenilo) \\
\hline 118 & 1797.14 & 870 & est $\mathrm{C}=\mathrm{O}$ \\
\hline 117 & 1652.91 & 107 & est $\mathrm{C}=\mathrm{C}$ (fenilo) \\
\hline 116 & 1641.85 & 311 & est $\mathrm{C}=\mathrm{C}($ anillo $\mathrm{A})$ \\
\hline 115 & 1639.00 & 57 & est $\mathrm{C}=\mathrm{C}$ (anillo A y fenilo) \\
\hline 114 & 1629.45 & 132 & est $\mathrm{C}=\mathrm{C}$ (anillo $\mathrm{A}$ ) + est $\mathrm{C}=\mathrm{C}$ (het) \\
\hline 113 & 1578.61 & 125 & est $\mathrm{C}=\mathrm{C}$ (anillo $\mathrm{A})+$ est $\mathrm{C}=\mathrm{C}$ (het) \\
\hline 112 & 1550.13 & 219 & est $\mathrm{C}-\mathrm{O}(\mathrm{OH})$ \\
\hline 95 & 1454.66 & 123 & est $\mathrm{C}=\mathrm{C}($ fenilo $)+$ flex sim $\mathrm{CH} 3$ \\
\hline 94 & 1436.26 & 92 & flex sim $\mathrm{CH} 3$ \\
\hline 93 & 1404.02 & 78 & est $\mathrm{C}=\mathrm{C}$ (fenilo) + bend ip $\mathrm{C}-\mathrm{O}-\mathrm{H}$ \\
\hline 92 & 1385.25 & 504 & est $\mathrm{C}=\mathrm{C}+$ bend ip $\mathrm{C}-\mathrm{O}-\mathrm{H}$ \\
\hline 91 & 1378.50 & 66 & est C-O (metoxi y het) + bend ip C-C-H \\
\hline 90 & 1349.39 & 58 & est C-O (metoxi) +bend ip C-C-H (het) \\
\hline 89 & 1331.88 & 93 & est $\mathrm{C}=\mathrm{C}($ anillo $\mathrm{A})$ \\
\hline 87 & 1281.39 & 84 & est $\mathrm{C}-\mathrm{O}(\mathrm{OH})+$ bend ip C-C-H \\
\hline 86 & 1265.41 & 86 & est C-O (metoxi A) + bend ip C-C-H \\
\hline 85 & 1251.09 & 180 & est C-O (metoxi) + bend ip C-C-H y C-O-H \\
\hline 84 & 1243.27 & 177 & est C-O (metoxi) + bend ip C-C-H y C-O-H \\
\hline 83 & 1231.33 & 160 & est $\mathrm{C}-\mathrm{O}$ (metoxi) + rock $\mathrm{CH} 3$ \\
\hline 77 & 1182.03 & 152 & est $\mathrm{C}-\mathrm{O}(\mathrm{het})+$ bend ip $\mathrm{C}-\mathrm{C}-\mathrm{H}+$ rock $\mathrm{CH} 3$ \\
\hline 70 & 1148.76 & 256 & est O-C (metilo) + bend ip C-O-H \\
\hline 69 & 1131.86 & 190 & bend $\mathrm{C}-\mathrm{O}-\mathrm{C}$ \\
\hline 67 & 1065.47 & 129 & est O-C (metilos) \\
\hline 66 & 1033.52 & 61 & est O-C (metilos) \\
\hline 37 & 460.01 & 56 & resp anillos \\
\hline 36 & 455.08 & 55 & bend op C-O-H \\
\hline
\end{tabular}

Tabla 3b4 


\section{Compuesto 5}

\begin{tabular}{|c|c|c|c|}
\hline $\operatorname{modo}$ & v & I & asignaciones \\
\hline 108 & 3035.78 & 48 & est $\operatorname{sim} \mathrm{CH} 3$ (anillo A) \\
\hline 107 & 3031.42 & 66 & est sim CH3 (anillo A) \\
\hline 106 & 3028.96 & 59 & est $\operatorname{sim} \mathrm{CH} 3$ (anillo A) \\
\hline 105 & 3016.45 & 135 & est $\operatorname{sim} \mathrm{CH} 2$ \\
\hline 104 & 1798.30 & 864 & est $\mathrm{C}=\mathrm{O}$ \\
\hline 101 & 1641.62 & 359 & est $\mathrm{C}=\mathrm{C}$ (anillo $\mathrm{A})$ \\
\hline 100 & 1630.58 & 119 & est $\mathrm{C}=\mathrm{C}$ (anillos) \\
\hline 99 & 1578.66 & 114 & est $\mathrm{C}=\mathrm{C}$ (anillos) \\
\hline 97 & 1526.38 & 191 & est $\mathrm{C}=\mathrm{C}$ (fenilo) + sciss $\mathrm{CH} 2$ \\
\hline 96 & 1521.77 & 70 & flex sim $\mathrm{CH} 3$ \\
\hline 87 & 1475.18 & 93 & est $\mathrm{C}=\mathrm{C}$ (dioxifenilo) + flex sim $\mathrm{CH} 3$ \\
\hline 85 & 1437.32 & 121 & flex sim $\mathrm{CH} 3$ \\
\hline 83 & 1391.46 & 318 & est $\mathrm{C}=\mathrm{C}$ (anillo A y het) \\
\hline 82 & 1378.11 & 48 & est $\mathrm{C}-\mathrm{O}$ (het) + est C-O (metoxi) + flex $\mathrm{CH} 3$ \\
\hline 81 & 1365.52 & 99 & bend ip C-C-H \\
\hline 80 & 1332.62 & 89 & est $\mathrm{C}=\mathrm{C}$ (anillo $\mathrm{A}$ ) \\
\hline 78 & 1284.84 & 212 & bend ip C-C-H \\
\hline 77 & 1265.24 & 111 & est $\mathrm{C}-\mathrm{O}$ (metoxi) + bend ip $\mathrm{C}-\mathrm{C}-\mathrm{H}$ \\
\hline 76 & 1251.20 & 85 & bend ip C-C-H \\
\hline 75 & 1234.26 & 53 & est $\mathrm{C}-\mathrm{O}$ (metoxi) + rock $\mathrm{CH} 3$ \\
\hline 74 & 1222.16 & 118 & rock $\mathrm{CH} 3+$ twist $\mathrm{CH} 2$ \\
\hline 70 & 1182.15 & 149 & bend ip C-C-H \\
\hline 65 & 1150.72 & 128 & bend $\mathrm{C}-\mathrm{C}-\mathrm{H}$ (dioxifenilo) + rock $\mathrm{CH} 2$ \\
\hline 63 & 1130.81 & 70 & bend ip C-C-H (dioxifenilo) \\
\hline 62 & 1113.62 & 63 & est C-O (dioxifenilo) + bend ip C-C-H \\
\hline 61 & 1063.43 & 127 & est O-C (metilo) +bend O-C-O (dioxifenilo) \\
\hline 60 & 1062.14 & 160 & est O-C (metilo) +bend O-C-O (dioxifenilo) \\
\hline 59 & 1028.68 & 65 & est O-C (metilo) \\
\hline 56 & 957.82 & 45 & est C-O (dioxifenilo) \\
\hline 54 & 928.02 & 48 & bend op C-C-H \\
\hline
\end{tabular}

Tabla $3 b 5$ 


\section{Compuesto 6}

\begin{tabular}{|c|c|c|c|}
\hline $\operatorname{modo}$ & v & I & asignaciones \\
\hline 88 & 1799.83 & 846 & est $\mathrm{C}=\mathrm{O}$ \\
\hline 86 & 1654.79 & 623 & est $\mathrm{C}=\mathrm{C}$ (anillo $\mathrm{A})$ \\
\hline 71 & 1384.49 & 287 & est C-O (oxociclo) +est C-O (metoxi) + flex CH3 \\
\hline 59 & 1185.30 & 269 & bend ip C-O-H \\
\hline 85 & 1637.51 & 207 & est $\mathrm{C}=\mathrm{C}$ (anillos) \\
\hline 55 & 1140.04 & 186 & est $\mathrm{C}-\mathrm{O}$ (oxociclo) +est $\mathrm{O}-\mathrm{C}(\mathrm{CH} 3)$ \\
\hline 64 & 1235.01 & 171 & est $\mathrm{C}-\mathrm{O}$ (metoxi) + rock $\mathrm{CH} 3$ \\
\hline 65 & 1253.27 & 162 & est $\mathrm{C}-\mathrm{O}($ metoxi) + bend ip $\mathrm{C}-\mathrm{C}-\mathrm{H}($ anillo $\mathrm{A})+$ rock $\mathrm{CH} 3$ \\
\hline 67 & 1289.23 & 146 & est C-O $(\mathrm{OH})+$ bend ip C-C-H (fenilo) \\
\hline 84 & 1627.14 & 119 & est $\mathrm{C}=\mathrm{C}$ (anillos) \\
\hline 19 & 340.29 & 108 & bend op C-O-H \\
\hline 60 & 1186.56 & 96 & bend ip C-C-H (anillo A) + bend ip C-O-H + rock CH3 \\
\hline 82 & 1548.94 & 95 & est $\mathrm{C}=\mathrm{C}($ fenilo $)$ \\
\hline 69 & 1346.92 & 82 & est $\mathrm{C}=\mathrm{C}($ anillo $\mathrm{A})+$ flex $\mathrm{CH} 3$ \\
\hline 102 & 3826.68 & 79 & est O-H \\
\hline 79 & 1504.06 & 63 & flex $\mathrm{CH} 3$ \\
\hline 90 & 3028.70 & 61 & flex asim $\mathrm{CH} 3$ \\
\hline 73 & 1455.61 & 55 & flex sim $\mathrm{CH} 3+$ bend ip C-C-H (anilloA) \\
\hline 89 & 3024.97 & 52 & est $\operatorname{sim} \mathrm{CH} 3$ \\
\hline 42 & 828.01 & 52 & bend op C-C-H (anillo A) \\
\hline 53 & 1079.04 & 52 & est O-C (CH3) + bend C-C-H (anillo A) \\
\hline 76 & 1496.64 & 49 & flex sim $\mathrm{CH} 3$ \\
\hline 56 & 1164.03 & 48 & resp anillos \\
\hline 87 & 1660.42 & 47 & est $\mathrm{C}=\mathrm{C}$ (fenilo) \\
\hline 80 & 1508.84 & 40 & flex asim $\mathrm{CH} 3$ \\
\hline 70 & 1365.88 & 39 & bend ip C-C-H (fenilo) + bend ip C-O-H \\
\hline 83 & 1585.35 & 38 & est $\mathrm{C}=\mathrm{C}($ anillo) \\
\hline 74 & 1460.66 & 38 & bend ip C-C-H (fenilo) + bend ip C-O-H \\
\hline 44 & 847.73 & 34 & bend op C-C-H (fenilo) \\
\hline 45 & 871.55 & 33 & bend op C-C-H (oxociclo) \\
\hline
\end{tabular}

Tabla $3 b 6$ 


\section{Compuesto 7}

\begin{tabular}{|c|c|c|c|}
\hline modo & v & I & asignaciones \\
\hline 114 & 3774.75 & 123 & est $\mathrm{O}-\mathrm{H}$ \\
\hline 101 & 3028.69 & 57 & est $\operatorname{sim} \mathrm{CH} 3$ \\
\hline 100 & 3025.65 & 54 & est $\operatorname{sim} \mathrm{CH} 3$ \\
\hline 99 & 3024.15 & 52 & est $\operatorname{sim} \mathrm{CH} 3$ \\
\hline 98 & 1798.65 & 846 & est $\mathrm{C}=\mathrm{O}$ \\
\hline 97 & 1655.85 & 378 & est $\mathrm{C}=\mathrm{C}$ anillos \\
\hline 96 & 1653.01 & 249 & est $\mathrm{C}=\mathrm{C}$ (anillos $\mathrm{A}$ y heteroanillo) \\
\hline 95 & 1645.30 & 74 & est $\mathrm{C}=\mathrm{C}($ fenilo $)$ \\
\hline 94 & 1629.99 & 249 & est $\mathrm{C}=\mathrm{C}$ (anillos A y fenilo) \\
\hline 93 & 1584.89 & 58 & est $\mathrm{C}=\mathrm{C}$ (anillos) \\
\hline 92 & 1551.03 & 200 & bend $\mathrm{C} \_\mathrm{C} \_\mathrm{H}$ (anillo fenilo) \\
\hline 89 & 1509.30 & 63 & flex asim $\mathrm{CH} 3$ \\
\hline 88 & 1504.01 & 53 & flex asim $\mathrm{CH} 3$ \\
\hline 85 & 1496.89 & 47 & flex $\mathrm{CH} 3$ \\
\hline 81 & 1457.94 & 99 & flex sim $\mathrm{CH} 3$ \\
\hline 77 & 1379.92 & 356 & est C-O (metoxi) + bend ip C-C-H (heteroanillo) \\
\hline 76 & 1348.55 & 93 & est $\mathrm{C}=\mathrm{C}($ anillo $\mathrm{A})+$ flex sim $\mathrm{CH} 3$ \\
\hline 74 & 1310.09 & 215 & est $\mathrm{C}-\mathrm{O}($ metoxi y $\mathrm{OH})+$ bend ip C-C-H \\
\hline 73 & 1278.05 & 70 & est $\mathrm{C}-\mathrm{O}(\mathrm{OH})+$ bend ip (anillos) \\
\hline 72 & 1257.11 & 208 & bend ip C-C-H (anillo A) + rock CH4 \\
\hline 71 & 1240.25 & 74 & bend ip C-O-H + bend ip C-C-H (anillos) \\
\hline 70 & 1234.43 & 168 & rock $\mathrm{CH} 3$ \\
\hline 69 & 1227.47 & 94 & bend ip C-O-H + bend ip C-C-H (fenilo) + rock CH3 \\
\hline 65 & 1186.57 & 208 & bend ip C-C-H (anillo A) + rock $\mathrm{CH} 3$ \\
\hline 61 & 1158.06 & 68 & est O-C (metilo) + bend ip C-C-H (fenilo) \\
\hline 59 & 1140.17 & 180 & est C-O (heteroanillo) + est O-C (metilo) \\
\hline 58 & 1080.00 & 58 & est O-C (metilo) + bend ip C-C-H (fenilo) \\
\hline 57 & 1062.14 & 50 & est O-C (metilo) + bend ip C-C-H (fenilo) \\
\hline 47 & 828.61 & 50 & bend op C-C-H (anillo A) \\
\hline 27 & 455.32 & 68 & bend op C-O-H \\
\hline
\end{tabular}

Tabla $3 b 7$ 


\section{Compuesto 8}

\begin{tabular}{|c|c|c|c|}
\hline $\operatorname{modo}$ & v & I & asignaciones \\
\hline 114 & 3778.15 & 119 & est $\mathrm{O}-\mathrm{H}$ \\
\hline 101 & 3028.77 & 58 & est $\operatorname{sim} \mathrm{CH} 3$ \\
\hline 100 & 3025.34 & 69 & est $\operatorname{sim} \mathrm{CH} 3$ \\
\hline 99 & 3024.93 & 52 & est $\operatorname{sim} \mathrm{CH} 3$ \\
\hline 98 & 1799.39 & 853 & est $\mathrm{C}=\mathrm{O}$ \\
\hline 96 & 1655.20 & 569 & est $\mathrm{C}=\mathrm{C}$ (anillo $\mathrm{A}$ ) \\
\hline 95 & 1636.14 & 204 & est $\mathrm{C}=\mathrm{C}$ (anillos) \\
\hline 94 & 1624.98 & 156 & est $\mathrm{C}=\mathrm{C}$ (anillos) \\
\hline 92 & 1547.84 & 228 & bend ip C-C-H (fenilo) \\
\hline 89 & 1509.59 & 39 & flex asim $\mathrm{CH} 3$ \\
\hline 88 & 1504.19 & 56 & flex $\operatorname{asim} \mathrm{CH} 3$ \\
\hline 84 & 1496.77 & 40 & flex sim $\mathrm{CH} 3$ \\
\hline 80 & 1456.13 & 76 & flex $\operatorname{sim} \mathrm{CH} 3$ \\
\hline 79 & 1399.98 & 80 & bend ip C-C-H (anillos) \\
\hline 78 & 1386.36 & 258 & est $\mathrm{C}=\mathrm{C}($ anillo $\mathrm{A})+$ rock $\mathrm{CH} 3$ \\
\hline 76 & 1346.24 & 97 & est $\mathrm{C}=\mathrm{C}($ anillo $\mathrm{A})+\operatorname{rock} \mathrm{CH} 3$ \\
\hline 74 & 1310.44 & 204 & est C-O (OH) + bend ip C-C-H (anillos) \\
\hline 73 & 1276.07 & 137 & est C-O (metoxi) + bend ip C-C-H (anillos) \\
\hline 72 & 1255.54 & 209 & bend ip C-C-H (anillos) \\
\hline 71 & 1236.82 & 79 & bend ip C-C-H (anillos) + rock $\mathrm{CH} 3$ \\
\hline 70 & 1234.54 & 145 & bend ip C-C-H (anillos) \\
\hline 69 & 1229.60 & 99 & bend ip $\mathrm{C}-\mathrm{O}-\mathrm{H}+$ bend ip $\mathrm{C}-\mathrm{C}-\mathrm{H}$ (anillos) \\
\hline 65 & 1186.63 & 187 & bend C-C-H (anillos) + rock CH3 \\
\hline 60 & 1150.34 & 54 & bend ip C-C-H (fenilo) \\
\hline 59 & 1139.57 & 189 & est C-O (heteroanillo) + est O-C (metilo) \\
\hline 58 & 1079.97 & 68 & est O-C (metilo) + bend ip C-C-H \\
\hline 57 & 1058.28 & 46 & est O-C (metilo) \\
\hline 52 & 912.35 & 42 & est C-O (heteroanillo) + bend op C-C-H \\
\hline 48 & 827.17 & 56 & bend op C-C-H \\
\hline 27 & 449.90 & 88 & bend op C-O-H \\
\hline
\end{tabular}

Tabla $3 b 8$ 


\section{Compuesto 9}

\begin{tabular}{|c|c|c|c|}
\hline modo & v & $\mathbf{I}$ & asignaciones \\
\hline 126 & 3774.93 & 124 & est $\mathrm{O}-\mathrm{H}$ \\
\hline 112 & 3028.79 & 59 & est $\operatorname{sim} \mathrm{CH} 3$ \\
\hline 111 & 3026.20 & 51 & est $\operatorname{sim} \mathrm{CH} 3$ \\
\hline 110 & 3024.36 & 57 & est $\operatorname{sim} \mathrm{CH} 3$ \\
\hline 109 & 3017.43 & 54 & est $\operatorname{sim} \mathrm{CH} 3$ \\
\hline 108 & 1799.25 & 850 & est $\mathrm{C}=\mathrm{O}$ \\
\hline 107 & 1655.69 & 484 & est $\mathrm{C}=\mathrm{C}($ anillos $)+$ bend ip $\mathrm{C}-\mathrm{O}-\mathrm{H}$ \\
\hline 106 & 1651.87 & 187 & est $\mathrm{C}=\mathrm{C}$ (anillos) + bend ip $\mathrm{C}-\mathrm{O}-\mathrm{H}$ \\
\hline 104 & 1631.73 & 311 & est $\mathrm{C}=\mathrm{C}($ anillos $)$ \\
\hline 102 & 1550.34 & 209 & est $\mathrm{C}-\mathrm{O}(\mathrm{OH})+$ bend C-C-H (fenilo) \\
\hline 99 & 1509.06 & 47 & flex asim $\mathrm{CH} 3$ \\
\hline 98 & 1508.21 & 53 & flex $\operatorname{asim} \mathrm{CH} 3$ \\
\hline 97 & 1503.80 & 50 & flex $\operatorname{asim} \mathrm{CH} 3$ \\
\hline 88 & 1456.68 & 82 & flex $\operatorname{sim} \mathrm{CH} 3$ \\
\hline 87 & 1453.49 & 100 & flex sim $\mathrm{CH} 3$ \\
\hline 86 & 1406.44 & 107 & bend ip C-C-H (anillos) + bend ip C-O-H \\
\hline 84 & 1383.17 & 365 & est $\mathrm{C}=\mathrm{C}($ anillos $)$ \\
\hline 83 & 1352.37 & 62 & bend ip C-C-H + resp fenilo \\
\hline 82 & 1344.81 & 108 & est $\mathrm{C}=\mathrm{C}($ anillo $\mathrm{A})$ \\
\hline 80 & 1278.41 & 77 & est C-O (metoxi) + bend ip C-C-H (anillos) \\
\hline 79 & 1258.41 & 119 & bend ip C-C-H (anillos) \\
\hline 78 & 1248.12 & 331 & bend ip C-C-H (anillos) \\
\hline 77 & 1237.99 & 79 & bend ip C-C-H (anillos) \\
\hline 76 & 1234.53 & 198 & est C-O (metoxi) + bend ip C-C-H (anillo A) \\
\hline 71 & 1185.97 & 171 & bend ip $\mathrm{C}-\mathrm{C}-\mathrm{H}+$ rock $\mathrm{CH} 3$ \\
\hline 65 & 1149.82 & 275 & est O-C (metilo) + bend ip C-O-H \\
\hline 64 & 1137.85 & 176 & est C-O (heteroanillo) + est O-C (metilo) \\
\hline 63 & 1083.44 & 62 & est O-C (metilo) + bend ip C-C-H (anillo A) \\
\hline 52 & 827.11 & 53 & bend op C-C-H (anillo A) \\
\hline 32 & 458.34 & 86 & bend op C-O-H \\
\hline
\end{tabular}

Tabla 3b9 


\section{Combretastatina A-4}

\begin{tabular}{|c|c|c|c|}
\hline $\operatorname{modo}$ & v & $\mathbf{I}$ & asignaciones \\
\hline 123 & 3779.10 & 111 & est $\mathrm{O}-\mathrm{H}$ \\
\hline 107 & 3026.44 & 67 & est $\operatorname{sim} \mathrm{CH} 3$ (anillo A y B) \\
\hline 106 & 3023.47 & 60 & est sim CH3 (anillo A) \\
\hline 105 & 3021.21 & 64 & est $\operatorname{sim} \mathrm{CH} 3$ (anillo A) \\
\hline 104 & 3016.94 & 65 & est sim CH3 (anillo A) \\
\hline 100 & 1624.19 & 67 & est $\mathrm{C}=\mathrm{C}($ anillo $\mathrm{B})$ \\
\hline 99 & 1614.60 & 149 & est $\mathrm{C}=\mathrm{C}$ (anillo $\mathrm{A})$ \\
\hline 98 & 1547.85 & 206 & est C-O (metoxi B) + bend ip C-C-H (B) + flex CH3 \\
\hline 97 & 1538.10 & 128 & est C-O (metoxi A) + bend ip C-C-H (A) + flex CH3 \\
\hline 94 & 1508.87 & 36 & flex asim CH3 (A) \\
\hline 83 & 1455.81 & 126 & bend ip C-C-H + flex CH3 (A) \\
\hline 82 & 1438.18 & 70 & bend ip C-C-H + flex CH3 (A) \\
\hline 81 & 1380.88 & 39 & bend ip C-O-H + bend ip C-C-H \\
\hline 80 & 1361.34 & 90 & est C-O (metoxi A) + bend ip C-C-H \\
\hline 77 & 1305.62 & 259 & bend ip C-C-H + resp anillo B \\
\hline 76 & 1283.62 & 124 & bend ip C-C-H \\
\hline 75 & 1269.58 & 77 & bend ip C-C-H \\
\hline 74 & 1265.54 & 145 & est C-O (metoxi anillo A) + bend ip C-C-H (anillo A) \\
\hline 73 & 1254.90 & 128 & est C-O (metoxi B) + bend ip C-O-H + bend ip C-C-H (B) + flex CH3 \\
\hline 72 & 1232.25 & 55 & bend ip C-O-H + bend ip C-C-H (anillo B) + rock CH3 \\
\hline 63 & 1169.25 & 199 & est O-C (metilos anillo A) \\
\hline 62 & 1164.91 & 66 & rock $\mathrm{CH} 3$ (anillo $\mathrm{A})$ \\
\hline 61 & 1157.71 & 54 & bend ip C-C-H (anillo B) \\
\hline 60 & 1142.38 & 97 & bend ip C-C-H (anillos) \\
\hline 58 & 1057.56 & 46 & est O-C (metilo anillo B) \\
\hline 57 & 1033.36 & 67 & bend C-C-H op (anillo B) \\
\hline 51 & 901.01 & 43 & bend C-C-H op (anillo B) \\
\hline 50 & 871.21 & 41 & bend C-C-H op (anillo A) \\
\hline 29 & 449.70 & 60 & bend C-O-H op \\
\hline 28 & 439.12 & 39 & bend C-O-H op \\
\hline
\end{tabular}

Tabla 3b10 


\subsection{La Resonancia Magnética Nuclear}

\subsubsection{Algunos apuntes}

La Resonancia Magnética Nuclear (RMN) es la técnica más ampliamente usada en investigaciones estructurales o dinámicas de compuestos químicos en fase condensada, tanto por los profesionales físicos como los químicos, y más recientemente, por los biólogos o los médicos. A diferencia de otras técnicas de investigación estructural, la RMN no se limita al caso de pequeñas moléculas de bajo peso molecular y alta simetría, sino que proporciona datos precisos y muy útiles incluso con biopolímeros de peso molecular relativamente elevado (proteínas), sin requerir la previa cristalización de la muestra.

La interacción de una muestra con radiación electromagnética circularmente polarizada en el plano perpendicular al campo magnético externo $\overrightarrow{\mathrm{B}}$ y cuya frecuencia sea la frecuencia de Larmor $\left(v_{0}\right)$, que es la frecuencia a la que precesionan los espines, lleva a la resonancia del sistema y a la generación de transiciones entre los niveles energéticos nucleares.

Esta frecuencia está relacionada con el campo magnético externo a través de la constante magnetogírica $\gamma$, característica de cada isótopo, por la expresión

$$
v_{0}=\frac{\gamma|\overrightarrow{\mathrm{B}}|}{2 \pi}
$$

Para el protón, $1 \mathrm{H}$, cuya constante magnetogírica vale $\gamma_{\mathrm{H}}=26.7510^{7} \mathrm{rad} \mathrm{T}^{-1} \mathrm{~s}^{-1}$ operando con un campo magnético $|\overrightarrow{\mathrm{B}}|=2.35 \mathrm{~T}$ (23500 gauss), da una frecuencia de Larmor de $100.00 \mathrm{MHz}$, dentro del rango de la radiofrecuencia.

La detección de la absorción de esta radiofrecuencia en un espectrómetro RMN no es inmediata porque las cantidades de energía involucradas son muy pequeñas, de unas pocas milicalorías por mol. Esto impide el uso de técnicas tradicionales como las usadas en la espectroscopía óptica (UV-Vis, IR), en las que se comparan las intensidades de dos haces de radiación, uno el que ha atravesado la muestra y el otro, el haz de referencia.

Debido al pequeño valor de las energías involucradas, la RMN es una técnica espectroscópica de muy baja sensibilidad. En condiciones óptimas, en un espectrómetro 
moderno de alto campo magnético, se requiere un mínimo de $10^{15}$ espines de una determinada especie isotópica (de las "fáciles" de medir) para poder detectar señales útiles en un período de una hora ${ }^{114}$.

La predicción teórica de las propiedades magnéticas de resonancia nuclear en moléculas es en estos tiempos un trabajo de rutina en el contexto de la química computacional moderna. Sin embargo, esto no siempre fue así. La razón se encuentra en la dificultad para modelar el efecto de un campo magnético sobre una función de onda multielectrónica, ya que se introduce una perturbación en el operador energía cinética (o momento) en forma de vector potencial, que por otra parte no está únicamente definido. Cualquier elección particular para este vector se conoce como la problemática del gauge.

Las propiedades magnéticas calculadas sólo son independientes del gauge de origen si la función de onda es exacta o se acerca al límite de un método dado (por ejemplo el límite de Hartree-Fock) ${ }^{115}$.

El método GIAO desarrollado por Ditchfield ${ }^{116}$ e implementado por Wolinsky y colaboradores ${ }^{117}$ significa, por sus siglas en inglés (gauge-including atomic orbitals), que usa las funciones base con dependencia explícita del campo magnético externo

$$
\chi(\mathrm{B})=\exp \left[-\frac{\mathrm{i}}{2 \mathrm{c}}(\overrightarrow{\mathrm{B}} \times \overrightarrow{\mathrm{R}}) \overrightarrow{\mathrm{r}}\right] \chi(0)
$$

Donde $\vec{R}$ es el vector posición de las funciones base y $\chi(0)$ denota las funciones base usuales independientes del campo magnético.

Cheeseman y colaboradores ${ }^{118}$ lograron una comparación sistemática de diferentes niveles de teoría para calcular los tensores de apantallamiento RMN con los métodos GIAO y de transformaciones gauge continuas en conjuntos (CSGT) y concluyeron que el nivel de teoría B3LYP/6-311+G(2d,p) predice corrimientos químicos con buena aproximación a los medidos experimentalmente. Estos corrimientos químicos se obtienen por sustracción de los apantallamientos magnéticos isotrópicos del átomo problema con su referencia correspondiente (para $1 \mathrm{H}$ y $13 \mathrm{C}$ se usa comúnmente

\footnotetext{
${ }^{114}$ F. Sánchez Ferrando; "Breve Resumen de la Resonancia Magnética Nuclear”: Dpto. de Química, U. A. de Barcelona

${ }^{115}$ C. Franca, R. Pis Diez, A. Jubert; J. Mol. Structure: THEOCHEM 856 (2008) 1-8

${ }^{116}$ R. Ditchfield, Mol. Phys. 27 (1974) 789

${ }^{117}$ K. Wolinski, J.F. Hinton, P. Pulay, J. Am. Chem. Soc. 112 (1990) 8251

118 J.R. Cheeseman, G.W. Trucks, T.A. Keith, M.J. Frisch, J. Chem. Phys. 104 (1996) 5497
} 
tetrametilsilano). También es posible obtener los valores de los corrimientos por métodos de correlación ${ }^{119}$.

El tensor de apantallamiento magnético se expresa como la derivada de la energía con respecto al campo magnético externo $\mathrm{B}$ y al momento magnético $\mu_{\mathrm{N}}$ del núcleo $\mathrm{N}$, para i componentes de campo magnético externo y j componentes del momento magnético inducido

$$
\sigma_{j i}^{N}=\frac{\partial^{2} E}{\partial B_{i} \partial \mu_{N_{j}}}
$$

La formulación DFT de Kohn -Sham es análoga a la teoría de Hartree-Fock en lo que respecta a derivar un conjunto de orbitales moleculares a partir de un potencial efectivo unielectrónico por un procedimiento autoconsistente. Se puede expresar la energía SCF y la matriz de Fock de la forma

$$
\begin{aligned}
& \mathrm{E}=\left\langle\mathcal{H}_{i}^{o} \mathbf{P}\right\rangle+\frac{1}{2}\langle\mathbf{P G}(\mathbf{P})\rangle+\mathrm{E}_{\mathrm{XC}}+\mathrm{V} \\
& \mathbf{F}=\frac{\partial \mathrm{E}}{\partial \mathrm{P}}=\mathcal{H}_{i}^{o}+\mathbf{G}(\mathbf{P})+\mathrm{G}_{\mathrm{XC}}=\mathcal{H}_{i}^{o}+\mathbf{G}
\end{aligned}
$$

Donde $\mathrm{P}$ es la matriz densidad, $\mathcal{H}_{i}^{o}$ es el hamiltoniano unielectrónico y $\mathrm{V}$ es la energía de repulsión nuclear. $\mathbf{G}(\mathbf{P})$ es una función definida como

$$
\mathbf{G}(\mathbf{P})=\sum \mathrm{P}(\mathrm{ij} / / \mathrm{kl})
$$

Donde (ij//kl) es la integral bielectrónica sobre las cuatro funciones espín-orbitales que incluye un coeficiente para el intercambio de Hartree Fock $\left(\mathrm{C}_{\mathrm{X}}^{\mathrm{HF}}\right)$

$$
(\mathrm{ij} / / \mathrm{kl})=\int \chi_{\mathrm{i}}^{*}(1) \chi_{\mathrm{j}}^{*}(2) \frac{1}{\mathrm{r}_{12}}\left[\chi_{\mathrm{k}}(1) \chi_{1}(2)-\mathrm{C}_{\mathrm{X}}^{\mathrm{HF}} \chi_{1}(1) \chi_{\mathrm{k}}(2)\right] d \tau_{1} d \tau_{2}
$$

La energía de intercambio y correlación toma la forma

$$
\mathrm{E}_{\mathrm{XC}}=\int f\left(\rho_{\alpha}, \rho_{\beta}, \gamma_{\alpha \alpha}, \gamma_{\alpha \beta}, \gamma_{\beta \beta}\right) d r
$$

\footnotetext{
${ }^{119}$ N.J.R. van Eikema Hommes, T. Clark, J. Mol. Model. 11 (2005) 175
} 
Donde $f$ es un funcional de intercambio y correlación de primer orden que no incluye un término explícito dependiente del campo magnético. Las densidades de espín se expresan de la forma

$$
\rho_{\alpha}=\sum_{\mathrm{ij}} \mathrm{P}_{\mathrm{ij}}^{\alpha} \chi_{\mathrm{i}} \chi_{\mathrm{j}}
$$

y el producto de los gradientes de la densidad como

$$
\begin{gathered}
\gamma_{\alpha \alpha}=\nabla \rho_{\alpha} \nabla \rho_{\alpha}, \quad \gamma_{\alpha \beta}=\nabla \rho_{\alpha} \nabla \rho_{\beta} \\
\nabla \rho_{\alpha}=\sum_{\mathrm{ij}} \mathrm{P}^{\alpha} \nabla\left(\chi_{\mathrm{i}} \chi_{\mathrm{j}}\right)
\end{gathered}
$$

La parte de $\mathbf{F}$ que corresponde al intercambio y correlación se expresa como

$$
\mathrm{G}_{\mathrm{XC}}^{\alpha}=\int\left[\frac{\partial f}{\partial \rho_{\alpha}} \chi_{\mathrm{i}}^{*} \chi_{\mathrm{j}}+\left(2 \frac{\partial f}{\partial \gamma_{\alpha \alpha}} \nabla \rho_{\alpha}+\frac{\partial f}{\partial \gamma_{\alpha \beta}} \nabla \rho_{\alpha}\right) \nabla\left(\chi_{\mathrm{i}}^{*} \chi_{\mathrm{j}}\right)\right] d r
$$

El coeficiente para el intercambio de Hartree Fock $\left(\mathrm{C}_{\mathrm{X}}^{\mathrm{HF}}\right)$ vale 1 para Hartree-Fock, vale 0 para funcionales puros de DFT y distinto de cero para métodos híbridos. De igual modo $f=0$ para la teoría de Hartree-Fock.

\subsubsection{Cálculo de los apantallamientos magnéticos isotrópicos}

El cálculo de los corrimientos magnéticos se efectuó sobre las mismas conformaciones a las cuales se realizó el cálculo de frecuencias y aplicando la misma distribución estadística de acuerdo a las energias de cada confórmero. Se asignaron los desplazamientos químicos de 13C para cada átomo y se compararon con los experimentales cuando esto fue posible. Cabe destacar que en la bibliografía en que se encuentran los datos experimentales, éstos no están asignados a cada átomo, por lo que cobra relevancia la asignación establecida.

Los apantallamientos magnéticos isotrópicos se calcularon con el nivel de teoría B3LYP/6-31G(d).

Para convertir los apantallamientos en desplazamientos químicos se pueden seguir en principio dos caminos. Uno es calcular con el mismo nivel de teoría el apantallamiento teórico del $\mathrm{Si}\left(\mathrm{CH}_{3}\right)_{4}$ (tetrametilsilano, TMS), compuesto que se usa como referencia en 
la rutina de la resonancia magnética, y restar ese valor al del carbono correspondiente. Otra vía es hacer uso de una regresión desarrollada por N. J. R. Van Eikema Hommes y Timothy Clark en la que correlacionan los apantallamientos calculados con los desplazamientos experimentales de una amplia base de datos con el fin de obtener una pendiente $\kappa$ y una ordenada al origen $\delta^{\circ}$, para establecer la recta

$$
\boldsymbol{\delta}=\boldsymbol{\delta}^{\mathbf{0}}+\kappa \boldsymbol{\sigma}
$$

en la que $\delta$ es el desplazamiento químico experimental y $\sigma$ es el apantallamiento isotrópico calculado en ppm. Para diferentes niveles de cálculo tendremos distintos valores de $\kappa$ y de $\delta^{o}$. Con tales valores de $\kappa$ y de $\delta^{\mathrm{o}}$ se obtienen los desplazamientos teóricos a partir la ecuación lineal usando los apantallamientos calculados como variable. En nuestro caso, de acuerdo al nivel de teoría usado, se usaron los valores

$$
\begin{aligned}
& \kappa=-1.0644 \\
& \delta^{0}=201.66
\end{aligned}
$$

Este método no esquiva la referencia del TMS ya que está en los valores experimentales de los compuestos y la conversión permite obtener los desplazamientos en relación a éste.

En las tablas de la $3 \mathrm{c} 1$ a $3 \mathrm{c} 10$ se muestran los resultados de los desplazamientos químicos calculados en ppm con referencia a TMS y sus asignaciones, comparandose con los valores experimentales cuando es posible. Al lado de la Tabla 3c2 se muestra la Figura 3.6.1 con el propósito de aclarar la asignación de acuerdo a la nomenclatura IUPAC de cada átomo de carbono. Se muestran los corrimientos químicos experimentales al lado de cada carbono y debajo de éstos entre paréntesis los experimentales para el compuesto 2. También al lado de la Tabla $3 \mathrm{c} 10$ se muestra la Figura 3.6.2 con la numeración IUPAC de combretastatina A-4. 
Compuesto 1

\begin{tabular}{|c|c|c|}
\hline $\exp$ & calc & asignación \\
\hline 56.4 & 56.53 & metoxilo en $\mathrm{C} 7$ \\
\hline \multirow[t]{2}{*}{61.3} & 61.03 & metoxilo en $\mathrm{C} 5$ \\
\hline & 61.50 & metoxilo en $\mathrm{C} 6$ \\
\hline 96.5 & 97.31 & $\mathrm{C} 8$ \\
\hline 107.4 & 111.27 & $\mathrm{C} 10$ \\
\hline 114.1 & 112.94 & C3' \\
\hline \multirow[t]{2}{*}{114.5} & 113.49 & $\mathrm{C}^{\prime}$ \\
\hline & 117.43 & $\mathrm{C} 3$ \\
\hline 129.2 & 130.39 & $\mathrm{C} 2^{\prime}$ \\
\hline 131.3 & 134.60 & $\mathrm{C}^{\prime}$ \\
\hline \multirow[t]{2}{*}{139.6} & 134.90 & $\mathrm{C6}^{\prime}$ \\
\hline & 142.76 & C6 \\
\hline 151.3 & 156.74 & $\mathrm{C} 5$ \\
\hline 151.8 & 157.49 & $\mathrm{C} 4^{\prime}$ \\
\hline 155.4 & 157.84 & C9 \\
\hline 156.0 & 158.56 & $\mathrm{C} 2$ \\
\hline 156.9 & 159.13 & $\mathrm{C} 4$ \\
\hline 161.0 & 159.42 & $\mathrm{C} 7$ \\
\hline
\end{tabular}

Tabla 3c1 
Compuesto 2

\begin{tabular}{c|c|c} 
exp & calc & asignación \\
\hline 56.1 & 55.98 & CH3 fenilo \\
\hline 56.3 & 56.52 & metoxilo en C7 \\
\hline 61.2 & 61.26 & metoxilo en C5 \\
\hline 61.3 & 61.36 & metoxilo en C6 \\
\hline 96.4 & 97.38 & C8 \\
\hline 107.4 & 111.67 & C10 \\
\hline 110.7 & 113.46 & C2' \\
\hline 113.6 & 113.98 & C5' \\
\hline 114.1 & 117.56 & C3 \\
\hline 120.7 & 122.80 & C6' \\
\hline 130.9 & 133.97 & C1' \\
\hline 139.6 & 142.82 & C6 \\
\hline 145.7 & 145.54 & C3' \\
\hline 145.9 & 148.33 & C4' \\
\hline 151.2 & 156.61 & C5 \\
\hline 151.8 & 157.91 & C9 \\
\hline 155.3 & 158.53 & C2 \\
\hline 156.9 & 159.27 & C7 \\
\hline 160.8 & 159.46 & C4
\end{tabular}

Figura 3.6.1

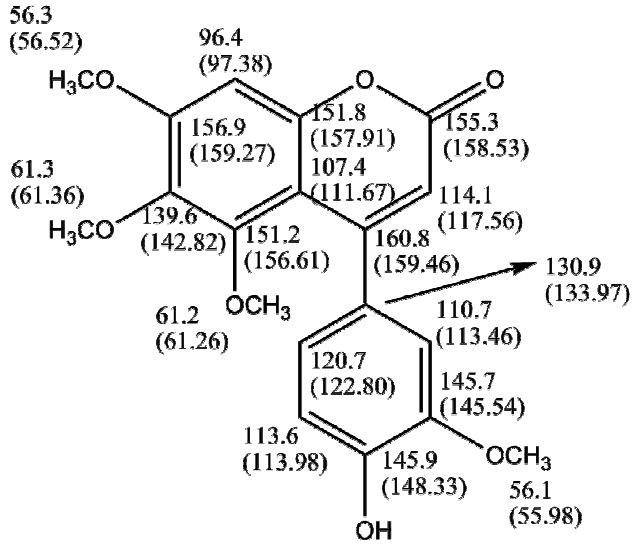

Tabla 3c2 
Compuesto 3

\begin{tabular}{c|c|c} 
exp & calc & asignación \\
\hline 56.0 & 55.97 & CH3 fenilo \\
\hline 56.3 & 56.52 & metoxilo C7 \\
\hline 61.1 & 61.09 & metoxilo C5 \\
\hline 61.2 & 61.54 & metoxilo C6 \\
\hline 96.3 & 97.22 & C8 \\
\hline 107.4 & 108.90 & $\mathrm{C}^{\prime}$ \\
\hline 109.8 & 111.64 & $\mathrm{C} 10^{\prime}$ \\
\hline 114.1 & 116.95 & $\mathrm{C}^{\prime}$ \\
\hline 114.2 & 117.47 & $\mathrm{C}^{\prime}$ \\
\hline 119.3 & 120.44 & $\mathrm{C}^{\prime}$ \\
\hline 132.3 & 137.27 & $\mathrm{C} 1^{\prime}$ \\
\hline 139.6 & 142.85 & $\mathrm{C} 6$ \\
\hline 144.7 & 146.72 & $\mathrm{C} 3^{\prime}$ \\
\hline 146.7 & 146.86 & $\mathrm{C} 4^{\prime}$ \\
\hline 151.3 & 156.88 & $\mathrm{C} 5$ \\
\hline 151.8 & 157.79 & $\mathrm{C} 9$ \\
\hline 155.2 & 158.61 & $\mathrm{C} 2$ \\
\hline 156.8 & 159.41 & $\mathrm{C} 7$ \\
\hline 160.8 & 159.58 & $\mathrm{C} 4$
\end{tabular}

Tabla 3c3 
Compuesto 4

\begin{tabular}{c|c|c} 
exp & calc & asignación \\
\hline 56.2 & 56.44 & metoxilo en C7 \\
\hline 56.4 & 56.45 & metoxilo en C5' \\
\hline & 56.47 & metoxilo en C3' \\
\hline 61.0 & 61.28 & metoxilo en C6 \\
\hline 61.2 & 61.61 & metoxilo en C5 \\
\hline 96.2 & 97.17 & C8 \\
\hline 104.7 & 105.56 & C2 $^{\prime}$ \\
\hline 107.2 & 108.62 & C6 $^{\prime}$ \\
\hline 113.9 & 111.75 & $\mathrm{C} 10^{\prime}$ \\
\hline & 117.19 & $\mathrm{C} 3^{\prime}$ \\
\hline 129.9 & 133.05 & $\mathrm{C}^{\prime}$ \\
\hline 134.8 & 138.66 & $\mathrm{C}^{\prime}$ \\
\hline 139.5 & 142.73 & $\mathrm{C} 6$ \\
\hline & 147.17 & $\mathrm{C}^{\prime}$ \\
\hline 146.3 & 147.35 & $\mathrm{C} 5^{\prime}$ \\
\hline 151.0 & 156.82 & $\mathrm{C} 5$ \\
\hline 151.7 & 157.86 & $\mathrm{C} 9$ \\
\hline 155.3 & 158.62 & $\mathrm{C} 2$ \\
\hline 156.8 & 159.41 & $\mathrm{C} 7$ \\
\hline 160.6 & 160.03 & $\mathrm{C} 4$
\end{tabular}

Tabla 3c4 
Compuesto 5

\begin{tabular}{c|c|c} 
exp & calc & asignación \\
\hline 56.3 & 56.54 & metoxilo en C7 \\
\hline 61.1 & 61.05 & metoxilo en C5 \\
\hline 61.2 & 61.54 & metoxilo en C6 \\
\hline 96.3 & 97.28 & C8 \\
\hline 101.3 & 105.70 & metileno \\
\hline 107.3 & 108.10 & $\mathrm{C}^{\prime}$ \\
\hline 107.6 & 111.38 & $\mathrm{C} 4 \mathrm{a}$ \\
\hline 108.5 & 112.23 & $\mathrm{C} 2^{\prime}$ \\
\hline 114.1 & 117.44 & $\mathrm{C} 3$ \\
\hline 120.9 & 122.88 & $\mathrm{C} 6^{\prime}$ \\
\hline 132.7 & 137.85 & $\mathrm{C} 1^{\prime}$ \\
\hline 139.5 & 142.89 & $\mathrm{C} 6$ \\
\hline 146.9 & 148.27 & $\mathrm{C} 3^{\prime}$ \\
\hline 147.6 & 149.43 & $\mathrm{C} 4^{\prime}$ \\
\hline 151.1 & 156.66 & $\mathrm{C} 5$ \\
\hline 151.7 & 157.81 & $\mathrm{C} 8 \mathrm{a}$ \\
\hline 154.9 & 158.53 & $\mathrm{C} 2$ \\
\hline 156.9 & 159.02 & $\mathrm{C} 4$ \\
\hline 160.6 & 159.53 & $\mathrm{C} 7$
\end{tabular}

Tabla $3 \mathrm{c} 5$ 
Compuesto 6

\begin{tabular}{c|c} 
calc & asignación \\
\hline 55.34 & metoxilo C5 \\
\hline 56.37 & metoxilo C7 \\
\hline 93.57 & C8 \\
\hline 94.97 & C6 \\
\hline 106.46 & C10 \\
\hline 112.63 & C3' $^{\prime}$ \\
\hline 114.23 & C5 $^{\prime}$ \\
\hline 115.84 & C3 $^{\prime}$ \\
\hline 130.28 & C $^{\prime}$ \\
\hline 132.35 & C6 $^{\prime}$ \\
\hline 136.41 & C1 $^{\prime}$ \\
\hline 157.09 & C4' \\
\hline 158.61 & C2 \\
\hline 159.02 & C4 \\
\hline 159.97 & C5 \\
\hline 163.28 & C9 \\
\hline 164.01 & C7
\end{tabular}

Tabla 3c6 
Compuesto 7

\begin{tabular}{c|c} 
calc & asignación \\
\hline 52.71 & metoxilo C5 \\
\hline 53.31 & metoxilo C3' \\
\hline 53.66 & metoxilo C7 \\
\hline 89.27 & C8 \\
\hline 90.14 & C6 \\
\hline 101.43 & C10 \\
\hline 105.09 & C2 $^{\prime}$ \\
\hline 108.47 & C5 $^{\prime}$ \\
\hline 109.98 & C3 $^{\prime}$ \\
\hline 118.08 & C6 $^{\prime}$ \\
\hline 128.92 & C1 $^{\prime}$ \\
\hline 139.32 & C3 $^{\prime}$ \\
\hline 140.58 & C4 $^{\prime}$ \\
\hline 151.98 & C4 \\
\hline 152.48 & C5 \\
\hline 155.45 & C9 \\
\hline 156.18 & C7 \\
\hline 158.70 & C2
\end{tabular}

Tabla 3c7 
Compuesto 8

\begin{tabular}{|c|c|}
\hline calc & asignación \\
\hline 55.44 & metoxilo C5 \\
\hline 55.92 & metoxilo $\mathrm{C} 4$ \\
\hline 56.31 & metoxilo C7 \\
\hline 93.33 & $\mathrm{C} 8$ \\
\hline 95.07 & C6 \\
\hline 106.49 & $\mathrm{C} 10$ \\
\hline 109.21 & $\mathrm{C} 5^{\prime}$ \\
\hline 115.74 & $\mathrm{C} 3$ \\
\hline 116.13 & $\mathrm{C}^{\prime}$ \\
\hline 119.65 & $\mathrm{C6}^{\prime}$ \\
\hline 138.70 & $\mathrm{Cl}^{\prime}$ \\
\hline 146.69 & $\mathrm{C} 4^{\prime}$ \\
\hline 146.69 & C3' \\
\hline 158.70 & $\mathrm{C} 2$ \\
\hline 159.28 & $\mathrm{C} 4$ \\
\hline 160.04 & $\mathrm{C} 5$ \\
\hline 163.20 & C9 \\
\hline 163.95 & $\mathrm{C} 7$ \\
\hline
\end{tabular}

Tabla 3c8 
Compuesto 9

\begin{tabular}{|c|c|c|}
\hline $\exp$ & calc & asignación \\
\hline 55.5 & 55.78 & metoxilo C5 \\
\hline 55.8 & 56.71 & metoxilo C3' \\
\hline \multirow[t]{2}{*}{56.4} & 56.74 & metoxilo C7 \\
\hline & 56.77 & metoxilo C5' \\
\hline 93.6 & 93.15 & $\mathrm{C} 8$ \\
\hline 95.8 & 94.83 & C6 \\
\hline 103.5 & 104.81 & $\mathrm{C6}^{\prime}$ \\
\hline \multirow[t]{2}{*}{104.5} & 106.39 & $\mathrm{C} 2^{\prime}$ \\
\hline & 106.43 & $\mathrm{C} 10$ \\
\hline 112.5 & 114.86 & $\mathrm{C} 3$ \\
\hline 130.8 & 134.33 & $\mathrm{C} 1^{\prime}$ \\
\hline 134.8 & 137.63 & $\mathrm{C}^{\prime \prime}$ \\
\hline \multirow[t]{2}{*}{146.3} & 146.88 & $\mathrm{C} 3^{\prime}$ \\
\hline & 147.28 & $\mathrm{C} 5^{\prime}$ \\
\hline 155.6 & 158.96 & $\mathrm{C} 2$ \\
\hline 157.2 & 159.73 & $\mathrm{C} 5$ \\
\hline 158.2 & 159.85 & $\mathrm{C} 4$ \\
\hline 160.9 & 163.27 & C9 \\
\hline 163.3 & 163.75 & $\mathrm{C} 7$ \\
\hline
\end{tabular}

Tabla 3c9 
Combretastatina A-4

\begin{tabular}{c|c|c} 
exp & calc & asignación \\
\hline 55.89 & 53.98 & metoxilo C4' \\
\hline 55.89 & 54.52 & metoxilo C3 \\
\hline 55.89 & 55.44 & metoxilo C5 \\
\hline 60.85 & 58.74 & metoxilo C4 \\
\hline 106.07 & 106.87 & $\mathrm{C} 2$ \\
\hline 106.07 & 108.11 & $\mathrm{C} 6$ \\
\hline 110.32 & 108.74 & $\mathrm{C} 5^{\prime}$ \\
\hline 115.02 & 115.27 & $\mathrm{C} 2^{\prime}$ \\
\hline 121.06 & 121.30 & $\mathrm{C}^{\prime}$ \\
\hline 128.98 & 131.37 & $\mathrm{C}^{\prime} \mathrm{a}^{\prime}$ \\
\hline 129.45 & 131.75 & $\mathrm{C} 1 \mathrm{a}^{\prime}$ \\
\hline 130.58 & 133.83 & $\mathrm{C} 1^{\prime}$ \\
\hline 132.67 & 135.31 & $\mathrm{C} 1$ \\
\hline 137.14 & 141.53 & $\mathrm{C} 4$ \\
\hline 145.22 & 146.18 & $\mathrm{C} 4^{\prime}$ \\
\hline 145.77 & 147.76 & $\mathrm{C} 3^{\prime}$ \\
\hline 152.82 & 156.73 & $\mathrm{C} 5$ \\
\hline 152.82 & 156.93 & $\mathrm{C} 3$
\end{tabular}

Figura 3.6.2

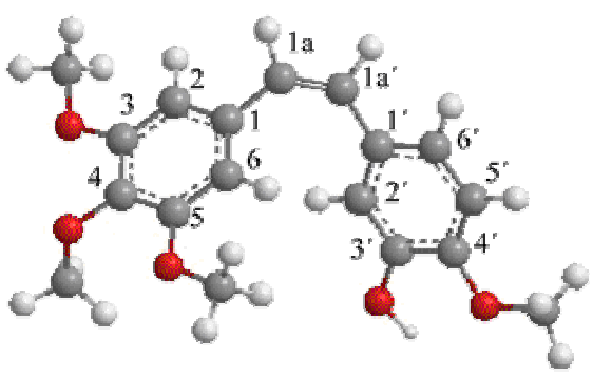

Tabla 3c10 


\subsection{El Potencial Electrostático Molecular}

El Potencial Electrostático Molecular (MEP, de sus siglas en inglés) se ha convertido en los últimos tiempos en una herramienta formidable para el estudio de la reactividad y las interacciones entre moléculas. El potencial electrostático $\mathrm{V}(\mathrm{r})$ se genera en el espacio alrededor de una molécula por causa de sus núcleos y sus electrones. El potencial V(r) es una propiedad física real y se puede determinar experimentalmente por métodos de difracción. Se supone que en el acercamiento de una molécula a otra se establece un reconocimiento desde sitios específicos en donde el potencial juega un papel importante. Por ejemplo, cuando un fármaco se acerca a un sitio receptor es de esperar que se establezca una primera atracción a partir de reconocerse ambos desde potenciales de diferente signo. Se entiende también la importancia de esta propiedad en reacciones electrofílicas y nucleofílicas ya que pueden describirse regiones del potencial en las moléculas con tales características.

El potencial electrostático está relacionado con la densidad de carga total $\mathrm{D}(\mathrm{r})$ a través de la ecuación de Poisson

$$
\nabla^{2} \mathrm{~V}(\mathrm{r})=-4 \pi \mathrm{D}(\mathrm{r})
$$

y por tal razón ha tenido desde los métodos computacionales un desarrollo sostenido en el área de la Teoría del Funcional de la Densidad.

Cualquier distribución de cargas en el espacio genera un potencial eléctrico V(r). Si tomamos una colección de cargas puntuales $Q_{i}$ localizadas a posiciones $\mathrm{r}_{\mathrm{i}}$ el potencial en un punto dado a una distancia r será

$$
\mathrm{V}(\mathrm{r})=\sum \frac{\mathrm{Q}_{\mathrm{i}}}{\left|\mathrm{r}_{\mathrm{i}-\mathrm{r}}\right|}
$$

Si la distribución de carga es continua se reemplaza la sumatoria por una integral

$$
V(r)=\int \frac{D\left(r^{\prime}\right) d r^{\prime}}{\left|r^{\prime}-r\right|}
$$

el signo de $\mathrm{D}(\mathrm{r})$ puede variar como una función de $\mathrm{r}$. 
En el caso de los sistemas moleculares el potencial eléctrico se denomina potencial electrostático y se trata como una distribución estática de carga alrededor de un esqueleto de núcleos y tiene la expresión

$$
V(r)=\sum \frac{Z_{A}}{\left|R_{A}-r\right|}-\int \frac{\rho\left(r^{\prime}\right) d r^{\prime}}{\left|r^{\prime}-r\right|}
$$

$Z_{A}$ es la carga sobre el núcleo A localizada a un radio $R_{A}$, y $\rho(r)$ es la función densidad electrónica de la molécula. Las ecuaciones están expresadas en unidades atómicas. Como la densidad electrónica es siempre positiva, a diferencia de $\mathrm{D}(\mathrm{r})$ que puede serlo o no, el segundo término de la ecuación anterior tiene antepuesto un signo negativo. El signo del potencial en una zona dependerá del efecto que domine entre los núcleos y los electrones en esa región.

Como el MEP toma diferentes valores en cada punto del espacio, éste se puede representar gráficamente. Una forma es elegir un plano que atraviese la molécula y representar en ese plano las curvas isopotenciales que unen puntos del mismo valor. Otra forma es representar superficies de alguna propiedad como la densidad electrónica envolviendo una representación tridimensional de la molécula y sobre la misma graficar los valores del MEP asignando colores según el signo del mismo. Convencionalmente se colorea de rojo los potenciales más negativos y azul los más positivos. Un valor de potencial de especial interés es el mínimo alrededor de la molécula ya que puede indicar, como señalamos anteriormente, la dirección de un posible ataque electrofílico. Incluso el valor del potencial mínimo puede ser usado para el estudio de relaciones de estructura actividad.

Los potenciales electrostáticos se calcularon para las conformaciones de más baja energía de los diez compuestos. También se calcularon las cargas atómicas derivadas del potencial usando tres métodos diferentes. El primero desarrollado por Chirlian y Francl $(\text { Chelp) })^{120}$, el segundo por Breneman y Wiberg $\left(\right.$ ChelpG) ${ }^{121}$ y el tercero por Merz, Singh y Kollman (MSK) ${ }^{122,123 .}$

\footnotetext{
${ }^{120}$ L. E. Chirlian and M. M. Francl, J. Comp. Chem. 8 (1987) 894-905

${ }^{121}$ C. M. Breneman and K. B. Wiberg, J. Comp. Chem. 11 (1990) 361-73

${ }^{122}$ U. C. Singh and P. A. Kollman, J. Comp. Chem. 5 (1984) 129-45

${ }^{123}$ B. H. Besler, K. M. Merz Jr., and P. A. Kollman, J. Comp. Chem. 11 (1990) 431-39
} 
En las siguientes tablas de la $3 \mathrm{~d} 1$ a la $3 \mathrm{~d} 10$ se muestran, para todas las moléculas, las cargas de los átomos de oxígeno de acuerdo a cada método en unidades atómicas (u.a) y los valores mínimos de los potenciales $\mathrm{V}(\mathrm{r})$ en u.a alrededor de los átomos de oxígeno.

\begin{tabular}{c|c|c|c|c} 
compuesto 1 & Chelp & CHelpG & MK & V ( r ) \\
\hline O1 & -0.407 & -0.451 & -0.480 & $-\mathbf{0 . 0 9 4 5}$ \\
\hline O2 & -0.577 & -0.602 & -0.595 & $-\mathbf{0 . 0 9 4 5}$ \\
\hline O6 & -0.303 & -0.359 & -0.256 & $-\mathbf{0 . 0 6 0 9}$ \\
\hline O4' & -0.552 & -0.627 & -0.622 & $\mathbf{- 0 . 0 5 2 9}$ \\
\hline O5 & -0.287 & -0.259 & -0.273 & $\mathbf{- 0 . 0 5 1 7}$ \\
\hline O7 & -0.443 & -0.284 & -0.265 & $-\mathbf{0 . 0 5 1 7}$
\end{tabular}

Tabla $3 \mathrm{~d} 1$ 


\begin{tabular}{c|c|c|c|c} 
compuesto 2 & Chelp & CHelpG & MK & V ( r ) \\
\hline O2 & -0.593 & -0.598 & -0.595 & $-\mathbf{0 . 0 9 4 1}$ \\
\hline O1 & -0.462 & -0.455 & -0.485 & $-\mathbf{0 . 0 6 0 8}$ \\
\hline O4' & -0.483 & -0.546 & -0.528 & $-\mathbf{0 . 0 5 9 4}$ \\
\hline O6 & -0.278 & -0.328 & -0.237 & $-\mathbf{0 . 0 5 9 0}$ \\
\hline O7 & -0.365 & -0.296 & -0.250 & $-\mathbf{0 . 0 4 9 2}$ \\
\hline O5 & -0.347 & -0.272 & -0.249 & $-\mathbf{0 . 0 4 6 7}$ \\
\hline O3' & -0.373 & -0.367 & -0.328 & $-\mathbf{0 . 0 3 4 3}$
\end{tabular}

Tabla $3 \mathrm{~d} 2$

\begin{tabular}{c|c|c|c|c} 
compuesto 3 & Chelp & CHelpG & MK & V ( r ) \\
\hline O2 & -0.605 & -0.604 & -0.596 & $-\mathbf{0 . 0 9 5 6}$ \\
\hline O6 & -0.257 & -0.329 & -0.254 & $-\mathbf{- 0 . 0 6 3 0}$ \\
\hline O1 & -0.382 & -0.462 & -0.481 & $-\mathbf{0 . 0 6 2 3}$ \\
\hline O3' & -0.489 & -0.539 & -0.537 & $-\mathbf{0 . 0 6 1 2}$ \\
\hline O5 & -0.338 & -0.280 & -0.271 & $-\mathbf{0 . 0 5 6 6}$ \\
\hline O7 & -0.444 & -0.303 & -0.265 & $-\mathbf{0 . 0 5 3 2}$ \\
\hline O4' & -0.381 & -0.329 & -0.281 & $-\mathbf{0 . 0 2 6 9}$
\end{tabular}

Tabla 3d3

\begin{tabular}{c|c|c|c|c} 
compuesto 4 & Chelp & CHelpG & MK & V ( r ) \\
\hline O2 & -0.656 & -0.602 & -0.595 & $-\mathbf{0 . 0 9 3 7}$ \\
\hline O4' & -0.491 & -0.538 & -0.535 & $-\mathbf{0 . 0 7 5 8}$ \\
\hline O5' & -0.435 & -0.277 & -0.251 & $\mathbf{- 0 . 0 7 4 5}$ \\
\hline O1 & -0.565 & -0.458 & -0.476 & $-\mathbf{0 . 0 6 0 5}$ \\
\hline O6 & -0.325 & -0.339 & -0.255 & $-\mathbf{0 . 0 5 9 2}$ \\
\hline O7 & -0.399 & -0.303 & -0.258 & $-\mathbf{0 . 0 4 9 8}$ \\
\hline O5 & -0.347 & -0.254 & -0.227 & $-\mathbf{0 . 0 4 9 7}$ \\
\hline O3' & -0.360 & -0.343 & -0.307 & $-\mathbf{0 . 0 3 0 1}$
\end{tabular}

Tabla 3d4 


\begin{tabular}{c|c|c|c|c} 
compuesto 5 & Chelp & CHelpG & MK & V ( r ) \\
\hline O2 & -0.539 & -0.538 & -0.525 & $-\mathbf{0 . 0 9 3 6}$ \\
\hline O6 & -0.298 & -0.303 & -0.237 & $-\mathbf{0 . 0 6 1 1}$ \\
\hline O1 & -0.406 & -0.413 & -0.441 & $-\mathbf{0 . 0 5 9 4}$ \\
\hline O5 & -0.343 & -0.259 & -0.264 & $-\mathbf{0 . 0 5 4 9}$ \\
\hline O7 & -0.315 & -0.263 & -0.235 & $-\mathbf{0 . 0 5 1 1}$ \\
\hline O3' $^{\prime}$ & -0.425 & -0.370 & -0.376 & $-\mathbf{0 . 0 4 4 8}$ \\
\hline O4' & -0.439 & -0.363 & -0.363 & $-\mathbf{0 . 0 4 3 2}$
\end{tabular}

Tabla 3d5

\begin{tabular}{c|c|c|c|c} 
compuesto 6 & Chelp & CHelpG & MK & V ( r ) \\
\hline O2 & -0.601 & -0.600 & -0.590 & $-\mathbf{0 . 0 9 5 5}$ \\
\hline $\mathbf{O 1}$ & -0.401 & -0.461 & -0.481 & $\mathbf{- 0 . 0 6 1 2}$ \\
\hline $\mathbf{O 4}$ & -0.571 & -0.616 & -0.619 & $-\mathbf{0 . 0 5 2 8}$ \\
\hline $\mathbf{O} \mathbf{1}^{\prime}$ & -0.542 & -0.401 & -0.344 & $\mathbf{- 0 . 0 4 1 9}$ \\
\hline $\mathbf{O 5}$ & -0.312 & -0.329 & -0.198 & $\mathbf{- 0 . 0 3 9 0}$
\end{tabular}

Tabla 3d6

\begin{tabular}{c|c|c|c|c} 
compuesto 7 & Chelp & CHelpG & MK & V ( r ) \\
\hline O2 & -0.596 & -0.604 & -0.587 & $-\mathbf{- 0 . 0 9 5 9}$ \\
\hline $\mathbf{O 1}$ & -0.473 & -0.451 & -0.453 & $-\mathbf{0 . 0 5 9 6}$ \\
\hline $\mathbf{O 4}$ & -0.497 & -0.555 & -0.540 & $-\mathbf{- 0 . 0 5 9 6}$ \\
\hline $\mathbf{O} \mathbf{1}^{\prime}$ & -0.520 & -0.393 & -0.346 & $\mathbf{- 0 . 0 4 2 2}$ \\
\hline $\mathbf{O 5}$ & -0.301 & -0.322 & -0.196 & $\mathbf{- 0 . 0 3 5 4}$ \\
\hline $\mathbf{O 3}^{\prime}$ & -0.545 & -0.334 & -0.293 & $-\mathbf{0 . 0 3 1 6}$
\end{tabular}

Tabla 3d7 


\begin{tabular}{c|c|c|c|c} 
compuesto 8 & Chelp & CHelpG & MK & V ( r ) \\
\hline O2 & -0.570 & -0.599 & -0.588 & $-\mathbf{0 . 0 9 7 8}$ \\
\hline O1 & -0.493 & -0.456 & -0.468 & $-\mathbf{0 . 0 6 3 0}$ \\
\hline O3' & -0.451 & -0.548 & -0.546 & $-\mathbf{0 . 0 6 0 0}$ \\
\hline O7 & -0.573 & -0.401 & -0.341 & $\mathbf{- 0 . 0 4 3 9}$ \\
\hline O5 & -0.453 & -0.314 & -0.176 & $-\mathbf{0 . 0 4 1 8}$ \\
\hline O4' & -0.413 & -0.340 & -0.285 & $-\mathbf{0 . 0 2 6 1}$
\end{tabular}

Tabla $3 \mathrm{~d} 8$

\begin{tabular}{c|c|c|c|c} 
compuesto 9 & Chelp & CHelpG & MK & V ( r ) \\
\hline O2 & -0.637 & -0.600 & -0.589 & $-\mathbf{0 . 0 9 5 4}$ \\
\hline $\mathbf{O 4}^{\prime}$ & -0.453 & -0.541 & -0.543 & $-\mathbf{0 . 0 7 6 2}$ \\
\hline $\mathbf{O 5}^{\prime}$ & -0.389 & -0.300 & -0.274 & $-\mathbf{0 . 0 7 4 5}$ \\
\hline O5 & -0.382 & -0.327 & -0.197 & $-\mathbf{0 . 0 6 6 4}$ \\
\hline O1 & -0.572 & -0.467 & -0.485 & $-\mathbf{0 . 0 6 3 4}$ \\
\hline O7 & -0.480 & -0.392 & -0.349 & $-\mathbf{0 . 0 4 1 8}$ \\
\hline O3' & -0.434 & -0.333 & -0.300 & $-\mathbf{0 . 0 2 7 9}$
\end{tabular}

Tabla 3d9

\begin{tabular}{c|c|c|c|c} 
combretastatina A-4 & Chelp & CHelpG & MK & V ( r ) \\
\hline O4 & -0.559 & -0.413 & -0.294 & $-\mathbf{0 . 0 8 8 1}$ \\
\hline O3 & -0.408 & -0.309 & -0.285 & $-\mathbf{0 . 0 8 1 6}$ \\
\hline O3' & -0.486 & -0.535 & -0.525 & $-\mathbf{0 . 0 6 3 7}$ \\
\hline O5 & -0.336 & -0.263 & -0.212 & $-\mathbf{0 . 0 5 9 1}$ \\
\hline O4' $^{\prime}$ & -0.469 & -0.336 & -0.284 & $-\mathbf{0 . 0 2 6 1}$
\end{tabular}

Tabla $3 \mathrm{~d} 10$ 
También se calcularon los máximos potenciales en el entorno del átomo de hidrógeno del grupo hidroxilo con el objetivo de cuantificar la capacidad aceptora de puente de hidrógeno. Este resultado se muestra en la Tabla 3d11 para todas las moléculas donde el potencial está en unidades atómicas

\begin{tabular}{c|c|c|c|c|c|c|c|c|c|c} 
& 1 & 2 & 3 & 4 & 5 & 6 & 7 & 8 & 9 & C A-4 \\
\hline OH & 4.6868 & 5.0793 & 9.8956 & 5.2859 & ------ & 4.3165 & 4.1013 & 14.2440 & 10.3910 & 6.2736
\end{tabular}

Tabla $3 \mathrm{~d} 11$ 
Capítulo 4: CONCLUSIONES 


\section{ALGUNAS CONCLUSIONES}

Las estructuras calculadas de todas las fenilcumarinas y de la combretastatina A-4 concuerdan con las estructuras reportadas en diversos trabajos ${ }^{124,125,126}$ que dan cuenta de las características geométricas necesarias para interactuar con la proteína tubulina en el entorno del sitio activo de la colchicina. Aquí mostramos los gráficos de las conformaciones de más baja energía y listamos en la Tabla 4.1 el ángulo de torsión más significativo.

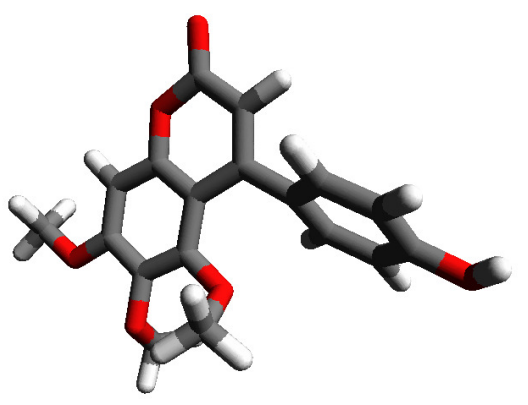

compuesto 2

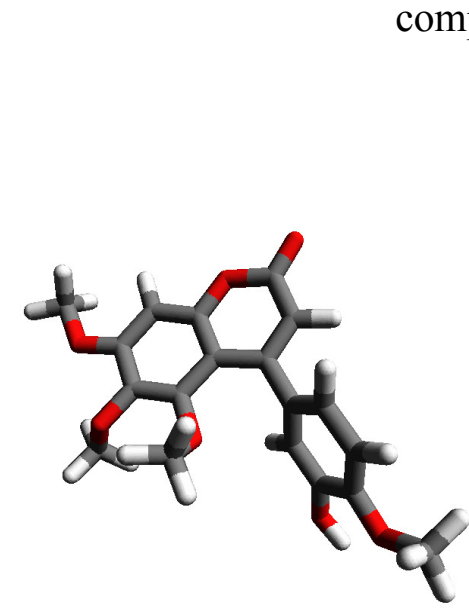

compuesto 1

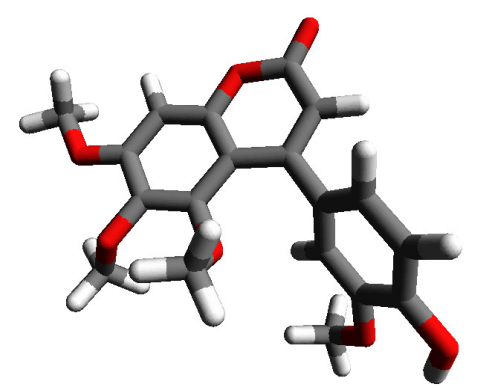

compuesto 3

\footnotetext{
${ }^{124}$ K. Gaukroger, J. A. Hadfield, L. A. Hepworth, N. J. Lawrence, A. T. McGown; J. Org. Chem. 66 (2001) 8135-8138 y referencias allí incluidas

${ }^{125}$ C. M. Lin, S. B. Singh, P. S. Chu, R. O. Dempcy, J. M. Schmidt, G. R. Pettit, E. Hamel; Mol. Pharmacol. 34 (1988) 200-208

${ }^{126}$ C. Bailly, C. Bal, P. Barbier, S. Combes, J. P. Finet, M. P. Hildebrand, V. Peyrot, N. Wattez; J. Med. Chem. 46 (2003) 5437-5444
} 
compuesto 4
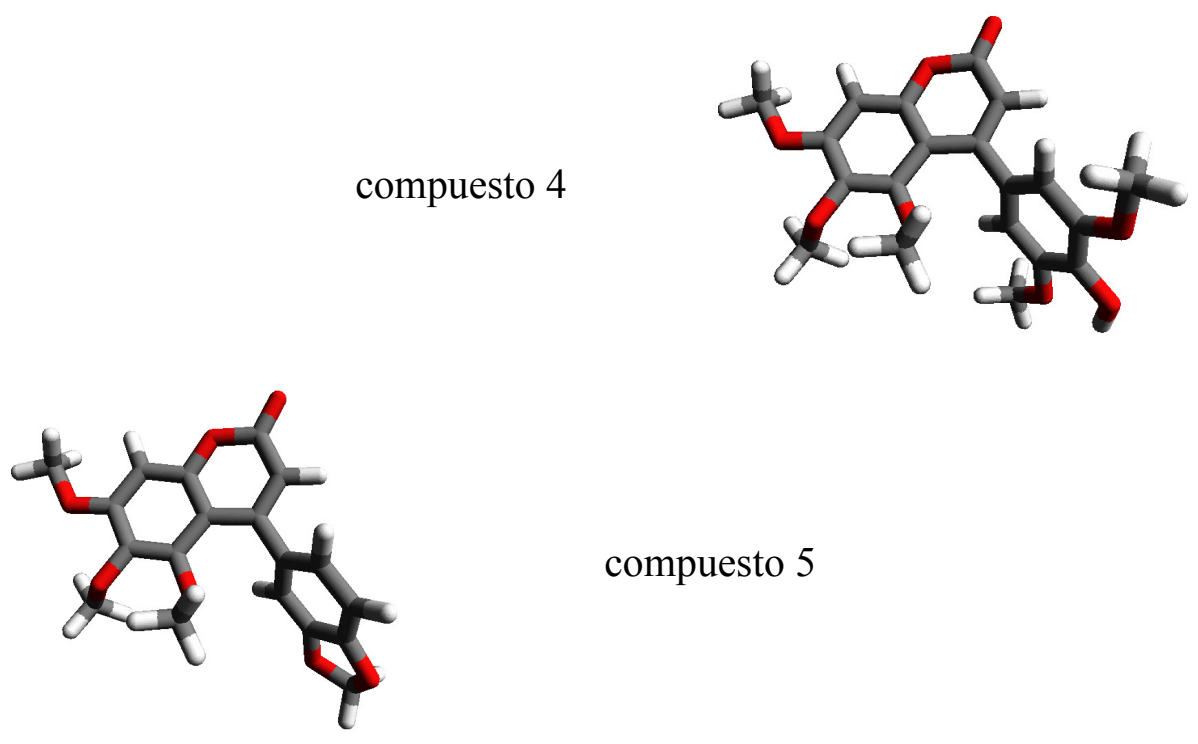

compuesto 5

compuesto 6
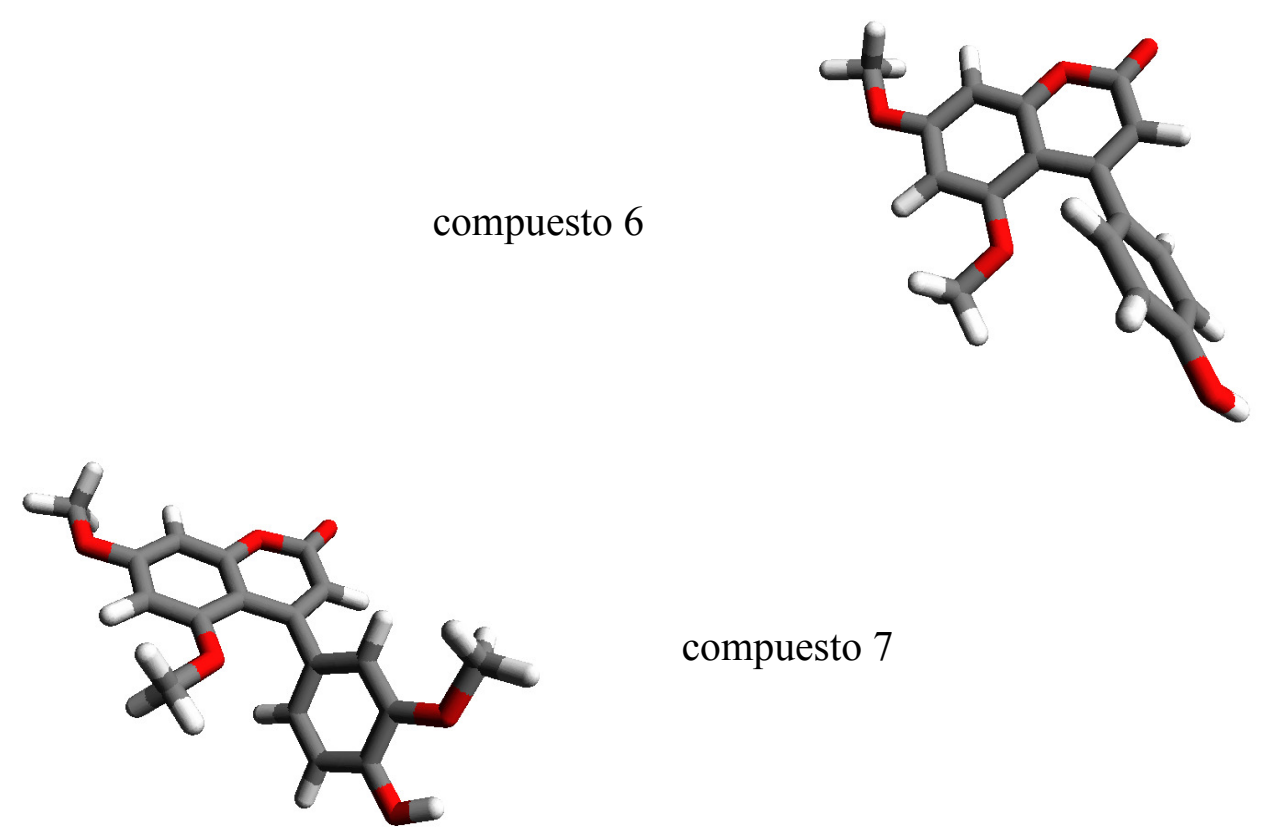

compuesto 7

compuesto 8

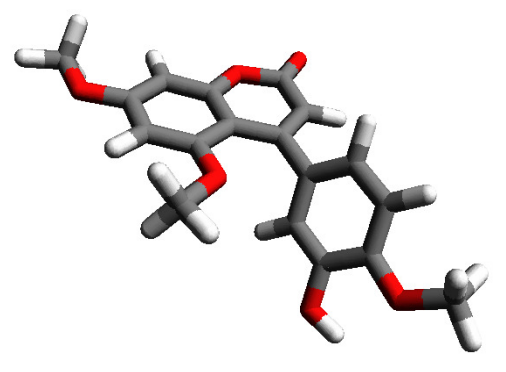




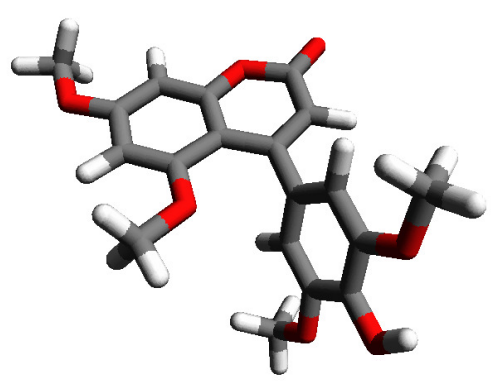

compuesto 9

combretastatina A-4

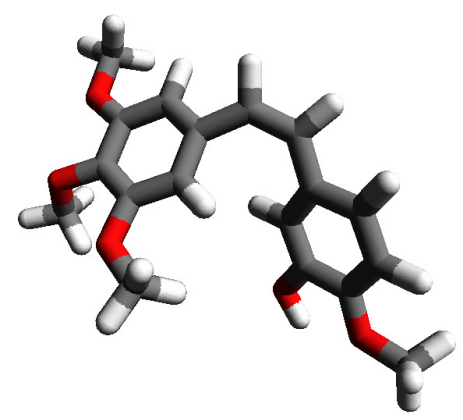

\begin{tabular}{|c|c|}
\hline & 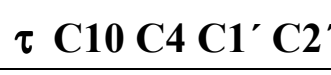 \\
\hline compuesto 1 & 59.676 \\
\hline compuesto 2 & 62.000 \\
\hline compuesto 3 & 62.678 \\
\hline compuesto 4 & 63.335 \\
\hline compuesto 5 & 62.330 \\
\hline compuesto 6 & -61.118 \\
\hline compuesto 7 & -124.025 \\
\hline compuesto 8 & 61.293 \\
\hline compuesto 9 & 65.256 \\
\hline
\end{tabular}

\begin{tabular}{c|c} 
& $\tau \mathrm{C1a} \mathrm{C1a}^{\prime} \mathrm{C} 1^{\prime} \mathrm{C} 2^{\prime}$ \\
\hline combretastatina A-4 & 31.269
\end{tabular}

Tabla 4.1: ángulo de torsión que da cuenta de la no planaridad de los anillos 
Dado un conjunto diverso de compuestos inhibidores del sitio de unión colchicinatubilina es posible encontrar un modelo común de farmacóforo ${ }^{127}$. Nguyen y colaboradores identificaron siete puntos para el farmacóforo de este tipo de compuestos. A1, A2 y A3 son diferentes zonas aceptoras de puentes de hidrógeno. Una región donora de puente hidrógeno se identificó como D1. Dos centros hidrofóbicos como H1 y H2. R1 es la denominación para un grupo plano. En este estudio encontraron que cuatro de ellos son esenciales para la actividad, y éstos son A2, H1, H2 y R1. Basados en estos puntos clasificaron los compuestos en siete grupos de acuerdo a qué conjunto de puntos tenga. La colchicina, la combretastatina A-4 y una variedad de análogos de combretastatina pertenecen al grupo I, que tiene los puntos A1, A2, H1, H2 y R1. En la Figura 4.1 se muestra la molécula de combretastatina A-4 y los puntos A1, A2 y H1 en rojo, anaranjado y azul respectivamente, mientras que los enlaces de la región H2 está en color verde y la R1 en color magenta.

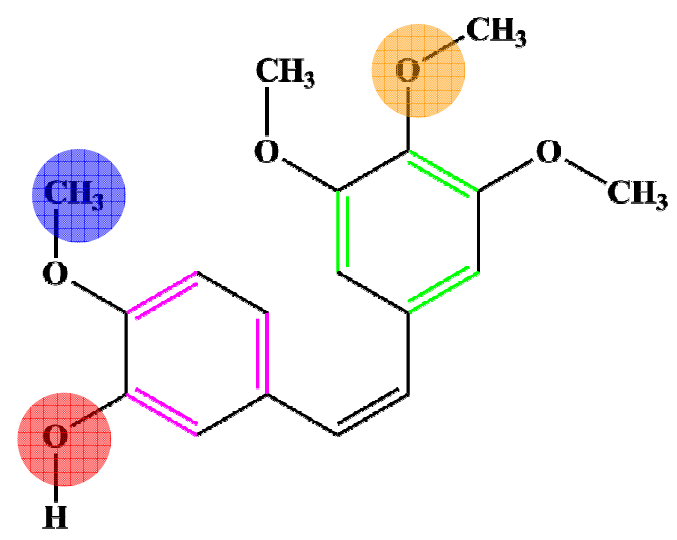

Figura 4.1

Para los siete puntos del farmacóforo existe un requisito estructural dado por las distancias entre los mismos. Los intervalos en Á entre los que se hallan estas longitudes se muestran en la Tabla 4.2. Además en este mismo trabajo encuentran que el ángulo entre los dos planos es de aproximadamente $45^{\circ}$.

\footnotetext{
${ }^{127}$ T. L. Nguyen, C. McGrath, A. R. Hermone, J. C. Burnett, D.W.Zaharevitz, B. W. Day, P. Wipf, E. Hamel, R. Gussio; J. Med. Chem. 482005 6107-6116
} 


\begin{tabular}{l|l} 
H1-A1 & $2.9-4.5$ \\
\hline H1-A2 & $8.6-10.7$ \\
\hline H1-R1 & $2.9-4.7$ \\
\hline H2-A2 & $1.7-2.4$ \\
\hline H2-A3 & $4.6-6.5$ \\
\hline H2-R1 & $5.1-7.4$ \\
\hline A1-R1 & $1.4-3.4$ \\
\hline A1-D1 & $2.3-2.9$ \\
\hline A2-A3 & $6.3-8.1$ \\
\hline A3-D1 & $5.4-5.9$ \\
\hline R1-D1 & $2.7-3.7$
\end{tabular}

Tabla 4.2

Las moléculas en estudio son derivados análogos de combretastatina A-4, de manera que en la clasificación antes descrita pertenecen al grupo I. Las distancias en $\AA$ de farmacóforo entre grupos esenciales para la combretastatina y los nueve compuestos se muestran en la Tabla 4.3 para las conformaciones más estables.

\begin{tabular}{l|l|l|l|l} 
& \multicolumn{1}{|c|}{ H1-A2 } & \multicolumn{1}{|c|}{ H1-R1 } & H2-A2 & H2-R1 \\
\hline compuesto 1 & H1 ausente & H1 ausente & 2.80 & 5.26 \\
\hline compuesto 2 & 8.87 & 2.81 & 2.79 & 5.19 \\
\hline compuesto 3 & 10.25 & 2.79 & 2.81 & 5.14 \\
\hline compuesto 4 & $8.89 / 9.91$ & 2.80 & 2.75 & 5.20 \\
\hline compuesto 5 & $8.90 / 10.17$ & 2.71 & 2.81 & 5.25 \\
\hline compuesto 6 & H1 ausente & H1 ausente & 2.77 & 5.23 \\
\hline compuesto 7 & 9.96 & 2.76 & 2.77 & 5.28 \\
\hline compuesto 8 & 10.20 & 2.79 & 2.76 & 5.29 \\
\hline compuesto 9 & $8.80 / 9.87$ & 2.79 & 2.77 & 5.21 \\
\hline combretastatina A-4 & $9.21 / 9.94$ & 2.78 & 2.79 & 5.43
\end{tabular}

Tabla 4.3

De la tabla anterior se puede ver que dos de los compuestos, el 1 y el 6 no cumplen con el requisito del farmacóforo por carecer de un punto esencial como es el H1. En los otros casos, incluida la combretastatina A-4, se ven valores que están dentro de los requerimientos para la actividad. También los ángulos de torsión están dentro lo esperado por los requisitos de no planaridad. Pero recordemos que aunque por propia 
definición de farmacóforo, éste es el mínimo conjunto de condiciones estructurales y electrónicas indispensable para una determinada actividad, ello no significa que su sola presencia en cualquier estructura química sea suficiente para tener actividad. Dos de los compuestos, el 3 y el 8, mostraron tener actividad de inhibición. Justamente estos dos son los únicos del conjunto con el grupo metoxi en el carbono en posición 4', de manera que parece ser que además de la existencia de un punto esencial como el H1 es importante también la ubicación del mismo en el anillo.

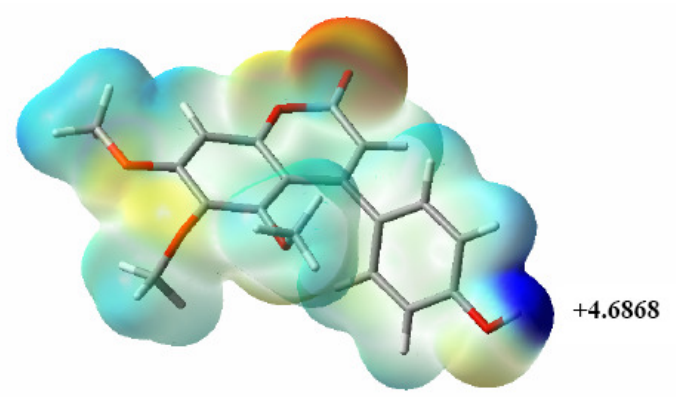

compuesto 1

compuesto 2
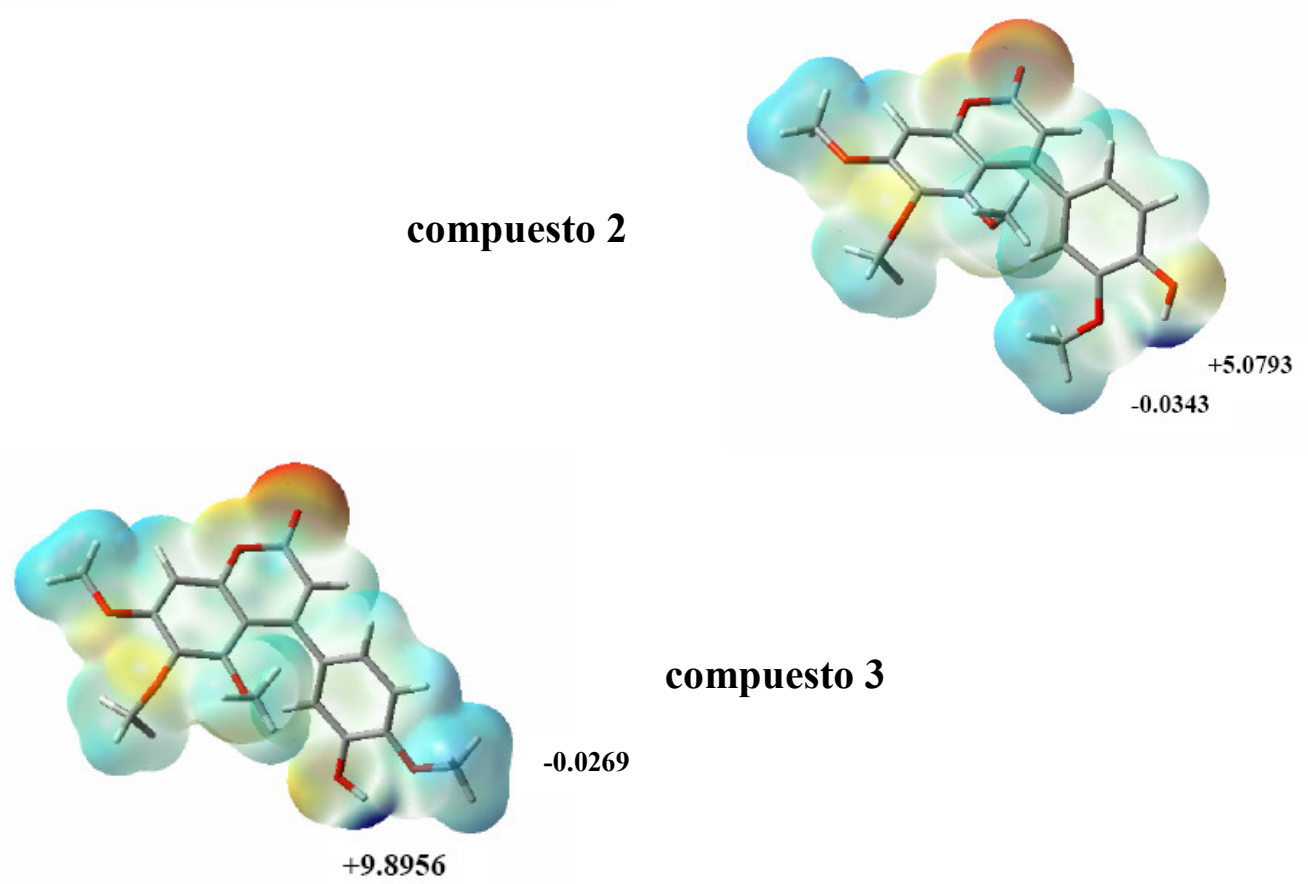

compuesto 3

compuesto 4

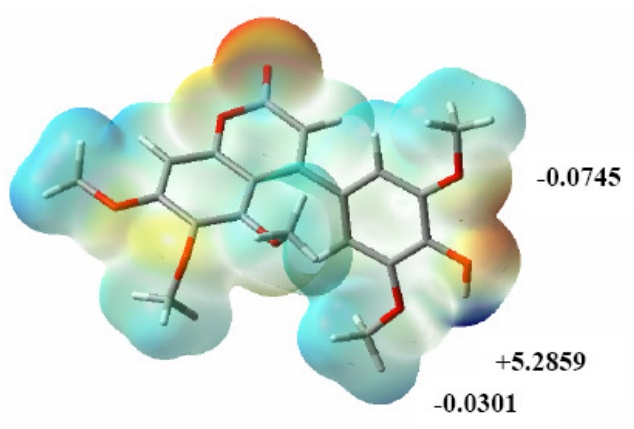




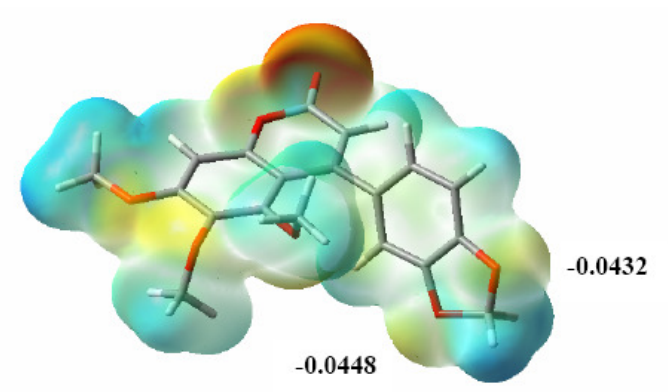

compuesto 5

compuesto 6
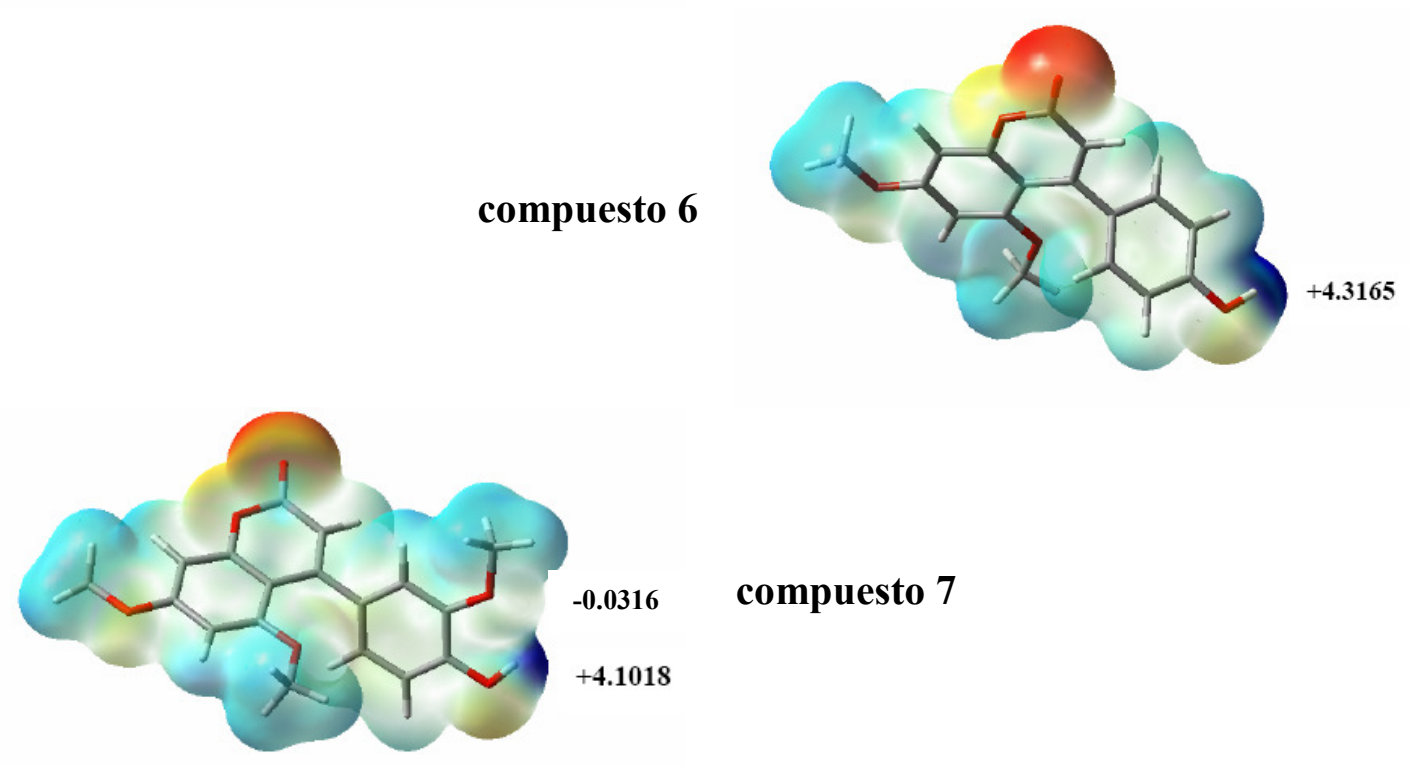

compuesto 7

compuesto 8
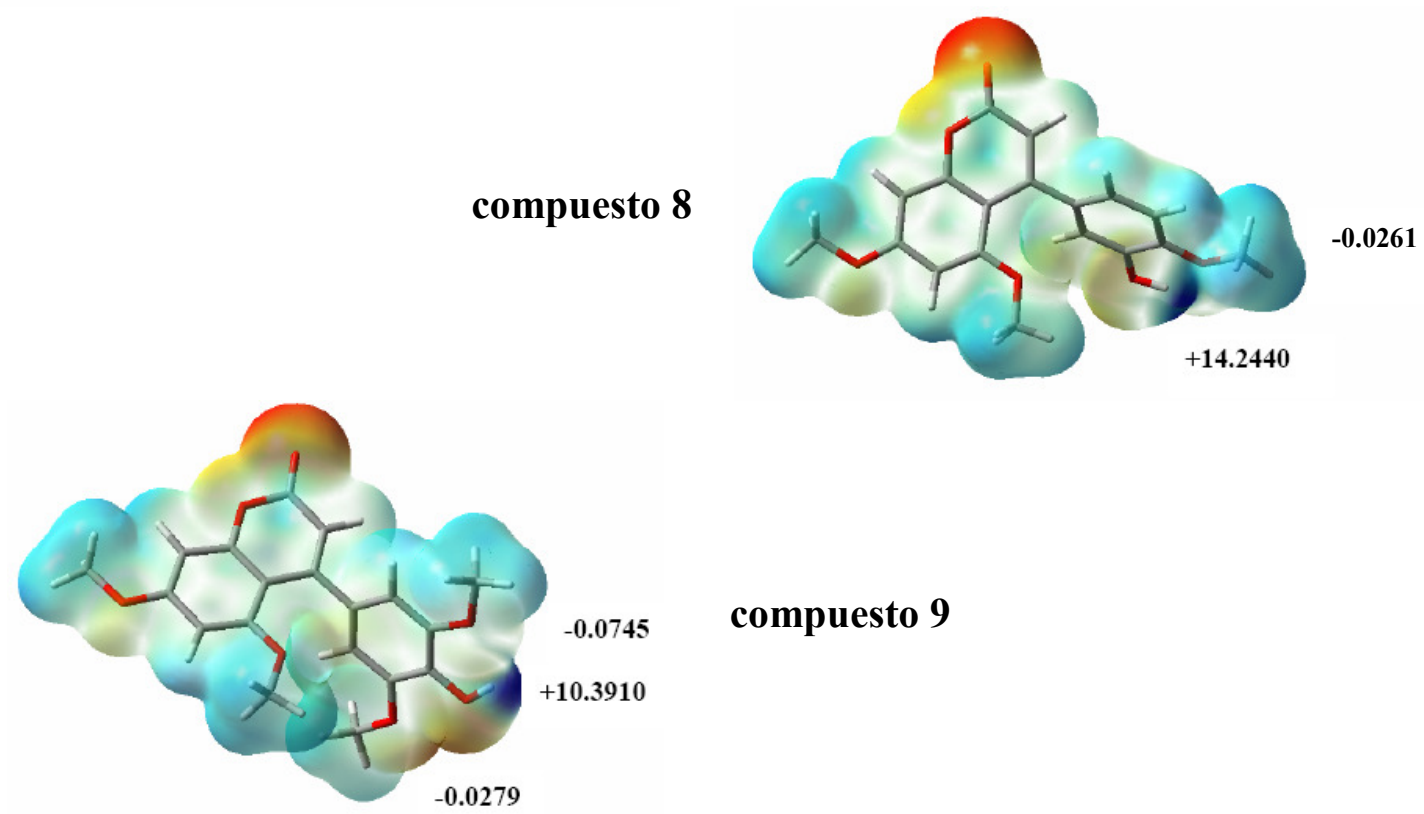

compuesto 9

combretastatina A-4

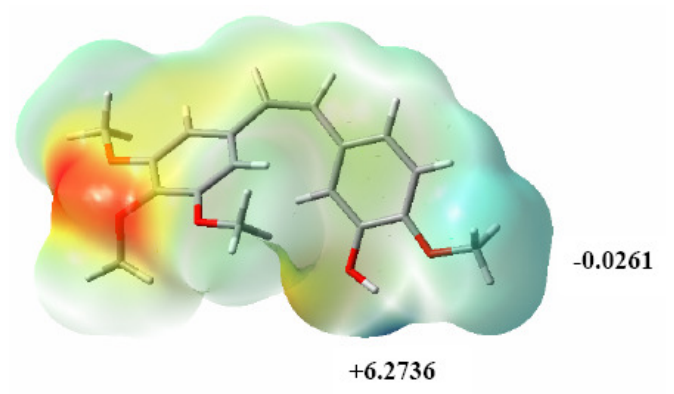


En los mapas de potenciales electrostáticos el color rojo da cuenta de potenciales negativos y el azul de potenciales positivos. Estos mapas muestran cualitativamente lo expresado en números en el capítulo 3. Sobre los gráficos de cada molécula están marcados los valores de potencial alrededor del átomo de hidrógeno del grupo hidroxilo, en donde este oxígeno fue identificado como punto farmacoforo pero no esencial según el trabajo de Nguyen y colaboradores. Además, en un trabajo de Ducki y colaboradores $^{128}$ se estudiaron los modos de binding de diversas chalconas análogas de combretastatina A-4 inhibidoras de la polimerización de microtúbulos. En ese trabajo se realizó un estudio de docking de la combretastatina y de las chalconas en el sitio activo colchicina-tubulina y se mostró que el grupo 3-hidroxilo del anillo B de CA4 está muy próximo al grupo carbonilo del aminoácido Thr179 de la subunidad alfa de la

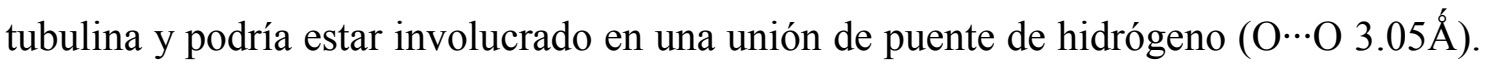
El modelo de Ducki sugiere que este grupo funcional también podría participar en un enlace de puente de hidrógeno con el aminoácido Lys352 de beta tubulina $(\mathrm{O} \cdots \mathrm{N} 4.59$ Á), y esto está en concordancia con la actividad GTPasa de CA4. Se puede ver que el potencial alrededor del hidrógeno de este hidroxilo es más alto para las moléculas activas, incluida la combretastatina, que para las inactivas excepto la molécula 9. Los valores de estos potenciales obtenidos por la vía del cálculo concuerdan con lo sugerido por Ducki a partir del modelado y el docking, y si bien en el trabajo de Nguyen no se le otorga a este grupo funcional carácter de punto esencial para la actividad, parecería que el mismo, por los resultados acá vistos, podría cobrar una mayor relevancia en la estabilidad del complejo y por tanto en su actividad.

Además se muestran sobre estos gráficos los potenciales alrededor de los átomos de oxígeno del metoxilo unido a C3', C4'o C5'según sea el caso. Estos últimos sí fueron descritos como puntos esenciales en el trabajo de Nguyen. Solamente en el caso de las molécula 3, 8 y combretastatina el potencial alrededor del oxígeno del metoxilo ubicado en el anillo de fenilo tiene un potencial cercano a -0.0260 . Respectivamente para estas moléculas vale $-0.0269,-0.0261$ y -0.0261 en unidades atómicas. Para las otras moléculas los potenciales se alejan de este valor, excepto otra vez en el oxígeno de un metoxilo del compuesto 9 (-0.0279). Esto reafirma la hipótesis de que además de la existencia de este grupo es importante también la posición en para del mismo. Esta

\footnotetext{
${ }^{128}$ S. Ducki, G. Mackenzie, B. Greedy, S. Armitage, J. Fournier Dit Chabert, E. Bennet, J. Nettles, J. Snyder, N. Lawrence; Bioorg. \& Med. Chem.; 17 (2009) 7711-7722
} 
especulación, así como también la posibilidad de que exista un impedimento para la unión a causa de los sustituyentes metoxilos en las posiciones $3^{\prime}$ o $5^{\prime}$, son susceptibles de ser estudiadas por Dinámica Molecular en otra etapa incluyendo el entorno proteico alrededor de las moléculas reemplazando a la colchicina de su sitio. Para eso contamos con información experimental ${ }^{129}$ del Protein Data Bank de la estructura de rayos X del complejo tubulina-DAMAcolchicina ${ }^{130}$

${ }^{129}$ R. Ravelli, B. Gigant, P. Curml, I. Jourdain, S. Lachkar, A. Sobel, M. Knossow; Nature 4282004198 202

${ }^{130} \mathrm{~N}$-diacetil-(N-mercaptoacetil)-colchicina 